DPST-84-398

ACC.NO. 41055

\title{
ADVANCED MASS SPECTROMETERS FOR HYDROGEN ISOTOPE ANALYSES
}

Compiled by

Philippe Chastagner

Contributors

Boyce T. Brock

Philippe Chastagner

Harold L. Daves

W. Bascom Hess

Approved by

C. E. Coffey, Research Manager Analytical Development Division

Publication Date: March 1984

E. I. du Pont de Nemours \& Co. Savannah River Laboratory

Aiken, SC 29808

PREPARED FOR THE U. S. DEPARTMENT OF ENERGY UNDER CONTRACT DE.AC09-76SR00001 
This document was prepared in conjunction with work accomplished under Contract No.

DE-AC09-76SR00001 with the U.S. Department of Energy.

\section{DISCLAIMER}

This report was prepared as an account of work sponsored by an agency of the United States Government. Neither the United States Government nor any agency thereof, nor any of their employees, makes any warranty, express or implied, or assumes any legal liability or responsibility for the accuracy, completeness, or usefulness of any information, apparatus, product or process disclosed, or represents that its use would not infringe privately owned rights. Reference herein to any specific commercial product, process or service by trade name, trademark, manufacturer, or otherwise does not necessarily constitute or imply its endorsement, recommendation, or favoring by the United States Government or any agency

thereof. The views and opinions of authors expressed herein do not necessarily state or reflect those of the United States Government or any agency thereof.

This report has been reproduced directly from the best available copy.

Available for sale to the public, in paper, from: U.S. Department of Commerce, National Technical Information Service, 5285 Port Royal Road, Springfield, VA 22161, phone: (800)

553-6847, fax: (703) 605-6900, email: orders@ntis.fedworld.gov online ordering: http://www.ntis.gov/ordering.htm

Available electronically at http://www.doe.gov/bridge

Available for a processing fee to U.S. Department of Energy and its contractors, in paper, from: U.S. Department of Energy, Office of Scientific and Technical Information, P.O. Box 62, Oak Ridge, TN 37831-0062, phone: (865 ) 576-8401, fax: (865) 576-5728, email: reports@ adonis.osti.gov 
Two advanced prototype mass spectrometers for the accurate analysis of mixtures of the hydrogen isotopes were evaluated by Du Pont personnel at the Savannah River Laboratory. One, a VGIsotopes GAZAB, was developed for the Mass Spectrometer Technical Group, a group representing ten. DOE contractors. The other, a MAT $250 \mathrm{HDT}$, was developed independently by Varian MAT (now Finnigan MAT) after extensive discussions with Du Pont personnel.

The GAZAB is a large double-focusing instrument with a resolution of 2,000 at mass 4 and an abundance sensitivity of $>100,000$ for the HT- $\mathrm{D}_{2}$ doublet. The MAT $250 \mathrm{HDT}$ is a smaller, simpler, stigmatic focusing instrument with exceptionally high ion intensities $\left(>1 \times 10^{-y} \mathrm{~A}\right.$ at 600 and about $1 \times 10^{-10} \mathrm{~A}$ at 1,300 resolution) for high signal-to-noise ratios.

Both instruments are computer controlled. Once a scan is started, peak switching, scanning, mass discrimination control, data collection and data reduction are done without operator intervention. Utility routines control hysteresis effects and instrument calibration.

A containment facility, with dual inlet systems and a standard distribution system, permits testing with tritium mixtures. Helium flow standards and tritium activity meters provide independent verification of the mass spectrometer calibrations. A recovery system prevents the release of tritium to the environment.

The performance of the mass spectrometers was essentially equal under simulated process control conditions. Precision and accuracy for the $\mathrm{D} / \mathrm{T}$ ratio was $<0.5 \%$ (rel $2 \sigma$ limits). Performance factors were: sample equilibration $<300 \mathrm{ppm}$; linearity within $\pm 0.3 \%$; and gas interference $<0.1 \%$. Mass discrimination was controlled reliably by the computers. Therefore, single focusing instruments are suitable for routine control laboratory operations. Double-focusing instruments are only needed for special applications.

SRL/SRP personnel worked closely with both manufacturers in this program. Both have incorporated resulting improvements in their commercial instruments. Both now market competitive singlefocusing mass spectrometers. 
Introduction 7

Analytical Problem 7

Mass Spectrometer Development Program 9 .

Mass Spectrometer Technical Group 11

MSTG Development Program 11

Independent Hydrogen Isotope Mass

Spectrometer Development 12

The MSTG GAZAB Mass Spectrometer 12

Summary 12

Instrument Description 12

Installation and Acceptance 16

Characterization Tests 17

The Finnigan (Formerly Varian) MAT 250 HDT

Mass Spectrometer 20

Summary 20

Instrument Description 20

Factory Acceptance Tests 24

Installation and Acceptance at SRL 26

Transition from Varian to Finnigan Management 29

Equilibration $\quad 29$

Characterization Tests 30

Emission Regulation Mode 36

GEND Tests at 1300 Resolution 36 
The Savannah River Laboratory Test Facility 40

Summary $\quad 40$

Facility Description 41

Baratron Comparison 48

Deuterium - Tritium Standards

Tritium Activity Meter 49

New Container for D-T Standards 51

Comparison of the GAZAB and MAT 250 HDT Mass Spectrometers 51

Results and Conclusions 51

Test Data Summaries 53

Mound Mixtures 53

Storage of pure HD 59

HD Cracking Pattern 61

References 71

Appendix I. DOE Mass Spectrometer Technical Group

Appendix II. MSTG Specifications for GAZAB

Mass Spectrometer

Appendix III. Memorandum (January 6, 1981)

J. W. Guthrie (SNLA)

to G. L. Thompson (SNLA Purchasing

Appendix IV. Acceptance Tests of the MSTG GAZAB, February 1981

Appendix V. GAZAB Performance at a Resolution of 1300, March and April 1981

Appendix VI. Specified Acceptance Tests for the Finnigan MAT 250 HDT Mass Spectrometer

Appendix VII. Acceptance Tests of the Finnigan (Formerly Varian) MAT 250 HDT, February 1981 


\section{ADVANCED MASS SPECTROMETERS FOR HYDROGEN ISOTOPE ANALYSIS}

\section{INTRODUCTION}

This report is a summary of the results of a joint Savannah River Laboratory (SRL) - Savannah River Plant (SRP) "Hydrogen Isotope Mass Spectrometer Evaluation Program." The program was undertaken to:

- Evaluate two prototype hydrogen isotope mass spectrometers

- Obtain sufficient data to permit SRP personnel to specify the mass spectrometers to be purchased under Schedule 44 Budget Project 81-SR-010 to replace obsolete instruments in Buildings 232- $\mathrm{H}$ and 234-H.

\section{ANALYTICAL PROBLEM}

Accurate mass spectrometric analyses of mixtures of the three hydrogen isotopes ( $D, H$, and $T$ ) are difficult to make because the mixtures contain six molecular species and ${ }^{3} \mathrm{He}$ (from the decay of $\mathrm{T}$ ). The heaviest species has three times the mass of the lightest, and mass discrimination is particularly severe.

In a mixture that contains two species with the same mass number, small mass differences and large concentration differences complicate the analysis. The mass difference between $\mathrm{HD}$ and ${ }^{3} \mathrm{He}$ is one part in 520 , while that between $H T$ and $D_{2}$ at mass 4 is only one part in 980 . The concentration ratio of the two species is often more than $1000: 1$. The scatter of the more-abundant species interferes with the measurement of the less-abundant species. To separate the $D_{2}-H T$ doublet reliably, the resolution of the mass spectrometer should be at least one part in 1300 , and the abundance sensitivity should be at least 10,000 .

Monatomic and polyatomic ions formed in the ion source (Table 1) further complicate the mass spectral analyses. The $\mathrm{T}^{+}$ and ${ }^{3}$ He differ by only one part in 155,000 and probably cannot be separated with any practical analytical mass spectrometers. Fortunately, $\mathrm{T}^{+}$ion production is a small constant fraction of the $\mathrm{T}_{2}, \mathrm{DT}$, and HT concentrations, and the error in correcting the ${ }^{3} \mathrm{He}$ mass peak is trivial. Trimer formation is a function of the pressure in the ion source and is usually very small. 


\section{TABLE 1}

Important Ions in the Mass 2 to 6 Range*

\begin{tabular}{|c|c|c|c|}
\hline Species & $\mathrm{M} / \mathrm{e}$ & $\begin{array}{l}\text { Specimen } \\
\text { Analysis } \\
\text { (Atom \%) }\end{array}$ & $\begin{array}{l}\text { Resolution } \\
\text { Required } \\
\end{array}$ \\
\hline $\mathrm{D}^{+}$ & 2.0140 & - & 1,220 \\
\hline $\mathrm{H}_{2}+$ & 2.01565 & 0.004 & 2.5 \\
\hline${ }^{3} \mathrm{He}^{+}$ & 3.01603 & 1.118 & 155,000 \\
\hline $\mathrm{T}^{+}$ & 3.01605 & - & 520 \\
\hline $\mathrm{HD}^{+}$ & 3.021825 & 1.036 & 1,830 \\
\hline $\mathrm{H}_{3}^{+}$ & 3.023475 & - & 3.5 \\
\hline${ }^{4} \mathrm{He}^{+}$ & 4.00260 & - & 160 \\
\hline $\mathrm{HT}^{+}$ & 4.023875 & - & 980 \\
\hline $\mathrm{D}_{2}{ }^{+}$ & 4.028 & 86.039 & 4.5 \\
\hline $\mathrm{DT}^{+}$ & 5.03005 & 11.259 & 5.5 \\
\hline $\mathrm{T}_{2}{ }^{+}$ & 6.032 & 0.382 & 610 \\
\hline $\mathrm{D}_{3}{ }^{+}$ & 6.0420 & & \\
\hline
\end{tabular}

* Isotope masses from Handbook of Chemistry and Physics (56th ed.). Robert C. West, ed. CRC Press, Cleveland, OH P. B-253 (1975).

$\begin{array}{lllll}\text { Isotope } & & \text { Mass, amu } & \text { Isotope } & \text { Mass, amu } \\ \mathrm{H} & 1.007825 & & { }^{3} \mathrm{He} & 3.01603 \\ \mathrm{D} & 2.0140 & & { }^{4} \mathrm{He} & 4.00260 \\ \mathrm{~T} & 3.01605 & & \end{array}$


Hydrogen isotopic mixtures can be analyzed with low $(<200)$, medium $(\sim 600)$, or high $(>1300)$ resolution mass spectrometers. When either low- or medium-resolution mass spectrometers are used, the sample must be at equilibrium. The relative amounts of $\mathrm{D}_{2}$ and $\mathrm{HT}$ at mass 4 are calculated using the equilibrium constants pub.lished by Jones. 1 . When high-resolution instruments are used, all of the species of interest are measured directly.

Helium-3 content is measured directly with medium- and highresolution instruments but must be measured by some other method, such as absorption of the hydrogen fraction of the sample on uranium or titanium, with low-resolution instruments. This technique is relatively imprecise as shown in Figure 1 . The error in the ${ }^{3}$ He determination causes a corresponding error in the HD value. The HD error is propagated directly to the HT value via the equilibrium calculation.

The specimen analysis in Table 1 is an example of a particularly difficult type of mixture to analyze accurately. About $0.5 \%$ of the total $\mathrm{T}$ is present as HT. With low resolution methods, gross errors can occur in the ${ }^{3} \mathrm{He}$ determination. These errors are propagated to the HD measurements; then to the HT value via the equilibrium calculation. The resulting errors in the HT value make it impossible to determine either total $T$ or the $D / T$ ratio accurately.

\section{MASS SPECTROMETER DEVELOPMENT PROGRAM}

In the past, hydrogen isotopic analyses usually were made with commercially available low- or medium-resolution mass spectrometers. Equilibrium among the isotopic species was assumed for mixtures containing tritium, but was not usually verified. 3 He was either estimated from the mass spectrum or determined separately by an auxiliary technique. The limit of accuracy was about \pm 2 to $\pm 4 \%$ and was adequate for many programs.

The available high-resolution mass spectrometers were expensive and produced low ion intensity; they were difficult and time consuming to operate and, judging by the work of Schott and Beau, 2 were no more accurate than the less expensive, low-resolution instruments.

By the 1970's, all of the hydrogen isotope mass spectrometers in the DOE complex had become obsolete. Modern replacements were sought. There were none that could be used for accurate analyses of mixtures of the hydrogen isotopes. The best of the available commercial instruments were designed for organic analyses and could not be used for quantitative hydrogen isotopic analyses without extensive modifications. It became evident that new instruments would have to be developed. 


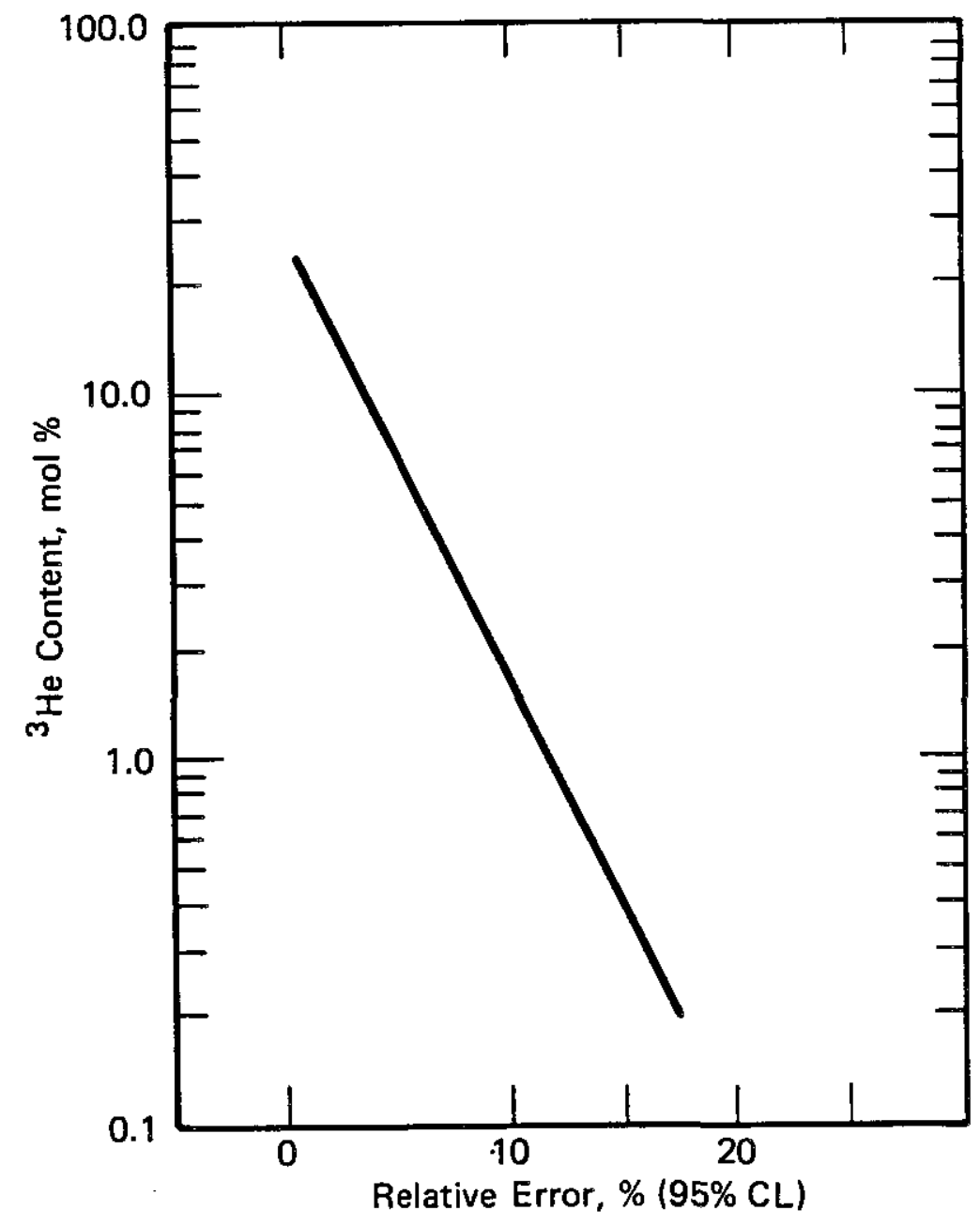

FIGURE 1. Determination of ${ }^{3} \mathrm{He}$ by Titanium-Sublimination Pumping 
At SRL, Chastagner, ${ }^{3}$ determined that construction of a practical high-resolution $(>1300)$ was within the state-of-the-art of mass spectrometry. Ferguson and Chastagner ${ }^{4}$ demonstrated the concepts that had been developed. A group led by Chastagner drew up tentative specifications for new hydrogen isotope mass spectrometers and contacted mass spectrometer manufacturers. None were willing to develop an instrument for such a limited market.

\section{MASS SPECTROMETER TECHNICAL GROUP}

The Mass Spectrometer Technical Group (MSTG) was formed to develop a hydrogen isotope mass spectrometer for the DOE complex. The group represented, and was funded by ten DOE contractors (Appendix I). Organization of the group followed program proposals to ERDA/ALO in 1975 by Alec Willis, SNLL, Clarence Sandy, SNLA, and approval by Vincent Vespe, Director, Weapons Development Division, ERDA/ALO. Sandia National Laboratory, Albuquerque, NM, was named as the coordinating agency, and James Guthrie, SNLA was selected to coordinate the group.

\section{MSTG DEVELOPMENT PROGRAM}

The MSTG drew up final specifications (Appendix II) and contracted with VG-Isotopes, the only responsive bidder, for the development and construction of a prototype hydrogen isotope mass spectrometer. The goal of the program was to develop a reliable, affordable mass spectrometer capable of accurately analyzing: mixtures of the hydrogen and helium isotopes regardless of the equilibrium state of the hydrogen isotopes; and mixtures of air components and various fixed gases. The instrument was to be; easy to operate, electrically and mechanically modular for easy maintenance, and adaptable to computer control and data handing.

The MSTG program consisted of four phases:

- paper design

- component and systems testing on a leased prototype instrument called the GAZAB

- refurbishing and purchase of the prototype instrument

- testing the prototype with tritium mixtures at a DOE laboratory.

The MSTG selected SRL/SRP to receive and test the prototype. 


\section{INDEPENDENT HYDROGEN ISOTOPE MASS SPECTROMETER DEVELOPMENT}

In the late 1970's, Varian MAT (now Finnigan MAT) developed a new mass analyzer design for geological and thermal ionization mass spectrometers. The analyzer appeared to be suitable for a hydrogen isotope mass spectrometer. The Varian MAT technical staff in Bremen was thought to have the technology required to design and build a satisfactory ion source. Extensive discussions between SRL/SRP personnel and Varian MAT personnel in the United States and Germany convinced MAT management that there was a market for hydrogen isotope mass spectrometers and that MAT probably could build a competitive instrument. MAT personnel then designed and built a prototype called the MAT $250 \mathrm{HDT}$. SRP purchased the prototype and added it to the hydrogen isotope mass spectrometer test program.

\section{The MSTG GAZAB MASS SPECTROMETER}

\section{Summary}

The MSTG prototype, GAZAB, is a large reversed-geometry double-focusing mass spectrometer. It features an ion source that was modified especially for hydrogen isotope analyses, high resolution and abundance sensitivity, and high transmission. The instrument is controlled by an HP desktop computer throughout the analytical cycle. Data is collected and reduced to final form by the computer.

The GAZAB is very versatile and can be used for a variety of analytical problems. It can be operated at a resolution of 1300 for routine analyses of mixtures of the hydrogen and helium isotopes, regardless of their state of equilibrium. It can also be operated at a resolution of 2000 for sophisticated analyses where all of the molecular species must be separated.

\section{Instrument Description}

The hydrogen isotope mass spectrometer prototype (GAZAB) that was developed for the MSTG is shown in Figure 2. It is a gas version of the VS-Isotopes ZERO ALPHA AND BETA (ZAB) mass spectrometer. The $Z A B$ was designed primarily for organic applications that require both high sensitivity and high resolution. It is a reversed geometry double-focusing mass spectrometer with a $30 \mathrm{~cm}$ radius magnetic sector followed by a $38 \mathrm{~cm}$ radius electric sector (Figure 3). The analyzer is designed to make all the first and second order abberation coefficients equal to zero. Thus the instrument is capable of retaining high resolution and sensitivity, with a gas source of good linearity and high repeller voltage, which would inevitably produce a strong energy abberation in a 


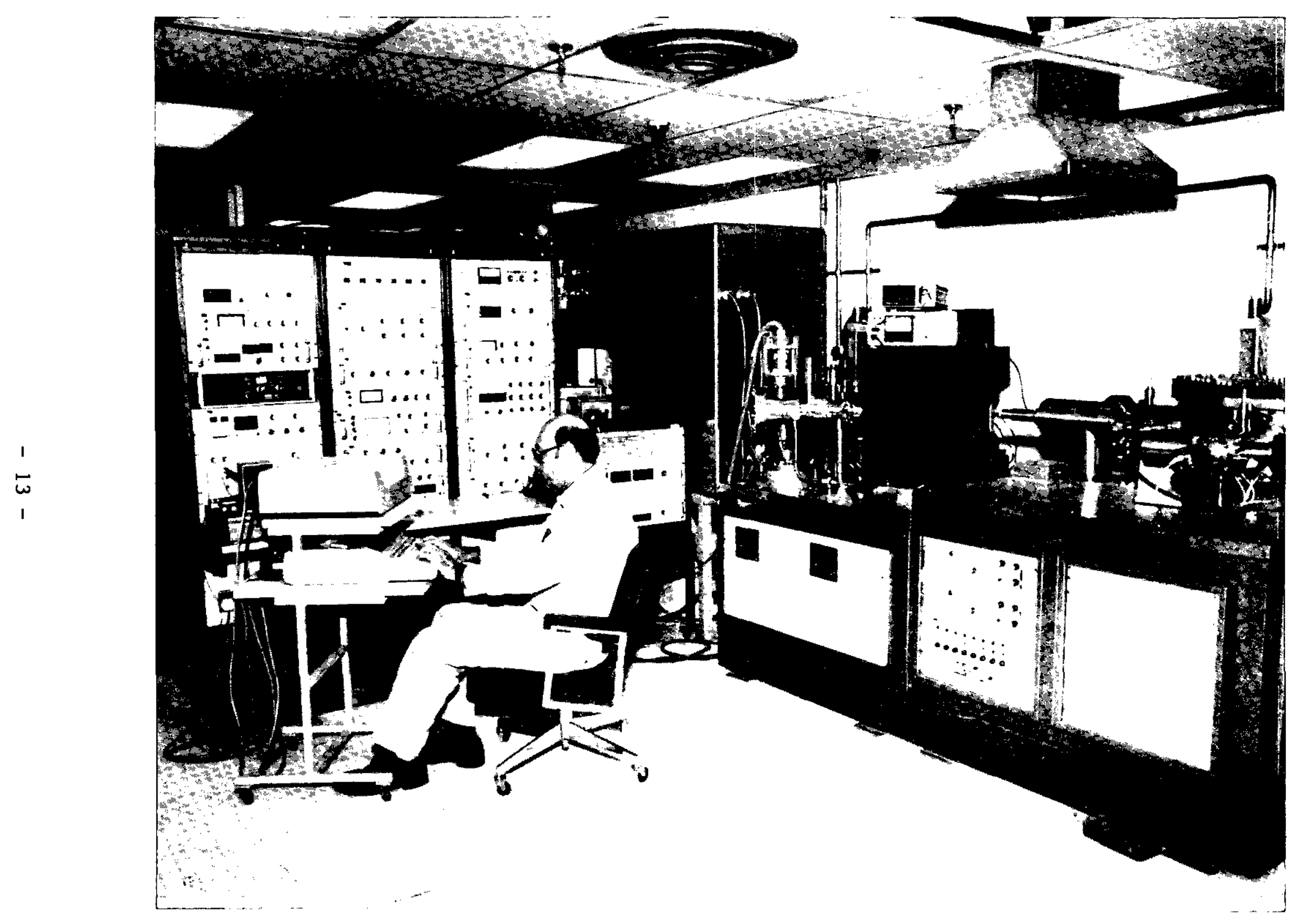

FIGURE 2. GAZAB Mass Spectrometer 


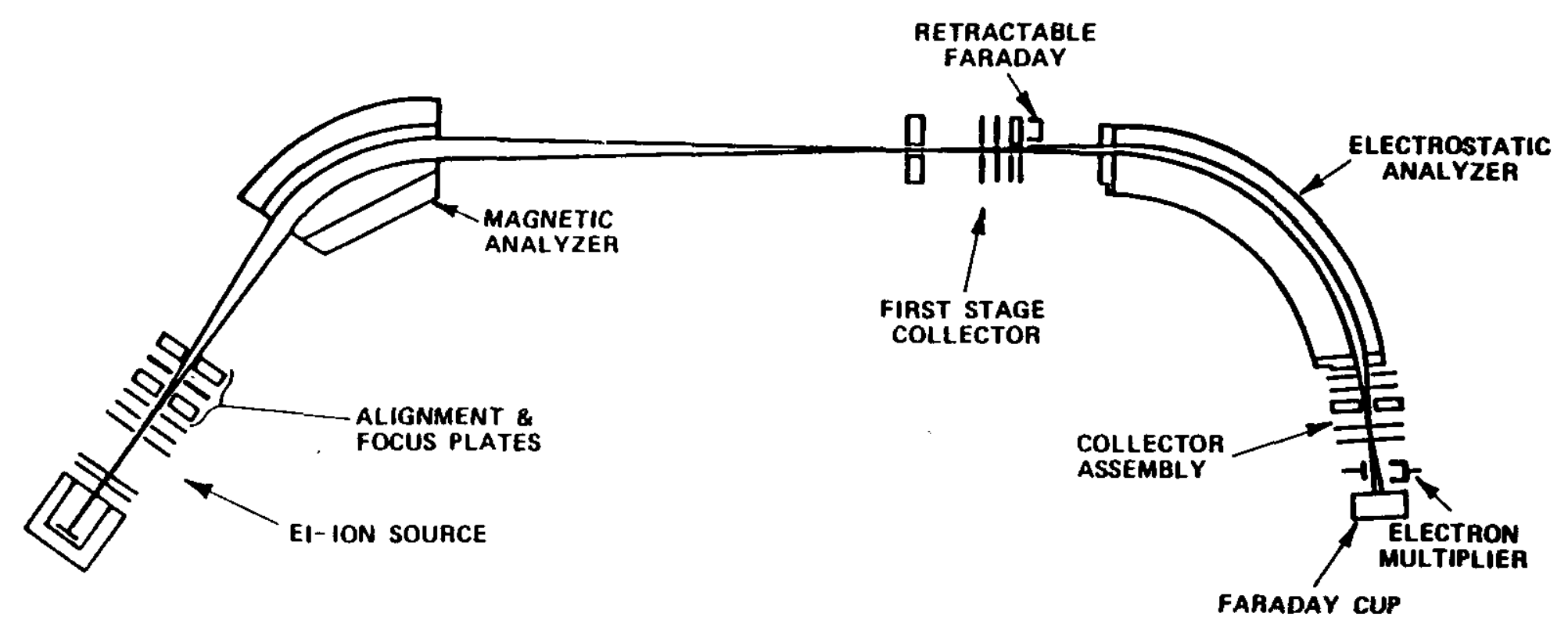

FIGURE 3. GAZAB Ion Optical System 
single focusing mass spectrometer. In addition, image curvature correction is incorporated which allows higher sensitivity to be achieved at a given resolution than would otherwise be the case. Also, by fitting slits which are variable in both the dispersion and magnetic field directions, optimum sensitivity can be established at a given resolution.

Deflector plates are incorporated after the alpha slit and before the intermediate slit so that the ion beam may be steered along a shorter or longer path through the magnet as desired. These steering voltages are fully programmable and are used to preserve resolution and peak shape as the mass numbers change. This feature is especially important in a hydrogen isotope mass spectrometer. Mass discrimination caused by magnetic fields in the ion source causes ions of different masses to diverge as they exit the source, and only one mass is in focus at a time.

The ion source is a modified Nier-type. An electron beam passes through a box-shaped ion chamber close to a narrow exit slit. Behind the electron beam is an ion repeller which creates a field of few electron volts per millimeter between the ionizing region and the ion exit slit. The ions also encounter an extraction field penetrating into the ionization chamber from the next electrode which is a pair of half plates with mean potential several hundreds of volts closer in potential to earth, and are steered by the differential voltage on these half plates through an adjustable source slit at earth potential. Further steering then occurs in both the $y$ and $z$ directions before the beam emerges from its alpha slit, which in the $\mathrm{ZAB}$ is contained in a separate "stack" of electrodes but is still in principle, a part of the ion source.

All the voltages applied to the source can be fully programmed. This feature gives the source great flexibility when run in its automatic mode. If necessary, each mass can have its own set of source parameters for best sensitivity and resolution, and lowest mass discrimination. However, the source is usually run with the ion repeller and focus voltages fixed during the peak jumping sequence. Only the voltages which deflect the beam in the $y$-direction are varied with mass.

The GAZAB is equipped with both Faraday cage and Daly scintillation-type ion collectors. Only the Faraday cage collector is used for accurate hydrogen isotopic analyses. The Daly collector is used for measuring trace level impurities during survey analyses.

Modern solid-state technology is used in all of the electronic units. All of the source, magnet, beam control, and electric sector power supplies are designed for computer control. Manual control is also provided. 
The analyzer system is evacuated by four polyphenyl ethercharged diffusion pumps. The pumps are equipped with integral water-cooled baffles. A liquid nitrogen trap is provided in the source pumping line. Isolation valves permit the source to be vented without venting either the analyzer or the pumping system. Dual stage mechanical pumps are provided for rough pumping and to back the diffusion pumps. Ion and Pirani vacuum gages monitor pressures and shut down the vacuum system and electronic supplies when excessive pressure is detected.

The entire mass spectrometer operates under control of a Hewlett-Packard HP-9831 with software provided by VG-Isotopes. This software was limited by the capacity of the HP-9831 computer to the hydrogen isotopes and two impurities. A complete version that $r$ uns on an HP-9845 computer is available.

Because the GAZAB was an experimental instrument, many of the components were prototypes and were the source of some operating problems. Initially, VG-Isotopes personnel replaced or repaired these units as problems developed. In June 1982, they overhauled all of the electronic units and brought the GAZAB up to current production standards at VG-Isotopes expense. From then until the end of the program, the GAZAB operated flawlessly.

\section{INSTALLATION AND ACCEPTANCE}

The GAZAB mass spectrometer was shipped by air from England to New York and by van from there to SRL. It arrived in good condition on February 2, 1981. Graham Wells and Barry Wright, VG-Isotopes Engineers, arrived from England at the same time. They immediately started to assemble the instrument, and had an ion beam through it by February 9. Only minor difficulties were encountered: source arcing; a source cable breakdown; an ESA supply problem; and failure of the vibrating reed electrometer (VRE). All problems except that with the VRE were fixed. The VRE could not be repaired on plant and was sent offsite for repair and recalibration. The VG-Isotopes solid-state amplifier in the GAZAB was used instead of the VRE in all the subsequent tests.

Acceptance testing began February 19 and was concluded successfully February 28. As shown in the Appendices, all requirements of Specification SLA-XMS-8-79 as amended in December 1980 were met without exception, Martin Elliott, the VG-Isotopes director in charge of the GAZAB development work, arrived February 23. He assisted Wright in the final phases of acceptance testing and remained another week to teach SRP personnel how to operate the instrument. 


\section{CHARACTERIZATION TESTS}

Cold testing to characterize the GAZAB was started immediately after its acceptance. The modified ion source performed reliably and data were within specification limits. The sensitivity at a resolution of 2,000 was about $110 \mathrm{mV} / \mu$ for hydrogen (with a $1 \times 10^{11}$ phm resistor). When the resolution was set to 1,300 and the instrument was set for maximum transmission at each mass, the sensitivity was doubled (Appendix II). The mass discrimination under those conditions was about $10 \%$, the resolution was adequate to separate the HT- $D_{2}$ doublet at mass 4 , and the abundance sensitivity was about 27,000 . The sensitivity was very stable with time (Table 2). The sensitivity measurements were made nine days apart.

TABLE 2

\section{Variation of GAZAB Sensitivity with Time}

Molecular Sensitivity, $\mathrm{mV} / \mu$

\begin{tabular}{|c|c|c|c|}
\hline Species & $3 / 24 / 81$ & $4 / 2 / 81$ & Diff., $\%$ \\
\hline $\mathrm{H}_{2}$ & 199.57 & 199.17 & -0.20 \\
\hline${ }^{3} \mathrm{He}$ & 56.17 & 56.02 & -0.27 \\
\hline $\mathrm{HD}$ & 209.44 & 208.62 & -0.39 \\
\hline $\mathrm{D}_{2}$ & 216.28 & 215.74 & -0.25 \\
\hline
\end{tabular}

Several changes in operating conditions improved the performance of the GAZAB mass spectrometer. The changes included revised ion source parameters and operation with liquid nitrogen in the ion source trap. The precision was excellent and was reproducible (Table 3). In these tests, Mound Laboratory mixture No. 1, and an SRP mixture with the same ${ }^{3} \mathrm{He}$ content $\left(4 \pm 0.25 \mathrm{M} \%{ }^{3} \mathrm{He}\right.$, the balance being $D_{2}$ ) were analyzed. Analyses of Mound Laboratory mixture No. 1 yielded ${ }^{3}$ He values slightly below the theoretical value and $\mathrm{H}_{2}$ values slightly above the theoretical value. These results were consistent with previous data for Mound mixture No. 1 . The ${ }^{3} \mathrm{He}$ value for the SRP mixture agreed with the theoretical value within the error of the latter. This test confirmed the accuracy of the GAZAB for ${ }^{3} \mathrm{He}$ at the $4 \mathrm{M} \%$ level. These data, together with the results of previous tests with Mound mixture No. 1 suggest that the theoretical values for that mixture are not correct.

The precision of calibrating the GAZAB mass spectrometer was evaluated for $\mathrm{H}_{2},{ }^{3} \mathrm{He}, \mathrm{HD}$, and $\mathrm{D}_{2}$. Calibration measurements were repeated at a rate of about two per minute for ten minutes. The ${ }^{3}$ He calibration precision (Table 4) is typical of these tests. 
TABLE 3

Tests of the Precision and Accuracy of the GAZAB Mass Spectrometer

SRP Mixture

Avg. ${ }^{3} \mathrm{He}, \quad$ Avg. ${ }^{3} \mathrm{He}-\mathrm{Theor}^{3} \mathrm{He}^{\top}$
mole $\mathrm{Z}^{\star}$

4.030

4.042

4.039

4.038

Average $\pm 0.38$

$\pm 0.41$

$\pm 0.30$

$\pm 0.34$
$+0.30$

$+0.22$

$+0.20$

$+0.18$
Mound Lab Mixture No. 1 Avg. ${ }^{3} \mathrm{He},{ }^{\text {Avg. }{ }^{3} \mathrm{He}-\text { Theor. }{ }^{3} \mathrm{He}}$

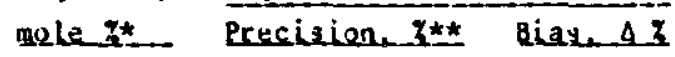

\subsection{5}

3.986

$\pm 0.35$
$-0.40$

$-0.37$

$-0.47$

$-0.52$

$-0.12$

$-0.33$

$3.980 \pm 0.38$

$\pm 0.38$
Mound Lab Mixcure No. 1 Avg. $\mathrm{H}_{2}$, Avg. $\mathrm{H}_{2}$ - Theor. $\mathrm{H}_{2} \mathrm{TH}$ mole $z^{*}$ Preciaion. $z^{*} \star$ Bias, $\Delta \bar{z}$

6.052

$\pm 0.23$

$+0.73$

5.045

$\pm 0.24$

$+0.62$

6.044

$\pm 0.20$

$+0.60$

6.050

$\pm 0.17$

$+0.70$

$+0.68$

$+0.67$

* Average of 10 runs.

* 4.2s, where $s=$ estirator of celative standard deviation ( $z$ ) for d small population; $4.2 \mathrm{~s}$ corresponds to 299.77 confidence limits.

$t$ Theoretical ${ }^{3}$ He content $=4.03 \mathrm{~mole} z$.

it Theoretical ${ }^{3} \mathrm{He}$ content $=4.001$ mole $\%$.

t† Theucetical $\mathrm{H}_{2}$ content $=6.008$ mole $\%$. 


\section{TABLE 4}

Precision of GAZAB Calibration with ${ }^{3} \mathrm{He}$

Inlet Pressure,

microns

93

92

92

91

90

90

89

88

88

87

87

86

86

84

84

83

82

82

Average
Sensitivity,

$\mathrm{mV} / \mathrm{micron}$

64.00

64.04

64.08

64.10

64.10

64.06

64.07

64.11

64.07

64.05

64.02

64.08

64.14

64.18

64.19

64.12

64.12

64.19

$64.096 \pm 0.054$

$\pm 0.087$ 
In the course of this work, Hess found that the linearity of the GAZAB mass spectrometer for hydrogen isotopes varied with the energy of the ionizing electrons. At $68 \mathrm{~V}$ energy, the $\mathrm{D}_{2}$ response was inear within $\pm 10 \%$. As the energy was either increased or decreased, the response became non-linear. The amount of the non1 inearity depended on the difference between the electron energy and $68 \mathrm{~V}$. $D_{2}$ sensitivity was directly proportional to pressure at electron energies below $68 \mathrm{~V}$ and inversely proportional to pressure at electron energies above $68 \mathrm{~V}$ (Figure 4). $\mathrm{H}_{2}$ sensitivity underwent a similar transition at about $72 \mathrm{~V}$, but was linear within $\pm 0.1 \%$ at electron energies below $70 \mathrm{~V}$. ${ }^{3} \mathrm{He}$ linearity was not affected by electron energy.

\section{THE FINNIGAN (FORMERLY VARIAN) MAT 250 HDT MASS SPECTROMETER}

\section{Summary}

The Finnigan MAT $250 \mathrm{HDT}$ is a modern single-focusing mass spectrometer. It features a high brightness ion source and an offaxis extended geometry magnetic analyzer with very high transmission. The ion source is linear over ten times the pressure range and emission current that we consider conventional. The instrument is controlled with an HP desktop computer.

The MAT 250 HDT is well adapted to routine analytical work. At a resolution of 600 it is used for the analysis of equilibrium mixtures of the hydrogen isotopes and helium. It is also used routinely at a resolution of 1300 to analyze mixtures in which the hydrogen isotopes may not be in equilibrium.

\section{Instrument Description}

The Finnigan MAT 250 HDT prototype is a refined singlefocusing mass spectrometer (Figure 5) that was developed from the recently-designed MAT 250 and 260 mass spectrometers. The analyzer (Figure 6) is a stigmatic-focusing $23 \mathrm{~cm}$ radius magnetic sector. The stigmatic design doubles the dispersion to that of a $46 \mathrm{~cm}$ radius normal entry analyzer. The design also provides " $Z$ " focusing which increases the transmission.

The ion source is similar to that of the standard MAT 250 source except that it has been shortened to reduce mass discrimination and to improve transmission. An electron beam passes through a box-shaped ion chamber close to an ion exit slit. Ions are drawn out of the chamber by an electric field created by a "drawout" plate located close to the ion exit slit. An ion lens system collimates the ions into a beam. The ion beam is focused in the " $\mathrm{Y}$ " and " $\mathrm{Z}$ " directions for maximum transmission through the source 


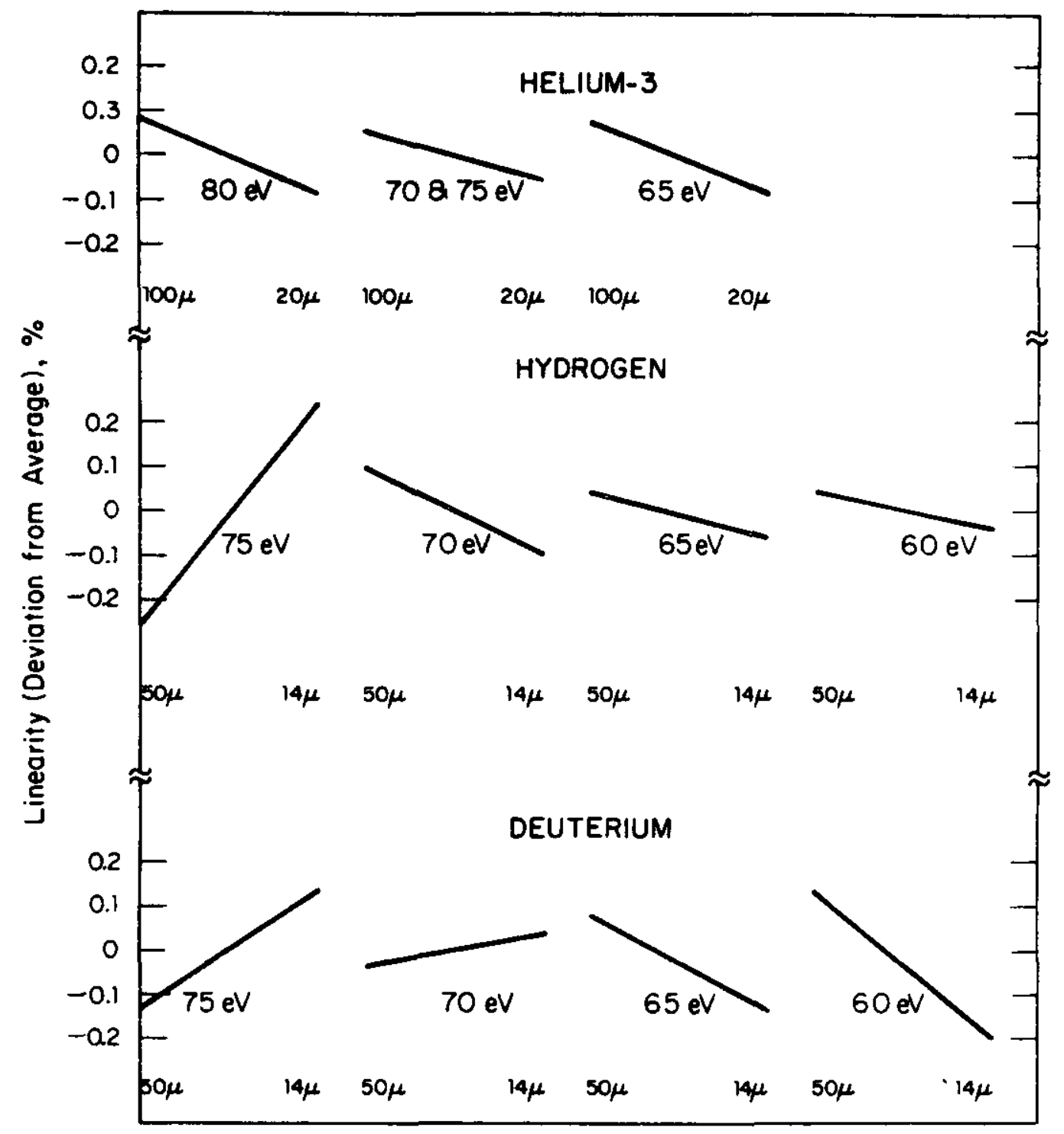

Inlet System Pressure, $\mu$

FIGURE 4. GAZAB Linearity as a Function of Ionizing Electron Energy 


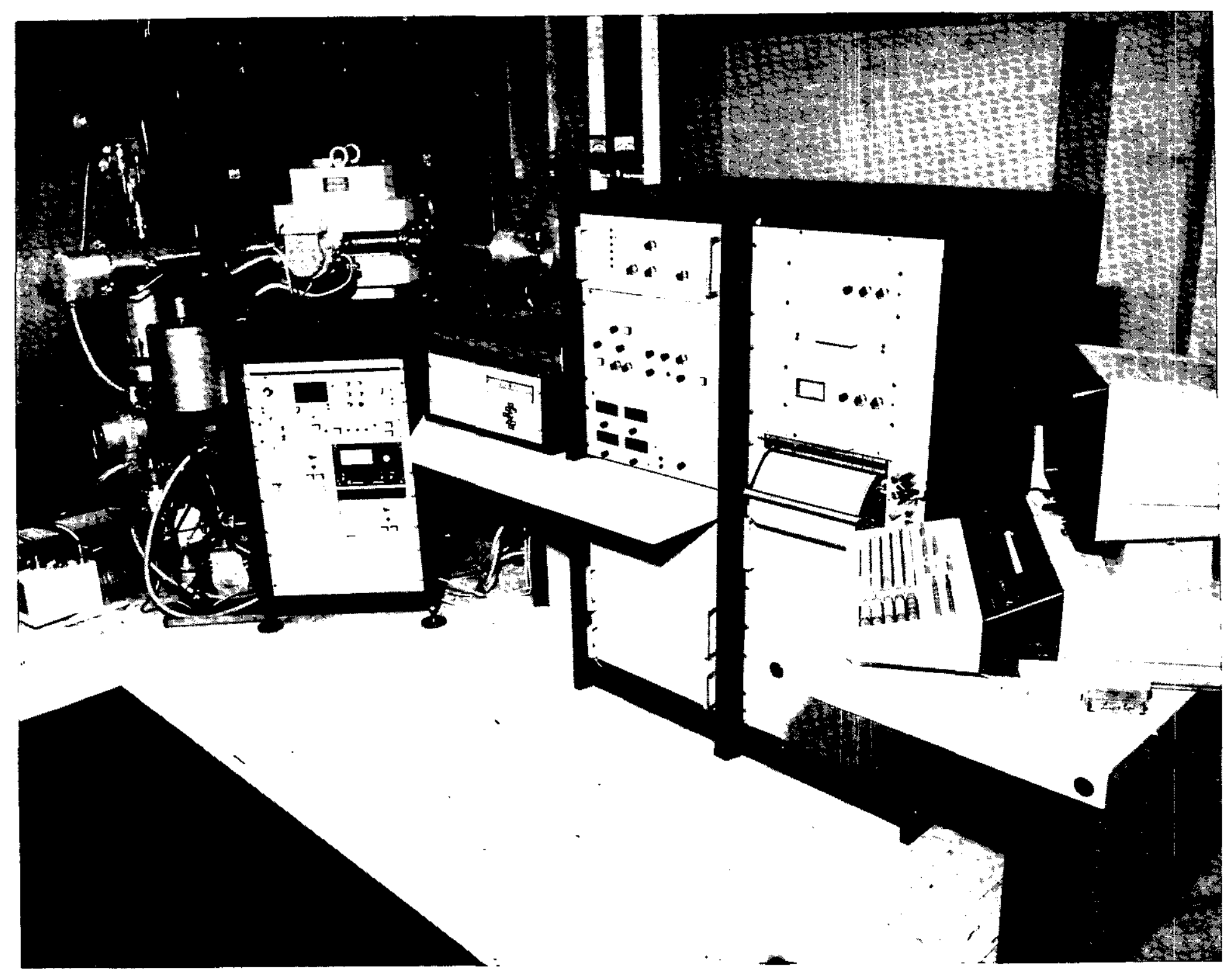

FIGURE 5. MAT 250 HDT Mass Spectrometer 


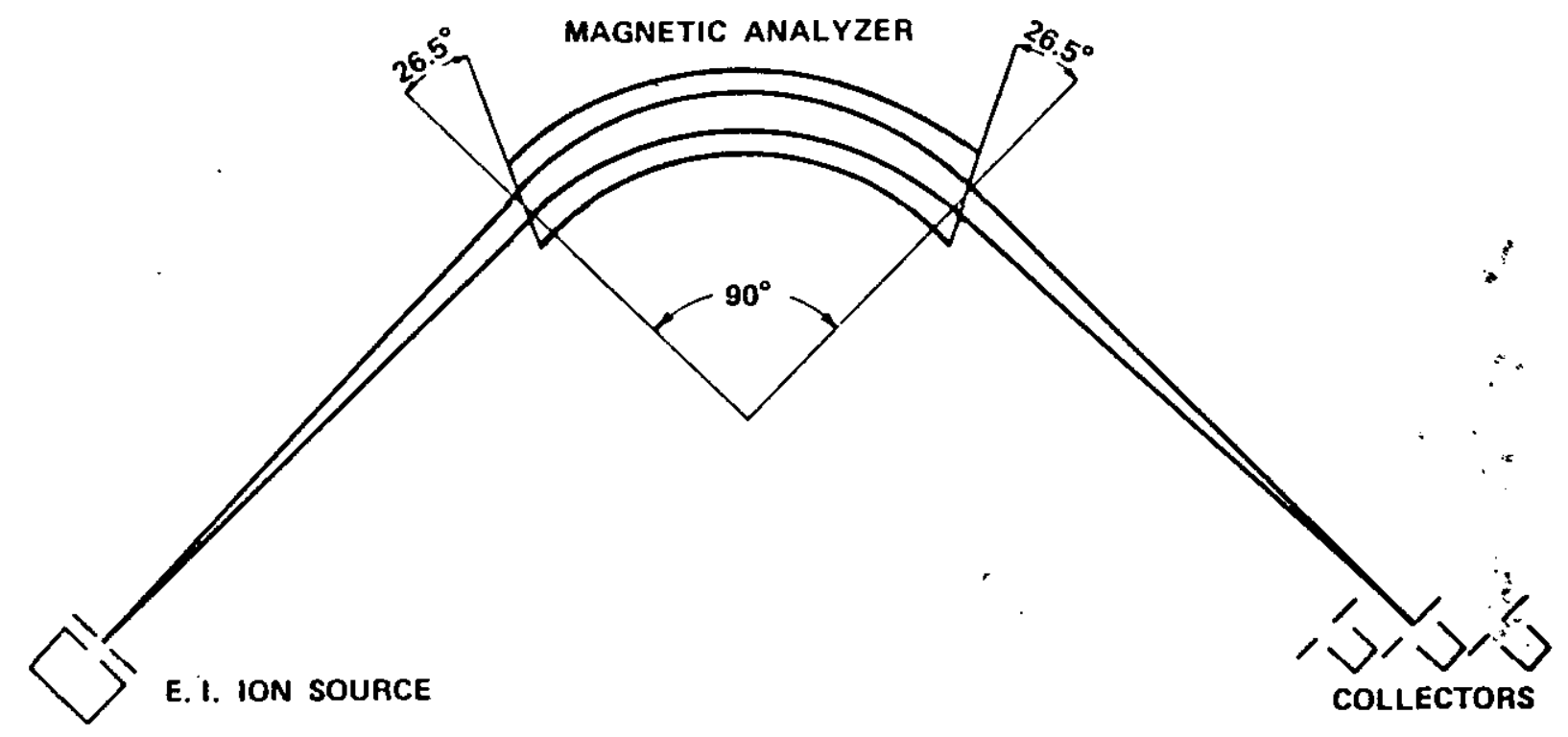

FIGURE 6. Ion Optical System Finnigan MAT 250 HDT 
exit slit and is directed into the analyzer. An einzel lens between the source and the analyzer further improves the " $Z$ " focusing.

The instrument is equipped with the triple Faraday cage ion collector system of the standard MAT 250. Only one collector is used at a time when analyzing $H, D$, and $T$ mixtures. Therefore, the collectors have been equipped with different sized slits. This allows the operator to $r$ un the instrument at different resolutions without having to vent the analyzer to change slits.

The voltages in the ion source are fixed, except for the single change needed to compensate for mass discrimination. A series of voltage taps, adjusted for masses $2,3,4,5,6$, and a mass $>12$, are provided for one focusing half plate. The taps are switched automatically when the mass spectrum is scanned.

Modern solid-state technology is used in all the electronic units. The high voltage and magnet power supplies are designed for both manual and computer control.

The analyzer system is evacuated by two turbomolecular pumps backed by a small diffusion pump and a dual-stage mechanical pump. The diffusion pump increases the hydrogen compression ratio of the pumping system. A liquid nitrogen trap is provided in the source pumping line. Ion and thermocouple gages monitor the pressure. Automatic controls shut down and vent the instrument safely if a pressure rise or a power failure occurs.

The entire mass spectrometer operates under control of a Hewlett-Packard HP-9845 computer with software provided by Finnigan MAT. The prototype software was satisfactory for $\mathrm{H}-\mathrm{D}{ }^{3} \mathrm{He}$ mixture tests at a resolution of 600 . It was not satisfactory for $D-T$ mixture tests. Final software for operation at a resolution of 600 was being written by the Finnigan MAT staff in Bremen, but it was not completed before the end of the SRL/SRP mass spectrometer evaluation program.

The MAT prototype software was modified for operation at a resolution of 1300 by T. Mehrhoff, General Electric Co., St. Petersburg, FL (GEND). The modified software proved sat isfactory for the analysis of D-T mixtures with a MAT $251 \mathrm{HDT}$, the production version of the MAT 250 HDT mass spectrometer.

\section{FACTORY ACCEPTANCE TESTS}

The Finnigan MAT 250 HDT mass spectrometer successfully passed all the specified acceptance tests shown in Appendix VI. $P$. Chastagner and $H$. L. Daves witnessed the tests in Bremen, Germany, on September 8-10, 1980. Additional tests in other modes 
of operation were conducted September 11 and 12 . The instrument was shipped to SRL and arrived October 3 .

Acceptance test conditions for the MAT 250 HDT were unusually severe in that magnetic collimation of the electron beam in the ion source was prohibited. Under these conditions, there is no mass discrimination, but ion intensity is usually diminshed and other characteristics are degraded. The result is a "worst case" test which established the minimum capabilities of the instrument. As shown in Table 5 , the sensitivity was almost four times the specified value and the instrument equalled or exceeded all other specifications.

TABLE 5

Performance Test Results for Varian MAT 250 HDT Mass Spectrometer

Operating Characteristic

$\mathrm{H}_{2}$ sensitivity

$\mathrm{H}_{2}$ linearity

Ar linearity

$\mathrm{H}_{2}-\mathrm{D}_{2}$ mass discrimination

$\mathrm{HD}-{ }^{3} \mathrm{He}$ abundance sensitivity

$\mathrm{D}_{3}$ production

Peak flatness
Specification*

$>10^{-9} \mathrm{~A} /$ torr

$<0.01$

$>0.01$

None detected

$>20,000$

$<120 \mathrm{ppm}$ at $10^{-9} \mathrm{~A}$

$<0.001$ over $\pm 5 \%$ width
Result**

$3.8 \times 10^{-9} \mathrm{~A} /$ torr

0.006

0.004

None detected 40,000 $58 \mathrm{ppm}$

0.00062

* Appendix VII

** Measured at Bremen, Germany on September 8-12, 1980

During the course of the testing, Chastagner and Daves concluded that, despite the good results, routine operation of the instrument without source magnets would not be practical. Without the magnets, only about $10 \%$ of the electrons emitted from the filament reach the trap. The other $90 \%$ impact the walls of the ionization chamber. Insulating deposits build up on the chamber walls during normal operation. These deposits become charged and deflect the electron beam; the source becomes unstable and frequent cleaning is required. However, when collimating magnets are in place, 80 to $90 \%$ of the electrons reach the trap, and few electrons impact the walls of the ionization chamber. Consequently, the effect of charging the deposits is minimized, stability is maintained, and normal source life is attained. 
With collimating magnets in place in the ion source, sensitivity is improved about $25 \%$, the ion peak shape is markedly better (Figure 7), and the resolution is substantially improved. When the collector slit was reduced from $0.6 \mathrm{~mm}$ to $0.34 \mathrm{~mm}$, the resolution was increased to about 850 (Figure 8 ) without loss of sensitivity. The sensitivity for $\mathrm{H}_{2}$ and $\mathrm{D}_{2}$, corrected to equivalent SRP and MSTG terms $\left(0.2 \mathrm{~cm}^{3} \mathrm{~N}_{2} / \mathrm{sec}\right.$ leak and $1 \times 10^{11}$ ohm input resistor) was about $920 \mathrm{mV} / \mu$ with a total emission of $1 \mathrm{~mA}$. This is equivalent to about $90 \mathrm{mV} / \mu$ with conventional electron beam intensities ( $100 \mu \mathrm{A}$ total emission). The high sensitivity and high ion output of the instrument are obtained with high ionizing currents and high sample pressures. The Varian source is linear at ionizing currents and sample pressures that are each ten times higher than those we consider conventional.

The collimating magnets introduced 15 to $20 \%$ mass discrimination between $\mathrm{H}_{2}$ and $\mathrm{D}_{2}$. Tests showed that a small voltage adjustment to one ion source focus lens would restore optimum transmission and eliminate the mass discrimination.

Equilibration, the formation of HD or HT in the ion source by reaction with the $\mathrm{H}_{2} \mathrm{O}$ background, produced about $0.2 \%$ HD when several hundred microns of $\mathrm{D}_{2}$ gas was introduced into the mass spectrometer. Although this was significantly less than observed with Varian's prototype instrument, this much equilibration is still undesirable. Further reduction of equilibration was made a major goal during the evaluation program.

Extrapolation of then current performance data suggested the possibility of increasing the resolution of 1500 to 1800 . The resolutions obtained in the tests at Bremen were about $90 \%$ of the theoretical values, which indicated very good focusing of the ion source and the stigmatic-focusing analyzer system. If this $90 \%$ figure is maintained with smaller slits, the resolution would be about 1600 with a $0.05-\mathrm{mm}$ source exit slit and a $0.20-\mathrm{cm}$ collector slit. Ion intensity, which is in theory proportional to the area of the ion-source exit slit, could be about $1 \times 10^{-9} \mathrm{~A}$. Even allowing for unspecified experimental losses, the intensity should be at least $3 \times 10^{-10}$ to $5 \times 10^{-10} \mathrm{~A}$. Under such conditions, abundance sensitivity at the mass $4 \mathrm{HT}-\mathrm{D}_{2}$ doublet should be 5,000 to 7,000. Varian furnished a variety of slits with the instrument so that higher-resolution performance could be tested at SRL.

\section{INSTALLATION AND ACCEPTANCE AT SRL}

Installation of the MAT 250 HDT was completed in January 1981 after a long series of delays. The primary cause of the installation problems appeared to be that the Varian engineer had little or no experience with the instrument. Problems included: shipping 


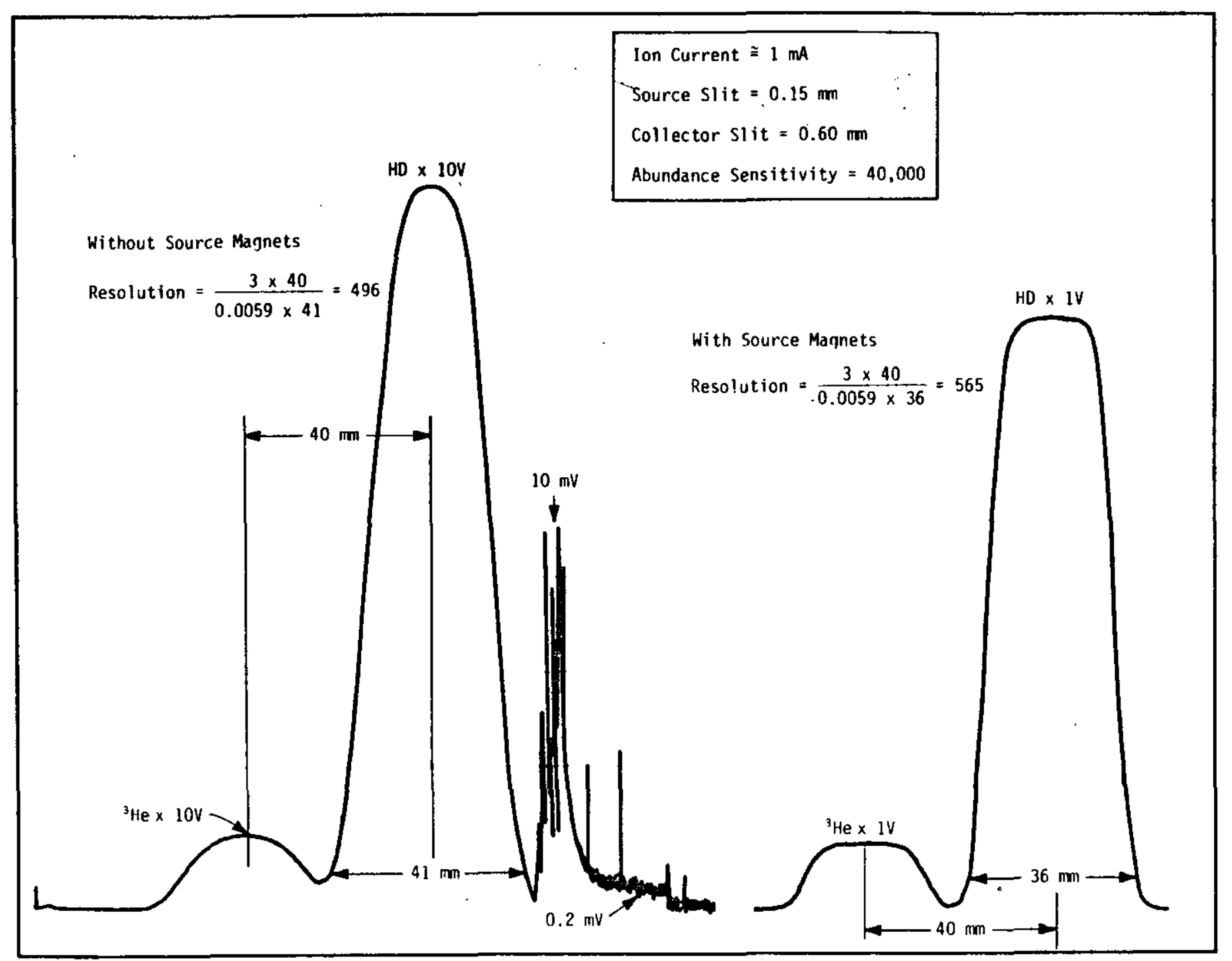

FIGURE 7. Use of Collimating Source Magnets Improves Ion Peak Shape 


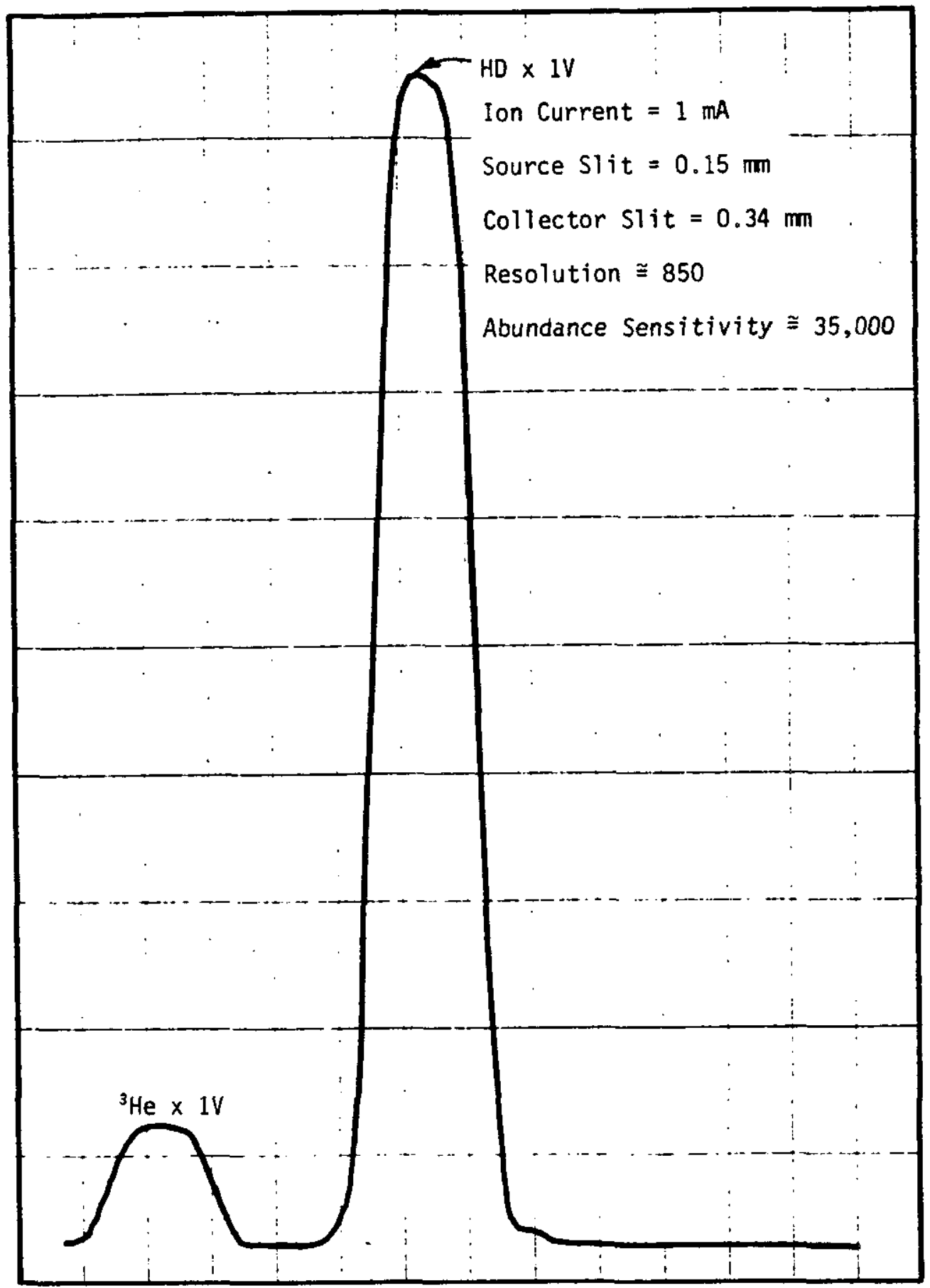

FIGURE 8. Improved Resolution Achieved by Ose of Collimating Source Magnets 
damage; delays in obtaining an inlet system; vacuum system accidents caused by improper operation; failure to order replacements for damaged parts; and inability to align the analyzer.

The MAT 250 HDT was accepted from Varian February 19, 1981 after a series of specification tests in which barely acceptable data were obtained (Appendix VII). An earlier set of test data was rejected because the instrument was not operated under a single set of conditions. The results of these tests were markedly poorer than those obtained in the Bremen tests. The sensitivity was less than half that obtained in Bremen and all other factors were worse. In post acceptance tests with source magnets in place, the sensitivity was still low, the peak shape was poor, and the linearity varied from about $0.4 \%$ to more than $1 \%$ in consecutive tests under constant conditions. Subsequently, Du Pont personnel found that the analyzer was out of alignment mechanically, and that the einzel lens system was "floating", i.e., was not connected to the electrical control system. When the analyzer was realigned and the einzel lens system was connected, the peak shape and the linearity were improved. But the sensitivity was still low and the resolution was poor.

\section{TRANSITION FROM VARIAN TO FINNIGAN MANAGEMENT}

In February 1981, Finnigan and Varian announced that the MAT operation would be sold to Finnigan. The transition was completed in May and Finnigan management immediately moved to rectify the problems with the MAT $250 \mathrm{HDT}$. In June, a factory engineer restored the instrument to the performance level obtained in the Bremen tests. In September, factory engineers upgraded, at Finnigan's expense, the instrument for full digital control. Essentially all of the original analog control circuitry was replaced. The instrument was then functionally equivalent to the MAT $251 \mathrm{HDT}$. The prototype software for operation at a resolution of 600 was written at that time and full computer control was implemented.

\section{EQUILIBRATION}

Equilibration of $\mathrm{H}$ and $\mathrm{D}$ in the ion source was reduced to $300 \mathrm{ppm}$ from the $2700 \mathrm{ppm}$ level when the original ribbon filament was replaced with a wire filament. Equilibration with the wire filament in place was essentially the same as that of the GAZAB ion source. 


\section{CHARACTERIZATION TESTS}

An SRP blended mixture, $4.03 \mathrm{M} \%{ }^{3} \mathrm{He}$, balance $\mathrm{D}_{2}$, was analyzed at five different times to evaluate the precision and accuracy of the MAT 250 HDT. The ${ }^{3} \mathrm{He}$ data from all of the $\mathrm{runs}$ are summarized in Table 6. A typical set of runs is given in Table 7. The precision obtained for the ${ }^{3} \mathrm{He}$ determination is a factor of two better than that obtained with the GAZAB mass spectrometer.

One of the Mound Laboratory mixtures, mixture No. 1, that was used for acceptance testing of the GAZAB, was analyzed repetitively over a four-day period on the MAT $250 \mathrm{HDT}$. The results are in Tables 8-11. Each day the mass spectrometer was calibrated in triplicate before the analyses were made. The results are consistent with those made with other mass spectrometers. All instruments have shown that the ${ }^{3} \mathrm{He}$ concentration is lower than the theoretical value and that the total H concentration is higher. The systematic changes in closure, becoming more negative in each successive analysis, as if the sensitivities were changing, were caused by the source contamination described above.

\section{TABLE 6}

\section{Replicate Analyses of SRP Mix by Finnigan MAT 250 HDT Mass Spectrometer}

\begin{tabular}{|c|c|c|c|c|c|}
\hline \multirow{2}{*}{ 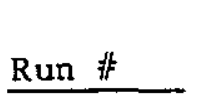 } & \multicolumn{2}{|c|}{ Precision-Accuracy } & \multicolumn{2}{|c|}{ SRP $\operatorname{Mix}\left(4.03 \%{ }^{3} \mathrm{He}-\right.$} & \multirow{2}{*}{$\frac{\text { Balance } \mathrm{D}_{2}}{\text { Time } 5}$} \\
\hline & Time 1 & Time 2 & Time 3 & Time 4 & \\
\hline 1 & 4.028 & 4.033 & 4.022 & 4.007 & 4.016 \\
\hline 2 & 4.028 & 4.033 & 4.026 & 4.012 & 4.018 \\
\hline 3 & 4.027 & 4.034 & 4.027 & 4.012 & 4.015 \\
\hline 4 & 4.026 & 4.033 & 4.025 & 4.012 & 4.014 \\
\hline 5 & 4.029 & 4.040 & 4.023 & 4.011 & 4.016 \\
\hline 6 & 4.027 & 4.031 & 4.023 & 4.013 & 4.016 \\
\hline 7 & 4.026 & & 4.024 & 4.014 & 4.016 \\
\hline 8 & 4.026 & & 4.025 & 4.013 & 4.014 \\
\hline 9 & 4.026 & & 4.024 & 4.011 & 4.014 \\
\hline 10 & 4.023 & & 4.026 & 4.012 & 4.016 \\
\hline Average & 4.026 & 4.032 & 4.024 & 4.012 & 4.016 \\
\hline RSD \% & $0.04 \%$ & $0.04 \%$ & $0.04 \%$ & $0.05 \%$ & $0.03 \%$ \\
\hline Accuracy & $-0.08 \%$ & $+0.05 \%$ & $-0.14 \%$ & $-0.45 \%$ & $-0.36 \%$ \\
\hline
\end{tabular}




\section{TABLE 7}

Typical Set of Runs with SRP Mix by Finnigan MAT 250 HDT Mass Spectrometer

\begin{tabular}{|c|c|c|c|c|c|}
\hline \multirow[b]{2}{*}{ Run No. } & \multirow[b]{2}{*}{$\mathrm{He}$} & Runs SRF & \multicolumn{2}{|c|}{$P \operatorname{Mix}(4.03 \%$} & \multirow{2}{*}{$\begin{array}{l}\left.- \text { Balance } \mathrm{D}_{2}\right) \\
\begin{array}{l}\text { Closure } \\
\text { Baratron }-\Sigma_{\mathrm{PP}} \\
\text { Percent }\end{array} \\
\end{array}$} \\
\hline & & $\underline{\mathrm{HD}}$ & $\underline{\mathrm{D}}$ & $\underline{\mathrm{N}}$ & \\
\hline 1 & 4.022 & 0.778 & 95.166 & 0.030 & -0.22 \\
\hline 2 & 4.026 & 0.731 & 96.211 & 0.031 & -0.37 \\
\hline 3 & 4.027 & 0.731 & 95.212 & 0.031 & -0.52 \\
\hline 4 & 4.025 & 0.730 & 95.214 & 0.030 & -0.63 \\
\hline 5 & 4.023 & 0.730 & 95.217 & 0.029 & -0.52 \\
\hline 6 & 4.023 & 0.729 & 95.217 & 0.030 & -0.40 \\
\hline 7 & 4.024 & 0.730 & 95.216 & 0.030 & -0.25 \\
\hline 8 & 4.025 & 0.729 & 95.215 & 0.030 & -0.36 \\
\hline 9 & 4.024 & 0.729 & 95.216 & 0.030 & -0.39 \\
\hline 10 & 4.026 & 0.730 & 95.213 & 0.030 & -0.42 \\
\hline
\end{tabular}


TABLE 8

Precision - Accuracy Finnigan MAT 250 - Mound Mixture No. 1, 4/19/82

\begin{tabular}{|c|c|c|c|c|c|c|}
\hline \multirow{2}{*}{$\begin{array}{l}\text { Run } \\
\text { No. } \\
\end{array}$} & \multirow[b]{2}{*}{$\underline{\mathrm{H}}_{2}$} & \multirow[b]{2}{*}{${ }^{3} \mathrm{He}$} & \multirow[b]{2}{*}{$\underline{H D}$} & \multirow[b]{2}{*}{$\underline{D}_{2}$} & \multirow[b]{2}{*}{ Total H } & $\begin{array}{l}\text { Closure, }{ }^{*} \\
\left(\text { Baratron }-\Sigma_{\mathrm{pp}}\right. \\
\end{array}$ \\
\hline & & & & & & (Baratron, \% \\
\hline 1 & 0.461 & 3.996 & 11.253 & 84.277 & 6.088 & +0.36 \\
\hline 2 & 0.452 & 3.995 & 11.249 & 84.288 & 6.077 & +0.12 \\
\hline 3 & 0.454 & 4.000 & 11.251 & 84.285 & 6.079 & -0.01 \\
\hline 4 & 0.460 & 3.995 & 11.250 & 84.275 & 6.085 & -0.05 \\
\hline 5 & 0.461 & 3.997 & 11.247 & 84.247 & 6.084 & -0.29 \\
\hline 6 & 0.460 & 3.996 & 11.250 & 84.278 & 6.085 & -0.39 \\
\hline 7 & 0.461 & 3.998 & 11.248 & 84.280 & 6.085 & -0.48 \\
\hline 8 & 0.463 & 3.994 & 11.250 & 84.274 & $\underline{6.084}$ & -0.49 \\
\hline Average & & 3.996 & & & 6.084 & \\
\hline Std. Dev. & & \pm 0.0019 & & & \pm 0.0039 & \\
\hline Rel. Std. & - Dev. & \pm 0.05 & & & \pm 0.06 & \\
\hline$\Delta_{\text {Theor }}$. & & -0.12 & & & +1.26 & \\
\hline
\end{tabular}

$\star \Sigma_{p p}=$ sum of partial pressures 
TABLE 9

Precision - Accuracy Finnigan MAT 250 - Mound Mixture No. 1, 4/20/82

\begin{tabular}{|c|c|c|c|c|c|c|}
\hline $\begin{array}{l}\text { Run } \\
\text { No. }\end{array}$ & $\mathrm{H}_{2}$ & ${ }^{3} \mathrm{He}$ & $\mathrm{HD}$ & $\mathrm{D}_{2}$ & Total H & $\begin{array}{l}\text { Closure, }{ }^{*} \\
\text { Baratron- } \Sigma_{\mathrm{pp}} \\
\text { Baratron, \% }\end{array}$ \\
\hline 1 & 0.457 & 3.983 & 11.231 & 84.317 & 6.072 & +0.19 \\
\hline 2 & 0.463 & 3.981 & 11.212 & 84.332 & 6.069 & +0.12 \\
\hline 3 & 0.462 & 4.981 & 11.211 & 84.335 & 6.067 & -0.32 \\
\hline 4 & 0.462 & 3.981 & 11.210 & 84.336 & 6.067 & -0.47 \\
\hline 5 & 0.462 & 3.982 & 11.209 & 84.335 & 6.066 & -0.57 \\
\hline 6 & 0.463 & 3.982 & 11.209 & 84.333 & 6.068 & -0.68 \\
\hline 7 & 0.458 & 3.982 & 11.207 & 84.341 & 6.062 & -0.75 \\
\hline 8 & 0.462 & 3.983 & 11.207 & 84.338 & 6.066 & -0.83 \\
\hline 9 & 0.450 & 3.983 & 11.207 & 84.350 & 6.054 & -0.90 \\
\hline Average & & 3.982 & & & 6.066 & \\
\hline Std. Dev. & & \pm 0.0009 & & & \pm 0.0051 & \\
\hline $\operatorname{Re} 1$. Std. & Dev. & \pm 0.02 & & & \pm 0.08 & \\
\hline$\Delta_{\text {Theor }}$ & & -0.47 & & & +0.96 & \\
\hline
\end{tabular}


TABLE 10

Precision - Accuracy Finnigan MAT 250 - Mound Mixture No. 1, 4/21/82

\begin{tabular}{|c|c|c|c|c|c|c|}
\hline & & & & & & $\begin{array}{l}\text { Closure, }{ }^{*} \\
\left.\text { Baratron- }-\Sigma_{p p}\right)\end{array}$ \\
\hline No. & $\mathrm{H}_{2}$ & ${ }^{3} \mathrm{He}$ & HD & $\mathrm{D}_{2}$ & Total H & Baratron, $\%$ \\
\hline 1 & 0.492 & 4.006 & 11.409 & 84.067 & 6.196 & +0.75 \\
\hline 2 & 0.474 & 3.994 & 11.260 & 84.246 & 6.104 & +0.13 \\
\hline 3 & 0.473 & 3.993 & 11.234 & 84.276 & 6.090 & -0.09 \\
\hline 4 & 0.471 & 3.993 & 11.228 & 84.286 & 6.085 & -0.21 \\
\hline 5 & 0.472 & 3.993 & 11.225 & 84.288 & 6.084 & -0.34 \\
\hline 6 & 0.472 & 3.993 & 11.231 & 84.279 & 6.088 & -0.40 \\
\hline 7 & 0.471 & 3.994 & 11.230 & 84.282 & 6.087 & -0.48 \\
\hline 8 & 0.471 & 3.994 & 11.227 & 84.286 & 6.084 & -0.53 \\
\hline 9 & 0.470 & 3.995 & 11.228 & 84.286 & $6.084^{\circ}$ & -0.58 \\
\hline 10 & 0.467 & 3.993 & 11.226 & 84.292 & 6.080 & -0.65 \\
\hline 11 & 0.469 & 3.996 & 11.226 & 84.287 & 6.082 & -0.69 \\
\hline 12 & 0.471 & 3.995 & 11.226 & 84.287 & 6.083 & -0.68 \\
\hline Average & & 3.994 & & & 6.086 & \\
\hline Std. Dev. & & \pm 0.0010 & & & \pm 0.0064 & \\
\hline Rel. Std. & - Dev. & \pm 0.03 & & & \pm 0.11 & \\
\hline$\Delta_{\text {Theor }}$ & & -0.17 & & & +1.29 & \\
\hline
\end{tabular}

* $\Sigma_{\mathrm{pp}}=$ Sum of partial pressures 
TABLE 11

Precision - Accuracy Finnigan MAT 250 - Mound Mixture No. 1, 4/22/82

\begin{tabular}{|c|c|c|c|c|c|c|}
\hline $\begin{array}{l}\text { Run } \\
\text { No. } \\
\end{array}$ & $\mathrm{H}_{2}$ & ${ }^{3} \mathrm{He}$ & HD & $\underline{\mathrm{D}_{2}}$ & Total H & $\begin{array}{l}\text { Closure, }{ }^{*} \\
\left(\begin{array}{l}\text { Baratron- }-\Sigma_{\mathrm{pp}} \\
\text { Baratron, } \%\end{array}\right)\end{array}$ \\
\hline 1 & 0.471 & 3.985 & 11.231 & 84.279 & 6.086 & +0.35 \\
\hline 2 & 0.471 & 3.983 & 11.215 & 84.298 & 6.078 & +0.02 \\
\hline 3 & 0.472 & 3.982 & 11.203 & 84.309 & 6.074 & -0.17 \\
\hline 4 & 0.472 & 3.982 & 11.199 & 84.313 & 6.072 & -0.33 \\
\hline 5 & 0.472 & 3.981 & 11.195 & 84.317 & 6.070 & -0.38 \\
\hline 6 & 0.477 & 3.992 & 11.209 & 84.286 & 6.082 & -0.07 \\
\hline 7 & 0.472 & 3.982 & 11.196 & 84.315 & 6.070 & -0.35 \\
\hline 8 & 0.471 & 3.982 & 11.194 & 84.318 & 6.068 & -0.44 \\
\hline 9 & 0.472 & 3.982 & 11.194 & 84.317 & 6.069 & -0.46 \\
\hline 10 & 0.471 & 3.982 & 11.194 & 84.319 & 6.068 & -0.55 \\
\hline Average & & 3.983 & & & 6.074 & \\
\hline Std. Dev. & & \pm 0.0032 & & & \pm 0.0063 & \\
\hline Rel. Std. & Dev & \pm 0.08 & & & \pm 0.10 & \\
\hline$\Delta_{\text {Theor }}$ & & -0.45 & & & +1.10 & \\
\hline
\end{tabular}




\section{EMISSION REGULATION MODE}

The mode of regulating the emission of ionizing electrons from the filament in the ion source was changed form the "total emission" mode originally used to the "trap current" mode in mid-July 1982. In the "total emission" mode, the total number of electrons that leave the filament is controlled. It is assumed that a constant percentage traverse the ionizing region. In the "trap current" mode, the number of electrons that traverse the ionizing region and arrive at the "trap" (ionizing electron collector) is controlled. The change improved the day-to-day stability of the ion source. Day-to-day changes in sensitivity for the July 15 to August 24 period are shown graphically in Figure 9. No values were plotted for the August 12-16 period because daily power outages prevented the source from stabilizing.

The source temperature regulator was al so turned off in midJuly. The source cooled and stabilized at a temperature below the 150 to $250^{\circ} \mathrm{C}$ range of the source monitor. The temperature was not measured. At the lower source temperature, the sensitivities were about $20 \%$ greater than they were when the source was stabilized at $150^{\circ} \mathrm{C}$.

\section{GEND TESTS AT 1300 RESOLUTION}

Norman Parsons, GEND, informed us that their MAT 251 HDT mass spectrometer passed its acceptance tests in Bremen. After the low resolution tests (resolution $>500$ ), Finnigan MAT personnel installed small slits and demonstrated a resolution of 1300 with good peak shape. Parsons furnished Figure 10 , which shows the $\mathrm{H}_{2}+-\mathrm{D}+$ doublet. Sensitivity for $\mathrm{H}_{2}$ was $7.2 \times 10^{-11} \mathrm{~A} /$ tor at high resolution anlet. $1.26 \times 10^{-9} \mathrm{~A} /$ torr at a low resolution with about $0.1 \mathrm{cc} / \mathrm{SPC}$ (ford $\mathrm{N}_{2}$ ) molecular leak in the inlet system. Ion output at high resolution was linear within $0.7 \%$ (extreme spread) over the inlet system pressure range of 0.12 to 1.02 torr.

After installation at GEND the MAT 251 HDT was put into tritium service. Norman Parsons reported that it was being operated routinely at a resolution of 1300 . Parsons sent the set of initial results shown in Table 12. These runs were made with a partially plugged molecular leak in the sample inlet system which is the reason for the relatively low sensitivity. Results obtained with the GEND Du Pont 21-104 mass spectrometer are given in Table 13 for comparison. The sample, SRP mix 非-MR was made up to be $50 \% \mathrm{D}$ $50 \% \mathrm{~T}$ in 1976. The values obtained with the MAT 251 HDT agree very well with the theoretically decayed values when corrected for protium ingrowth. Tom Mehrhoff, GEND, modified the low resolution Finnigan MAT software extensively. The modified software operates the MAT 251 HDT reliably at 1300 resolution. 


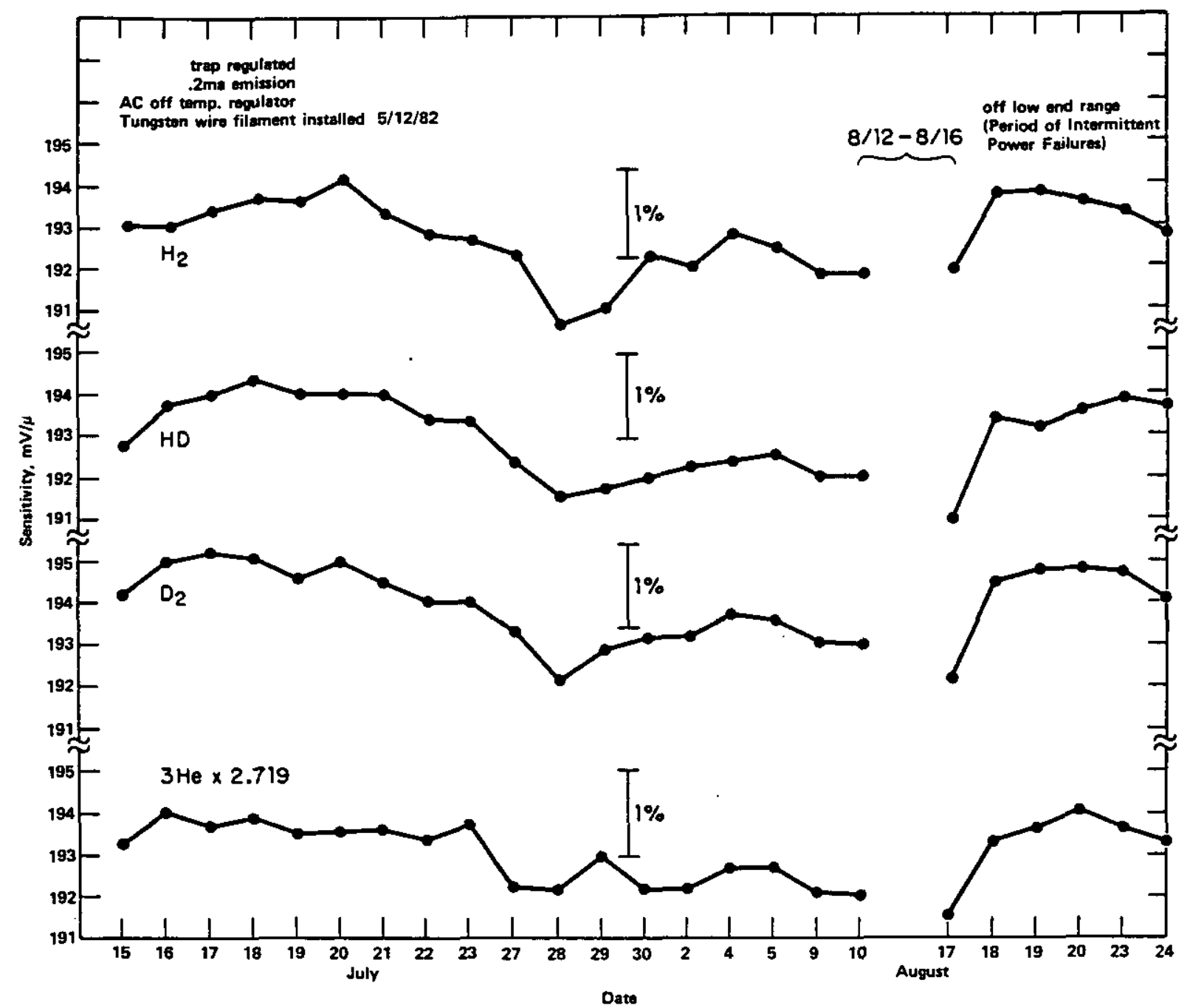

FIGURE 9. Sensitivity Change vs Time SRP MAT 250 HDT 


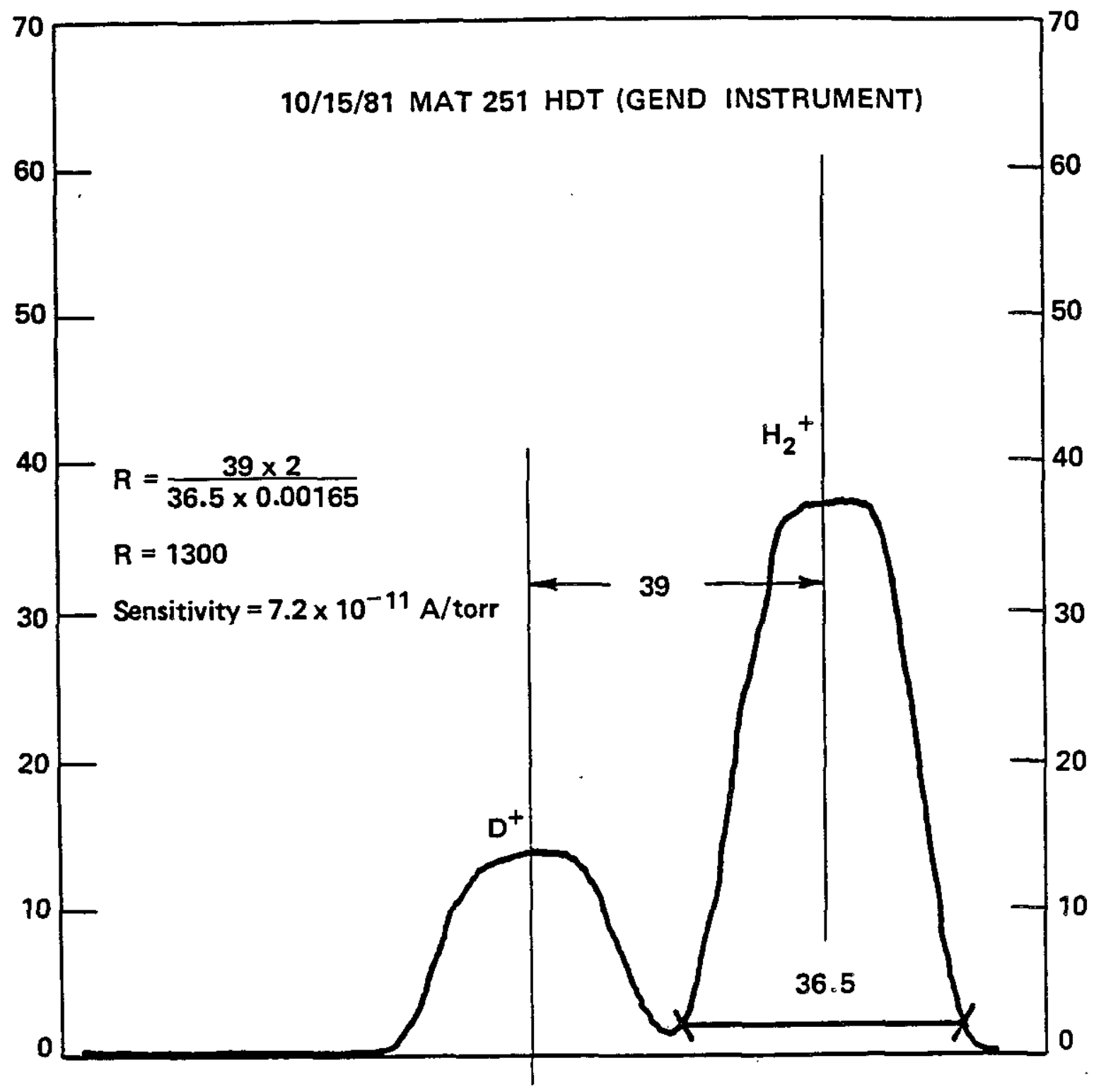

FIGURE 10. High-Resolution Test (in Bremen) 
TABLE 12

Operation of Finnigan MAT 251 Mass Spectrometer at GEND*

Operating Parameters

Resolution $-\sim 1300$

Ribbon Filament; Emission - 0.400 MA

Ion Source Temperature $-149.6^{\circ} \mathrm{C}$

Trap - 149.6 volts

Electron Energy - 80.1 volts

Electron Plate -96.9 volts

Amplifier IV - $1 \times 10^{11}$ ohms

Sensitivity $-D_{2}=3.65 \mathrm{mV} / \mu$

Calibrated $3 / 29 / 82$ using SRP Mix $\# 5$ T330

Analysis of SRP Mix 非3-MR (50-50) Vessel 非274-07,3/30/82

\begin{tabular}{|c|c|c|c|c|c|}
\hline & $\begin{array}{l}\text { Total } \mathrm{H}_{2}, \\
\text { mol } \%\end{array}$ & $\begin{array}{l}\text { Total } \mathrm{D}_{2}, \\
\text { mol } \%\end{array}$ & $\begin{array}{l}\text { Total } \mathrm{T}_{2}, \\
\text { mol } \% \\
\end{array}$ & $\begin{array}{l}{ }^{3} \mathrm{He}, \\
\text { mol } \%\end{array}$ & $\begin{array}{l}\text { Inlet Press., } \\
\mathrm{mT}\end{array}$ \\
\hline & 0.383 & 44.306 & $29.34 \mathrm{I}$ & 25.971 & 275.9 \\
\hline & 0.386 & 44.229 & 29.313 & 26.072 & 238.0 \\
\hline & 0.377 & 44.289 & 29.281 & 26.053 & 166.0 \\
\hline & 0.369 & 44.258 & 29.263 & 26.111 & 164.1 \\
\hline & 0.375 & 44.228 & 29.320 & 26.078 & 161.8 \\
\hline & 0.391 & 44.308 & 29.333 & 25.968 & 251.2 \\
\hline & 0.394 & 44.236 & 29.317 & 26.054 & 211.8 \\
\hline & 0.390 & 44.235 & 29.281 & 26.096 & 178.5 \\
\hline & 0.398 & 44.273 & 29.279 & 26.050 & 150.5 \\
\hline & 0.391 & 44.215 & 29.318 & 26.077 & 151.8 \\
\hline Mean & 0.385 & 44.258 & 29.305 & 26.053 & \\
\hline S.D. & 0.009 & 0.034 & 0.026 & 0.048 & \\
\hline S.D. \% & 2.34 & 0.18 & 0.08 & 0.09 & \\
\hline Std. Value & $0.105^{* *}$ & 44.312 & 29.541 & 26.038 & \\
\hline Difference \% & & -0.12 & -0.80 & +0.06 & \\
\hline
\end{tabular}

* GEND data courtesy of N. H. Parsons.

** This mix has been in use since October 1975. Pressure is 52 torr. Hydrogen ingrowth has been confirmed to be higher than theoretical. Theoretical value appears to be close to value obtained in the analyses. 
TABLE 13

Operation of Du Pont 21-104 Mass Spectrometer at GEND*

Operating Parameters

Resolution $-\sim 1300$

Analys is of SRP Mix 非3-MR (50-50) Vessel 非1274-07

\begin{tabular}{|c|c|c|c|}
\hline $\begin{array}{l}\text { Total } \mathrm{H}_{2} \text {, } \\
\text { mol } \%\end{array}$ & $\begin{array}{l}3 \mathrm{He}, \\
\text { mol } \%\end{array}$ & $\begin{array}{ll}\text { Total } & D_{2}, \\
\text { mol } \% & \\
\end{array}$ & $\begin{array}{l}\text { Total } \mathrm{T}_{2}, \\
\text { mol } \%\end{array}$ \\
\hline 0.420 & 25.575 & 44.335 & 29.670 \\
\hline 0.387 & 25.328 & 44.331 & 29.954 \\
\hline 0.324 & 25.255 & 44.443 & 29.977 \\
\hline 0.386 & 25.293 & 44.470 & 29.850 \\
\hline 0.402 & 25.449 & 44.368 & 29.781 \\
\hline 0.384 & 25.380 & 44.389 & 29.847 \\
\hline 0.029 & 0.135 & 0.059 & 0.123 \\
\hline 7.55 & 0.53 & 0.13 & 0.41 \\
\hline \multirow[t]{2}{*}{0.105} & 26.038 & 44.312 & 29.541 \\
\hline & -2.53 & +0.17 & +1.04 \\
\hline
\end{tabular}

* GEND data courtesy of N. H. Parsons.

THE SAVANNAH RIVER LABORATORY TEST FACILITY

Summary

The test facility was a large air conditioned laboratory that was equipped with duplicate inlet systems for the mass spectrometers and containment facilities for tritium. A series of tests established that the inlet systems were identical and that meaningful comparisons could be made between the two mass spectrometers. $\mathrm{T} / \mathrm{D} /{ }^{3} \mathrm{He}$ and $\mathrm{D} / \mathrm{H} /{ }^{3} \mathrm{He}$ standards were provided to allow assessment of both the precision and the absolute accuracy of the mass

spectrometers. 


\section{Facility Description}

The Savannah River Laboratory Test Facility (Figure 11) was designed so the GAZAB and MAT 250 HDT mass spectrometers could be tested simultaneously with the same standard materials. The facility is air conditioned and has:

- Duplicate mass spectrometer inlet systems supplied by common standard manifolds

- A tritium recovery system

- Hood exhausts for the ion sources

- A tritium monitoring system

- Full containment for all tritium handling operations.

The dual inlet systems and standard distribution systems were designed and built by H. L. Daves and W. B. Hess. The systems are located in a 8-foot long glove box (Figure 12) that is located between the mass spectrometers.

As shown in Figure 13, each mass spectrometer has its own dedicated inlet system that includes a 3 liter volume, Baratron pressure sensors, a tritium activity meter for measuring total tritium, a molecular leak and a ${ }^{4} \mathrm{He}$ flow standard. Manifolds for nonradioactive gases and for tritium mixtures are shared by both mass spectrometers. The manifold for nonradioactive gases is isolated from the rest of the system by valve, V2, and is located outside the glove box. All valves except the dispensing valves on the tritium containers are pneumatic and can be operated from either mass spectrometer console.

The various sampling and storage vessels used on the system are diagrammed in Figure 14. The "cold gas bottles" are used for all nonradioactive pure gases except HD. They are equipped with internal capillary leaks to 1 imit the gas flow and with pneumatic valves for operator convenience. $\mathrm{D}-\mathrm{T}$ mixtures and $\mathrm{HD}$ are stored in "passivated stainless steel standard bottles". A $\mathrm{T}_{2}$ storage vessel equipped with a "palladium diffuser" is used to provide pure $\mathrm{T}_{2}$ to the mass spectrometers. The total tritium inventory, $\sim, 000 \mathrm{Ci}$, is stored in these vessels at subatmospheric pressures.

A tritium recovery system, designed by $P$. Chastagner, was installed in a 4-foot-long glove box (Figure 15). As shown in Figure 16, effluents from the mass spectrometer and inlet system pumps are piped into the recovery system. Traps are provided in the collection system to remove entrained oil and a ballast volume reduces pressure surges during pumpdown from atmospheric pressure. 


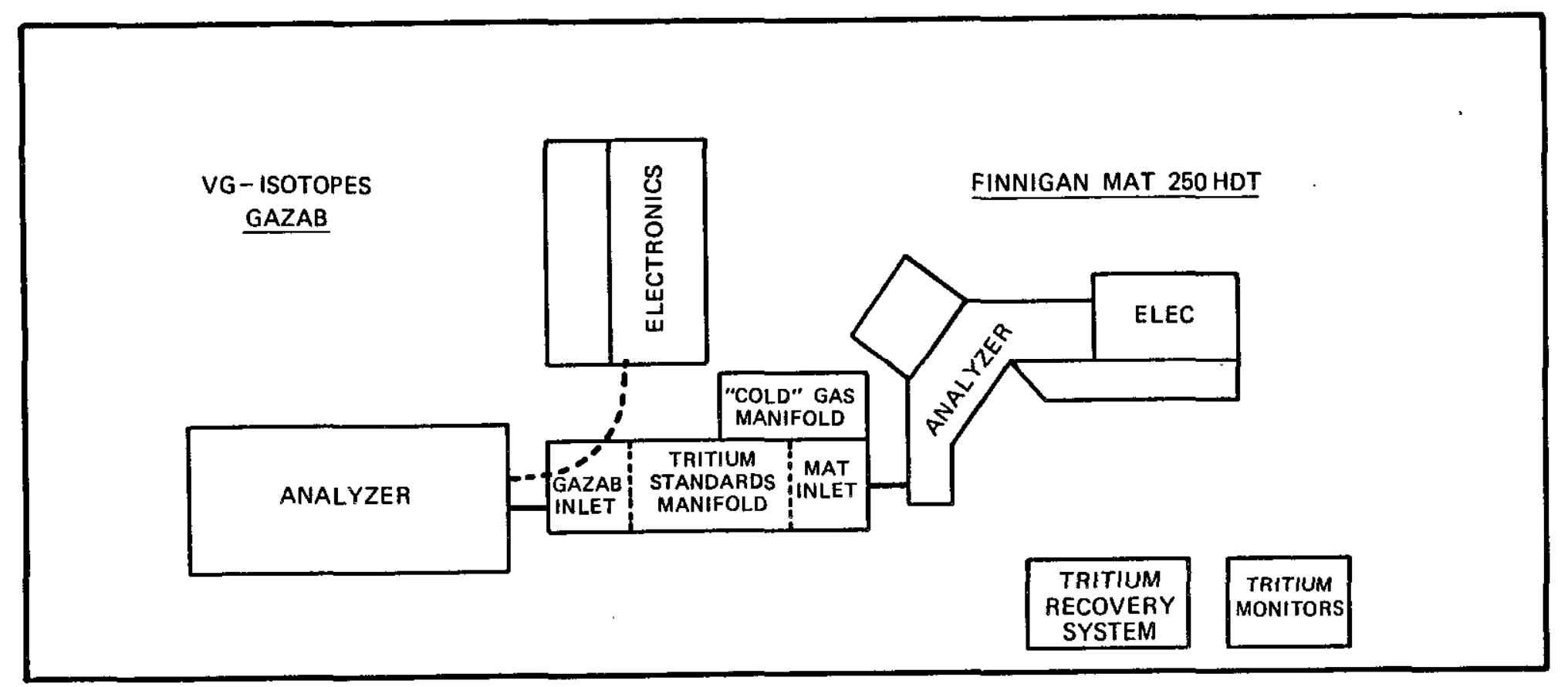

FIGURE 11. Savannah River Laboratory Test Facility 


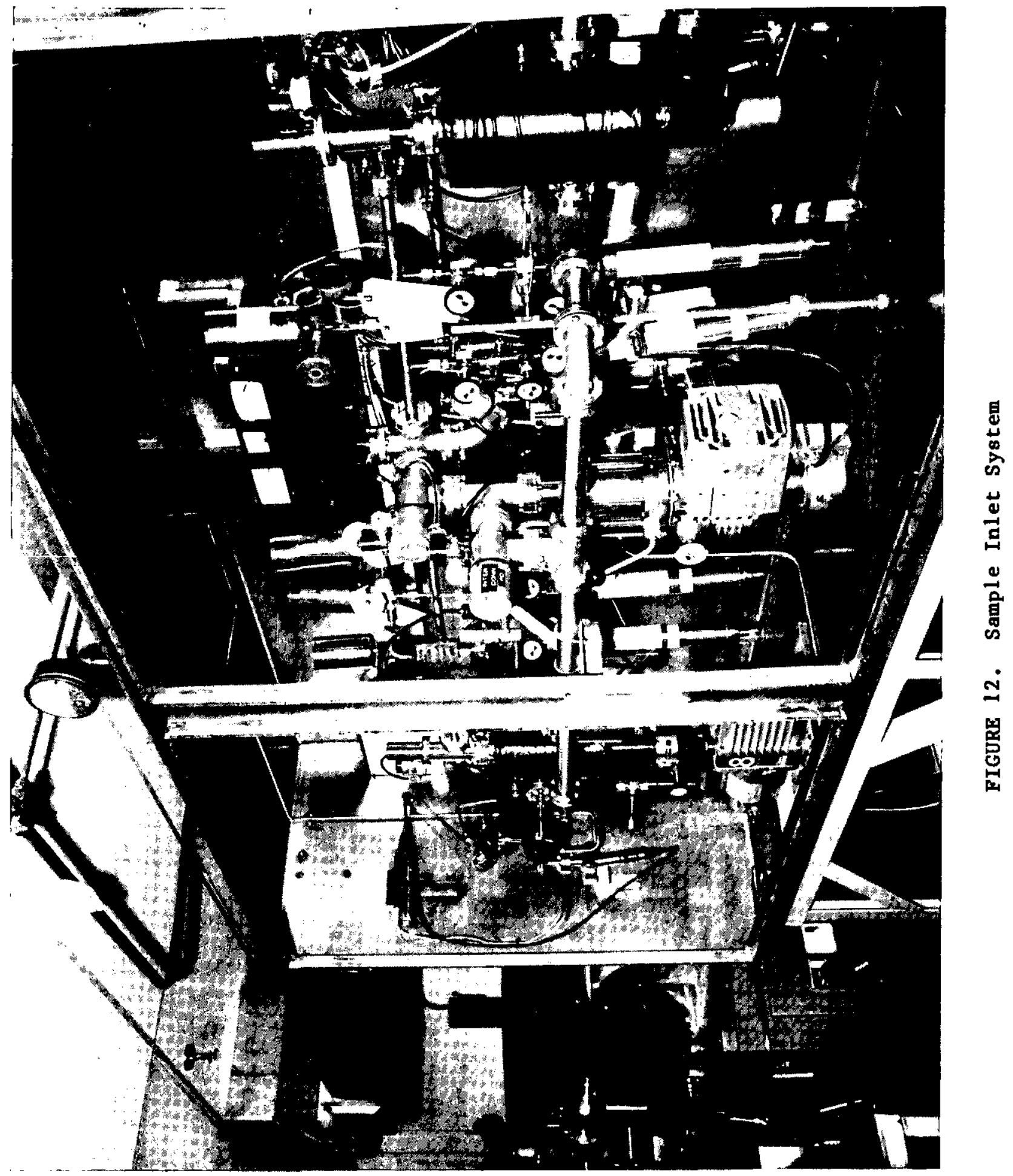




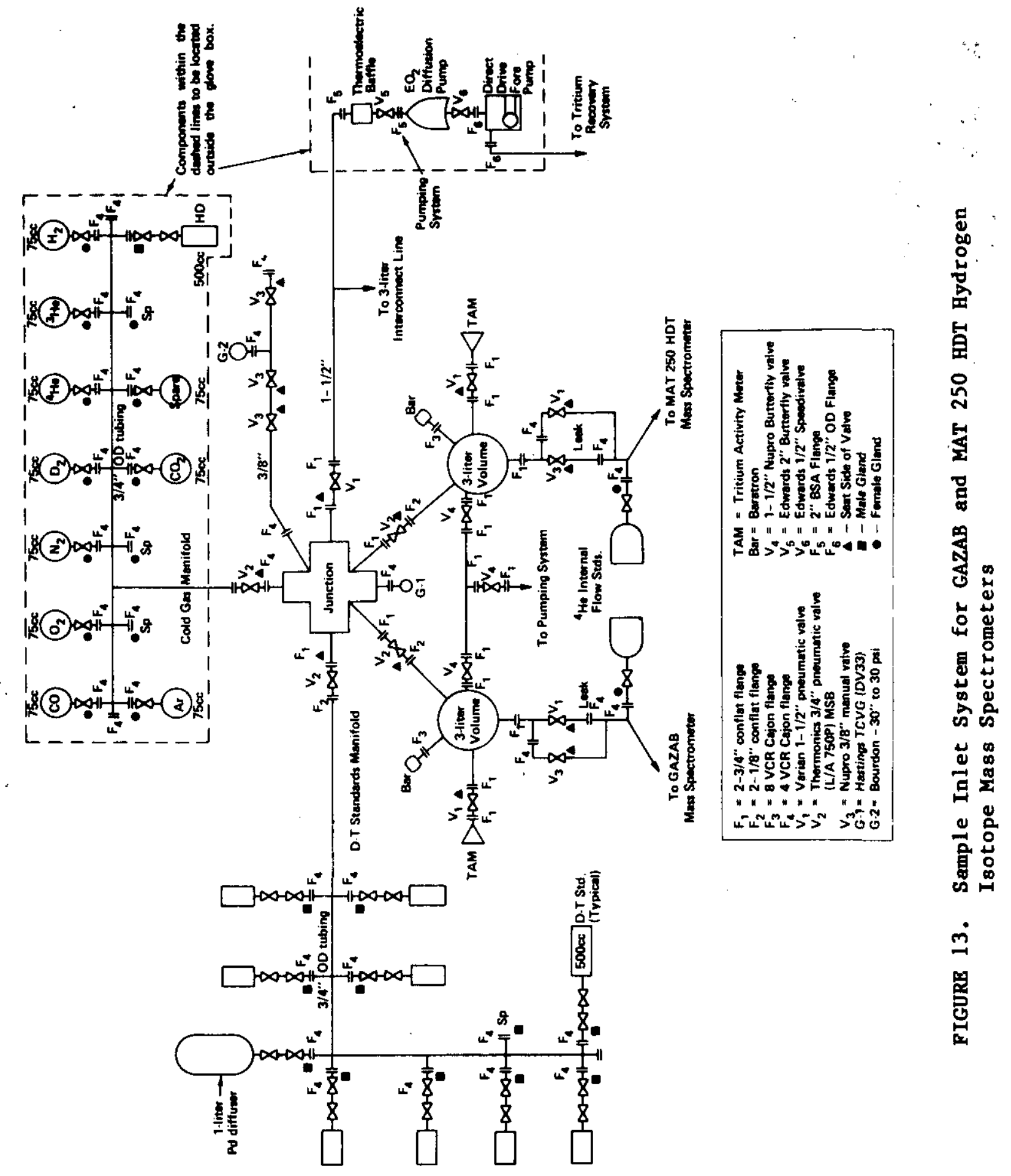


COLD GAS BOTTLE

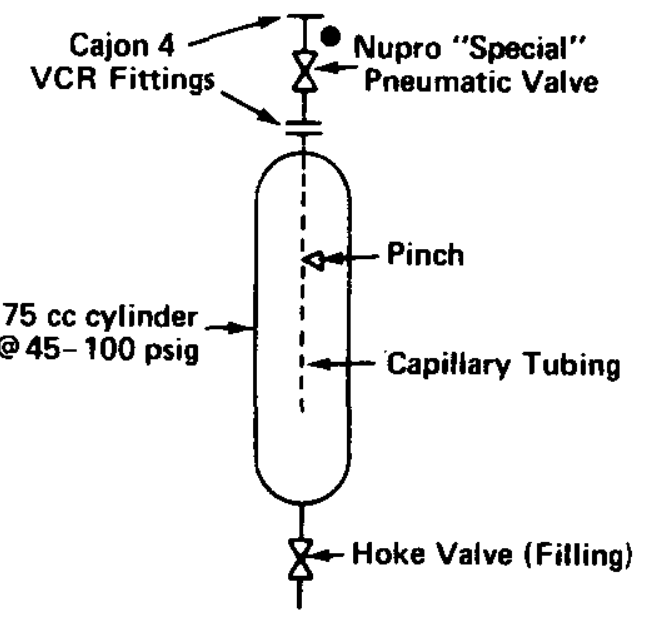

D-T AND HD STANDARDS BOTTLE

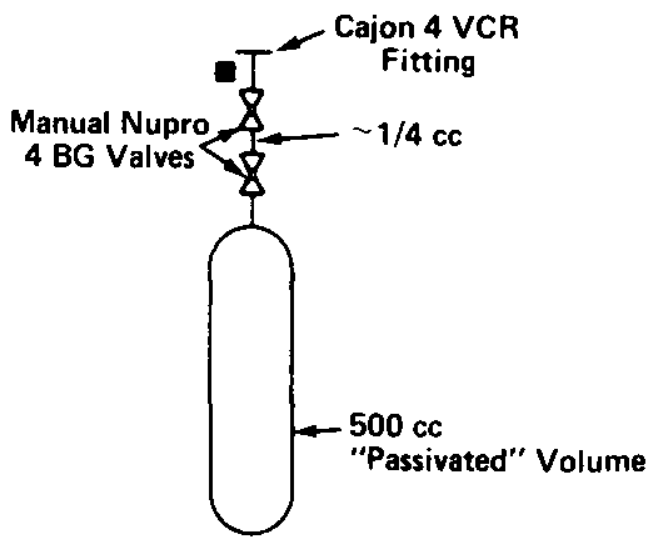

- FEMALE 4 VCR GLAND

- MALE 4 VCR GLAND
PALLADIUM DIFFUSER

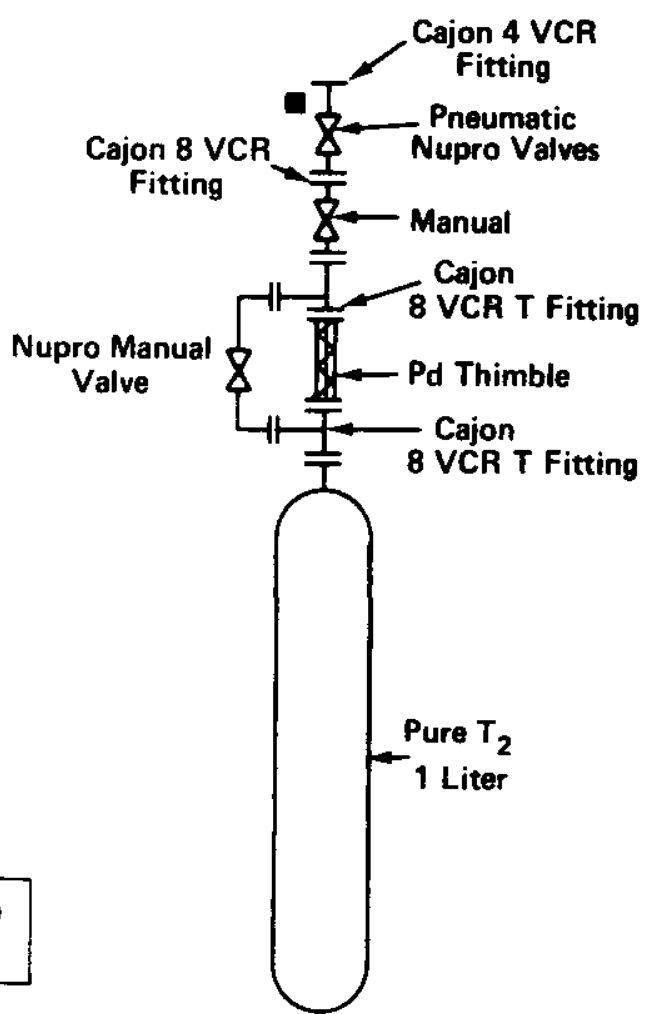

FIGURE 14. Details of Sampling Vessels in Mass Spectrometer Inlet System 


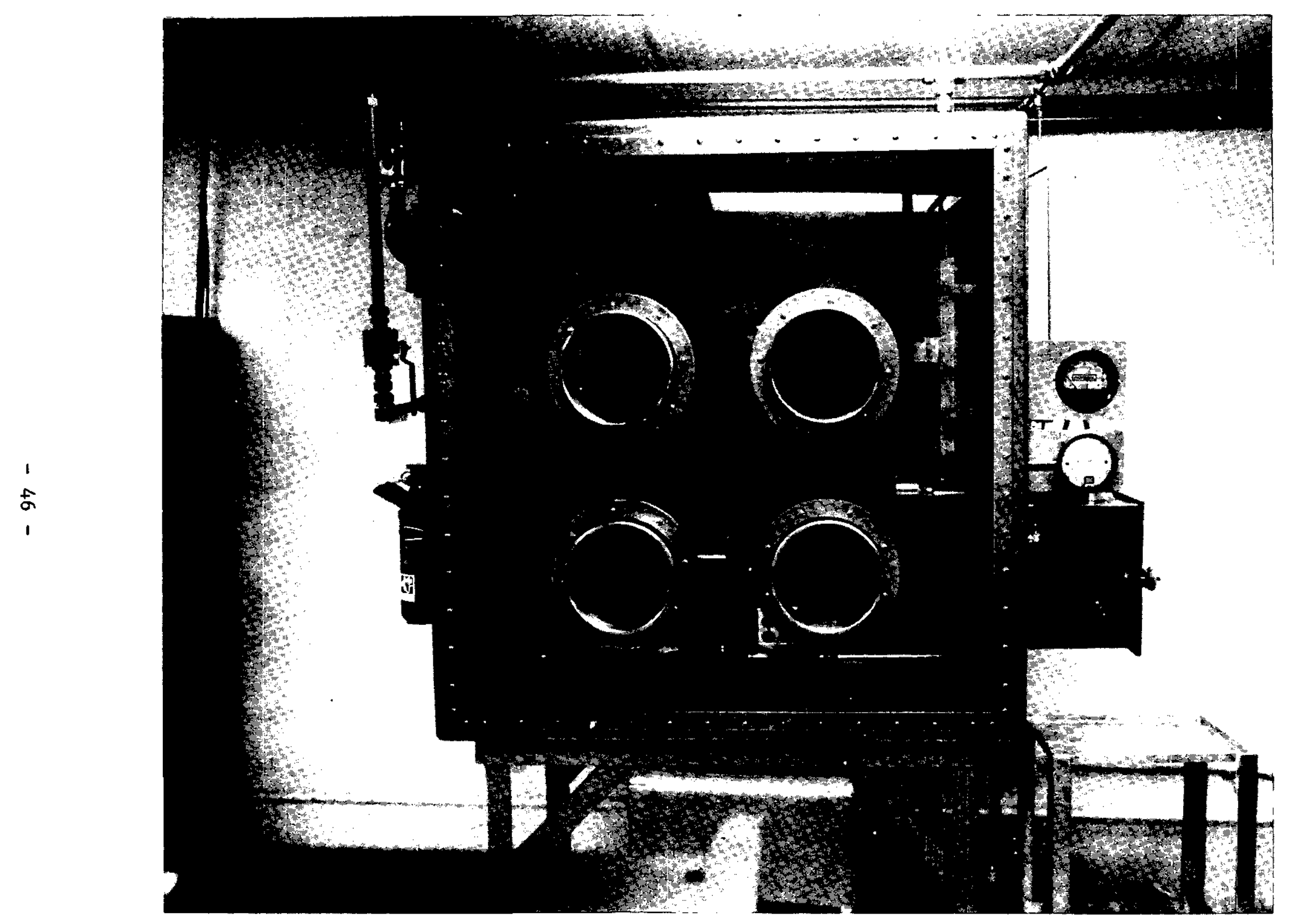

FIGURE 15. Tritium Recovery System 


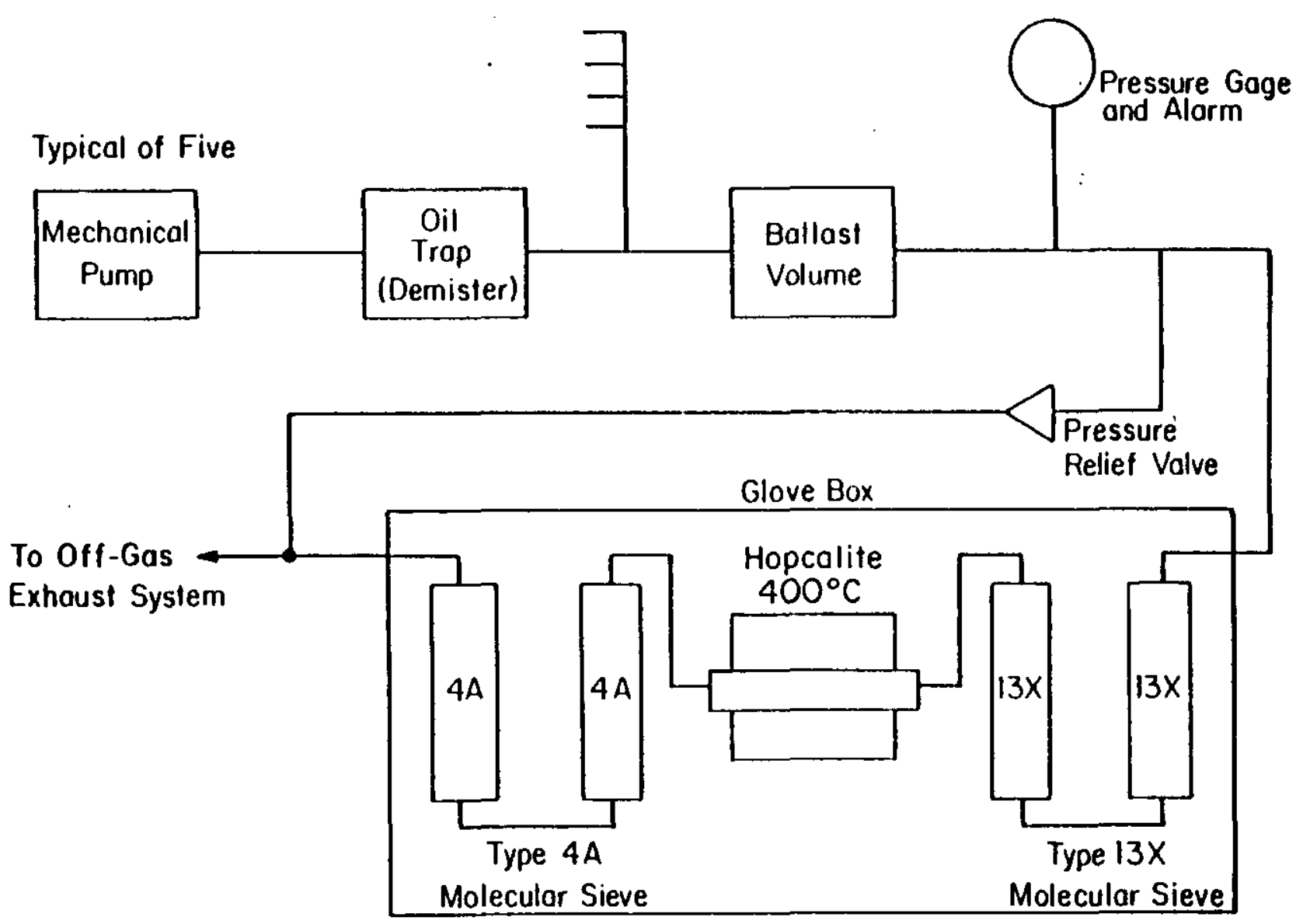

FIGURE 16. Diagram of the Tritium Recovery System 
A bypass of the off-gas exhaust system opens automatically if a major air leak causes the system to become pressurized. In the recovery unit, organics are removed by beds of Type $13 \mathrm{X}$ molecular sieve and the hydrogen passes through heated Hopcalite where it is converted to water. The water is trapped on tandem Type 4A molecular sieve beds and gases such as $\mathrm{N}_{2}$, Ne, and $\mathrm{Ar}$ pass through into the off-gas exhaust system.

The effluents from the tritium recovery system and the two glove boxes are monitored continuously by a pair of Kanne ionization chambers. A manifold system permits cross-monitoring of the inlet and recovery systems. Local hoses are provided for monitoring individual pieces of equipment anywhere in the laboratory module. The outputs of the two monitors are recorded on strip chart recorders and alarms sound if tritium is detected in the exhaust system.

\section{BARATRON COMPARISON}

After the new inlet systems were connected to the GAZAB and MAT $250 \mathrm{HDT}$ mass spectrometers, Hess compared the Baratrons to each other. As shown in Table 14, he found that they were linear within $0.1 \%$ in the $<150$ micron range. They were less linear at higher pressures. The nonlinearity was about $0.5 \%$ in the 250 to 350 micron range.

TABLE 14

\begin{tabular}{lll}
\multicolumn{2}{c}{ Baratron Comparison (pressure in microns) } \\
VG Baratron & $\begin{array}{l}\text { Finnigan } \\
\text { MAT Baratron }\end{array}$ & $\begin{array}{l}\text { Delta VG } \\
\text { Baratron, \% }\end{array}$ \\
\cline { 1 - 2 } 24.39 & 24.09 & -1.2 \\
46.21 & 45.67 & -1.2 \\
68.25 & 67.44 & -1.2 \\
100.13 & 98.92 & -1.2 \\
155.36 & 153.6 & -1.1 \\
176.32 & 174.3 & -1.2 \\
197.16 & 194.9 & -1.2 \\
$208.3 *$ & 204.7 & -1.7 \\
304.3 & 299.5 & -1.6 \\
350.3 & 345.0 & -1.5 \\
498.7 & 491.6 & -1.4 \\
715.5 & 705.9 & -1.3 \\
970.9 & 958.7 & -1.3
\end{tabular}

* VG Baratron has a range change at 200 microns. 
The inlet system was checked for fractionation effects with a ${ }^{4} \mathrm{He}-\mathrm{Ar}$ mixture. The mixture was analyzed after different expansions between the GAZAB inlet system three liter volume and other parts of the inlet system. The data are given in Table 15. The data show that fractionation effects are $<0.2 \%$ for the ${ }^{4} \mathrm{He}-\mathrm{Ar}$ mixture. Therefore, there should be no fractionation problem with $\mathrm{D} / \mathrm{T}$ mixtures.

TABLE 15

Inlet System Fractionation Tests with Mixture of $30 \%{ }^{4} \mathrm{He}$ and $70 \% \mathrm{Ar}$

\begin{tabular}{|c|c|c|c|c|}
\hline Day & $\begin{array}{l}\text { No. } \\
\text { Runs }\end{array}$ & $\frac{\text { Measured }{ }^{4} \mathrm{He}}{1 \text { Expansion }}$ & $\%$ & $\begin{array}{l}\Delta(\operatorname{Re} 1) \\
1 \text { Expansion, \% }\end{array}$ \\
\hline 1 & 9 & 29.972 & 29.909 & -0.21 \\
\hline $2\left(a_{.} m_{.}\right)$ & 4 & 29.969 & 29.985 & +0.05 \\
\hline 2 (p.m.) & 3 & 29.903 & 29.815 & -0.29 \\
\hline 3 & 3 & 29.961 & 29.957 & -0.01 \\
\hline 4 & 4 & 29.960 & 29.923 & -0.12 \\
\hline \multicolumn{2}{|c|}{ Theoretical } & 30.01 & & \\
\hline
\end{tabular}

\section{DEUTERIUM - TRITIOM STANDARDS}

The four D-T standards used in the evaluation program were made in the SRP gas blending system. Their compositions are 1 isted. in Table 16 . Standard $\$$ 非 4 is a $50 \% \mathrm{D}-50 \% \mathrm{~T}$ mixture intended for calibrating the mass spectrometers accurately for DT. Standards 非 and $\# 3$ are typical of D-T mixtures with low and high concentrations of $\mathrm{T}$. Standard 非 contains $0.44 \%$ (relative) more $\mathrm{T}$ than Standard \#1 and is designed to test the ability of the mass spectrometers to detect and measure small differences between samples. The standards were loaded into double-valved passivated $500 \mathrm{~cm}^{3}$ containers. The vessels were made by Quant um Mechanics (QM) and by Western Air Products (WAP) as shown in the table.

\section{TRITIOM ACTIVITY METER}

The tritium activity meter (TAM) located on the three-liter volume in the MAT $250 \mathrm{HDT}$ inlet system was tested with a $7 \% \mathrm{~T}$ standard. The standard-sample-standard sequence of analyses was followed in this test. SRP Standard $\mathrm{T} 500(\sim 50 \%$ total $\mathrm{T})$ was used 
as a calibration standard. The results are given in Table 17. The $0.14 \%$ relative standard deviation and $+0.19 \%$ relative bias are approximately the same as the precision and bias values obtained previously with a TAM in the SRP tritium facilities.

TABLE 16

D-T Standards for Evaluation of the GAZAB - MAT 250

\begin{tabular}{|c|c|c|c|}
\hline $\begin{array}{l}\text { Standard } \equiv_{1} 1 \\
\text { SRP T0700 }\end{array}$ & $\begin{array}{l}\text { Standard \#2 } \\
\text { SRP T0702 }\end{array}$ & $\begin{array}{l}\text { Stand ard 非 } \\
\text { SRP T930 }\end{array}$ & $\begin{array}{l}\text { Standard 非 } \\
\text { SRP T500 }\end{array}$ \\
\hline 93.000 & 92.969 & 7.000 & 50 \\
\hline 7.000 & 7.031 & 93.000 & 50 \\
\hline \multirow[t]{2}{*}{ WAP \#1 } & WAP 非 & QM 非3 & WAP 非2 \\
\hline & WAP "\#4 & QM $\# 4$ & QM \#2 \\
\hline
\end{tabular}

Double-valved $500 \mathrm{cc}$ passivated vessels

Aliquot volume $.25-.3 \mathrm{cc}$

TABLE 17

Tritium Analysis by Tritiun Activity Meter TAM Located on MAT 250 HDT Inlet System

\begin{tabular}{lll}
$\begin{array}{ll}\text { Run } \\
\text { No. }\end{array}$ & \multicolumn{2}{l}{$\begin{array}{l}\text { Mole } \% \\
\text { Total T }\end{array}$} \\
1 & 6.913 \\
2 & 6.919 \\
3 & 6.901 \\
4 & 6.902 \\
5 & 6.912 \\
6 & 6.917 \\
7 & 6.931 \\
8 & 6.921 \\
9 & 6.915 \\
10 & 6.914 \\
11 & 6.913 \\
12 & 6.935 \\
Average & 6.916 \\
S & \pm 0.0099 \\
RSD & \pm 0.14 \\
Rel. Bias & \pm 0.19
\end{tabular}




\section{New Container for $D-T$ Standards}

A newly designed passivated shipping container was evaluated for protium ingrowth, $\mathrm{CT}_{4}$ formation and other potential problems. The new container is a double-valved $500 \mathrm{~cm}^{3}$ stainless steel vessel. The volume between the valves is $\sim 0.25 \mathrm{~cm}^{3}$. This feature allows the user to meter the gas out in small aliquots with essentially no waste.

The new container was designed to replace the one-liter, single-valved passivated stainless steel containers currently used for $D-T$ standards. The single-valved design is inherently wasteful. The volume between the valve and the user's sample system is always much larger than the volume of gas needed for an analysis. Most of the gas released from the container is not used and must be discarded.

Two of the newly designed containers were loaded with $99.8 \%$ pure $\mathrm{T}_{2}$ at 275 torr. The contents were analyzed 53 days and 174 days after loading. The data shown in Table 18 show that there are neither protium ingrowth nor $\mathrm{CT}_{4}$ formation problems. The valves also functioned properly and there were no leaks or other mechanical problems. This design will now be evaluated for smaller vessels, some as small as $10 \mathrm{~cm}^{3}$.

\section{TABLE 18}

Evaluation of "Passivated" $500 \mathrm{~cm}^{3}$ Containers

for Protium and $\mathrm{CT}_{4}$ Ingrowth

\begin{tabular}{rlll} 
Day No. & Total $\mathrm{H}$ & $\mathrm{CT}_{4}$ \\
\cline { 1 - 1 } 5 & $0.068 \%$ & $0.014 \%$ \\
53 & 0.078 & 0.021 \\
174 & & 0.074 & 0.019
\end{tabular}

\section{COMPARISON OF THE GAZAB AND MAT 250 HDT MASS SPECTROMETERS}

\section{Results and Conclusions}

This hydrogen isotope mass spectrometer evaluation program established that both the VG-Isotopes GAZAB and the Finnigan MAT 250 HDT prototype mass spectrometers are superior to older instruments used for hydrogen isotope analyses. The results also showed that single-focusing instruments are suitable for routine for routine control laboratory operations. As shown in Table 19, factors that were serious problems in older mass spectrometers have 
been addressed successfully. Linearity is very good with both mass spectrometers when they are properly adjusted. Mass discrimination is minimal for the mass optimized. Automatic, computer-controlled refocusing is required and provided with both instruments. With automatic control, linearity and mass discrimination errors are $<0.5 \%$ with either instrument. Gas interference and trimer formation are not problems, and equilibration, i.e., the production of excess $\mathrm{HD}$ in a mixture of $\mathrm{H}_{2}+\mathrm{D}_{2}$ is $<300 \mathrm{ppm}$.

\section{TABLE 19}

\section{Potential Problems}

Problem

Linearity*

Mass discrimination*

Gas interference

Sample equilibration
GAZAB

$<0.5 \%$

$<0.5 \%$

$<0.1 \%$

$270 \mathrm{ppm}$
MAT $250 \mathrm{HDT}$

$<0.5 \%$

$<0.5 \%$

N.D.

$<300 \mathrm{ppm}$

* Optimum conditions for each mass

The two prototype mass spectrometers proved to be very competitive as shown in Table 20. The higher resolution and abundance sensitivity of the GAZAB facilitates the analysis of mixtures that are not at equilibrium. At a resolution of 600 , the less expensive MAT 250 HDT has an exceptionally high signal-to-noise ratio. It is capable of excellent precision and accuracy for mixtures that are at equilibrium. At a resolution of 1300 , it is competitive with the GAZAB for many applications. Both instruments are fully automated and are well adapted to routine analytical work.

In the course of this program, SRL/SRP personnel worked with both manufacturers to resolve problems that developed. Both manufacturers have incorporated the resulting improvements in their commercial instruments, and both now market competitive single-. focusing mass spectrometers.

As a direct result of this program, single-focusing mass spectrometers were specified for hydrogen isotopic analyses at SRP and several other DOE sites. To date, a total of 17 single-focusing and one double-focusing hydrogen isotope mass spectrometers have been ordered in the United States, and additional instruments have been sold in Europe. 
TABLE 20

Comparative Factors

Factor

Resolution

Abundance sensitivity

${ }^{3} \mathrm{He}-\mathrm{HD}$

$\mathrm{HT}-\mathrm{D}_{2}$

Low intensity

Signal-to noise ratio

Precision for $D / T(2 \sigma)$

Approximate cost
GAZAB

\begin{tabular}{llll}
\hline 2,000 & 1300 & 1300 & $600 *$ \\
$>100,000$ & 90,000 & $>40,000$ & -0.000 \\
$>100,000$ & 50,000 & 10,000 & -- \\
$5 \times 10^{-11} \mathrm{~A}$ & $1 \times 10^{-10} \mathrm{~A}$ & $1 \times 10^{-10} \mathrm{~A}$ & $5 \times 10^{-4} \mathrm{~A}$ \\
$1 \times 10^{5}$ & $2 \times 10^{5}$ & $2 \times 10^{5}$ & $>1 \times 10^{6}$ \\
$0.5 \%$ & $0.5 \%$ & $0.5 \%$ & 0.41
\end{tabular}

* Minimum SRP requirements

\section{Test Data Summaries}

Tests to compare the performance of the GAZAB and MAT 250 HDT mass spectrometers were made with $\mathrm{HD}-{ }^{3} \mathrm{He}$ mixtures and with pure HD. The GAZAB was also tested with DT standards. Comparative tests with the MAT 250 GDT were not possible because of the software problem noted in Section 3. Informal tests were made to ensure that the precision with tritium mixtures was the same as that with HD mixtures. Tests with SRP-blended HDT $s$ tandards were made at GEND with the MAT 251 HDT mass spectrometer operating at a resolution of 1300. The data are included here by courtesy of Norman Parsons, GENA.

\section{Mound Mixtures}

All four cylinders of each of the two $\mathrm{HD}-{ }^{3} \mathrm{He}$ mixtures Mound made for the acceptance testing of the GAZAB mass spectrometer were analyzed with the GAZAB and MAT 250 HDT mass spectrometers in June (Tables 21-24). The four cylinders of Mixture No. 2 were reanalyzed in July (Tables 25 and 26 ). The between-day relative standard deviations (RSD) for total $\mathrm{H}$ in Mixture No. 1 were $60.07 \%$ with both instruments. But the between-day RSDs for total D in the June data for Mixture No. 2 were about $0.3 \%$. The July data for Mixture No. 2 show between-day RSD values $<0.05 \%$. The improvements in the July data are due to extensive upgrading of the GAZAB in June, and the conversion of the MAT $250 \mathrm{HDT}$ ion source to trap regulation and improved operating techniques. 
TABLE 21

Mound Mixture Ho. 1 Analyzed - June 1982*

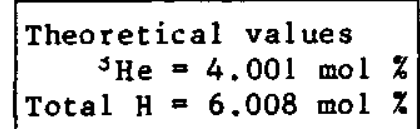

\begin{tabular}{|c|c|c|c|c|c|c|c|c|}
\hline Component & Cylinder & 1 & & & Cylinder & 2 & & \\
\hline $\begin{array}{l}\text { Total mol } 7 \\
\text { Average of } 6\end{array}$ & $\frac{\mathrm{GAZAB}}{6 / 4}$ & $6 / 8$ & $\begin{array}{l}\text { MAT } 250 \\
6 / 4\end{array}$ & $\frac{\mathrm{HDT}}{6 / 8}$ & $\frac{\text { GAZAB }}{6 / 4}$ & $6 / 8$ & $\begin{array}{l}\text { MAT 250 } \\
6 / 4\end{array}$ & $\frac{\mathrm{HDT}}{6 / 8}$ \\
\hline${ }^{\mathrm{S}} \mathrm{H}$, mol $\%$ & 3.970 & 3.977 & 3.994 & 3.993 & 3.947 & 3.953 & 3.964 & 3.964 \\
\hline $\mathrm{SD}_{\mathrm{b}}$ & \pm 0.0101 & \pm 0.0043 & \pm 0.0028 & \pm 0.0019 & \pm 0.0044 & \pm 0.0073 & \pm 0.0046 & \pm 0.0038 \\
\hline $\operatorname{RSD}_{b}, \%$ & \pm 0.35 & \pm 0.11 & \pm 0.07 & \pm 0.05 & \pm 0.11 & \pm 0.18 & \pm 0.12 & \pm 0.10 \\
\hline$\approx \Delta$ Theo & -0.77 & -0.59 & -0.18 & -0.20 & -1.34 & -1.20 & -0.92 & -0.92 \\
\hline Total H, mol \% & 6.053 & 6.070 & 6.051 & 6.034 & 6.056 & 6.072 & 6.054 & 6.038 \\
\hline $\mathrm{SD}_{6}$ & $\overline{ \pm 0.0122}$ & $\overline{ \pm 0.0079}$ & $\overline{ \pm 0.0031}$ & \pm 0.0040 & $\overline{ \pm 0.0107}$ & \pm 0.0089 & \pm 0.041 & \pm 0.0020 \\
\hline $\mathrm{RSD}_{b}, z$ & \pm 0.20 & \pm 0.13 & \pm 0.05 & \pm 0.07 & \pm 0.18 & \pm 0.15 & \pm 0.07 & \pm 0.03 \\
\hline$\% \Delta$ Theo & +0.75 & +0.03 & +0.71 & +0.43 & +0.79 & +1.06 & +0.76 & +0.50 \\
\hline Component & Cylind & 3 & & & Cylind & 4 & & \\
\hline Total mol $\%$ & GAZAB & & MAT 250 & HDT & GAZAB & & MAT 250 & HDT \\
\hline Average of 6 & $6 / 4$ & $6 / 8$ & $6 / 4$ & $6 / 8$ & 674 & $6 / 8$ & $6 / 4$ & $6 / 8$ \\
\hline${ }^{3} \mathrm{He}$, mol $\%$ & 3.946 & 3.954 & 3.974 & 3.971 & 3.954 & 3.965 & 3.986 & 3.984 \\
\hline $\mathrm{SD}_{6}$ & $\overline{ \pm 0.0075}$ & \pm 0.0049 & $\overline{ \pm 0.0012}$ & $\overline{ \pm 0.0026}$ & $\overline{ \pm 0.0082}$ & \pm 0.0060 & \pm 0.0023 & \pm 0.0033 \\
\hline $\mathrm{RSD}_{b}, \%$ & \pm 0.19 & \pm 0.12 & \pm 0.029 & \pm 0.07 & \pm 0.21 & \pm 0.15 & \pm 0.06 & \pm 0.08 \\
\hline$\% \Delta$ Theo & -1.39 & -1.17 & -0.69 & -0.74 & -1.17 & -0.90 & -0.37 & -0.41 \\
\hline Total H, mol \% & 6.052 & 6.076 & 6.058 & 6.044 & 6.058 & 6.070 & 6.060 & 6.041 \\
\hline $\mathrm{SD}_{b}$ & $\overline{ \pm 0.0073}$ & \pm 0.0061 & $\overline{ \pm 0.0027}$ & $\overline{ \pm 0.0078}$ & $\overline{ \pm 0.0130}$ & $\overline{ \pm 0.0099}$ & \pm 0.0042 & $\overline{ \pm 0.0043}$ \\
\hline $\mathrm{RSD}_{b}, \%$ & \pm 0.12 & \pm 0.10 & \pm 0.04 & \pm 0.13 & \pm 0.21 & \pm 0.16 & \pm 0.07 & \pm 0.07 \\
\hline$\% \Delta$ Theo & +0.73 & +1.14 & +0.83 & +0.60 & +0.83 & +1.04 & +0.87 & +0.55 \\
\hline
\end{tabular}

* Note: No $L N_{2}$ was used in traps $6 / 4$ on either instrument. $\mathrm{LN}_{2}$ was used in both inst ruments $6 / 8$. 
TABLE 22

Mound Mixture No. 1 - Average of June Analyses

\begin{tabular}{|c|c|c|c|c|c|c|c|c|}
\hline & Cylind & & Cylind & 2 & Cyl ind & 3 & Cyl ind & I 4 \\
\hline & 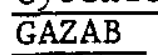 & MAT & GAZAB & MAT & GAZAB & MAT & $\overline{\mathrm{GAZAB}}$ & MAT \\
\hline le, avg., mol \% & 3.974 & 3.994 & 3.950 & 3.964 & 3.950 & 3.973 & 3.960 & 3.985 \\
\hline$\Delta$ Theo & -0.69 & -0.18 & -1.27 & -0.92 & -1.27 & -0.71 & -1.04 & -0.40 \\
\hline & 6.062 & 6.043 & 6.064 & 6.064 & 6.064 & 6.051 & 6.064 & 6.051 \\
\hline Nos & +0.89 & +0.57 & +0.93 & +0.63 & +0.93 & +0.72 & +0.93 & +0.72 \\
\hline
\end{tabular}




\section{TABLE 23}

Mound Mixture No. 2 Analgzed - June 1982*

$$
\begin{gathered}
\text { Theoretical values } \\
\text { J } \mathrm{He}=3.924 \mathrm{~mol} \% \\
\text { Total D }=6.026 \mathrm{~mol} \%
\end{gathered}
$$

Component Total mol \% Average of 6

Cylinder 5

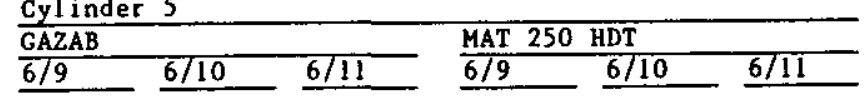

Cylinder 6

GAZAB

$\mathrm{AB}$

$6 / 10$

$6 / 11$

MAT 250 HDT

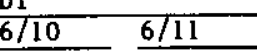

${ }^{3} \mathrm{He}$

$\bar{x}_{0}, \operatorname{mol} x$

3.898

$3.888 \quad 3.890$

$\begin{array}{lll}3.945 & 3.958 \quad 3.947\end{array}$

$\begin{array}{lll}3.890 & 3.887 & 3.893\end{array}$

$\begin{array}{lll}3.932 & 3.937 & 3.931\end{array}$

$\sigma$

RSD, $\chi$

* $\Delta$ Theo

$\pm 0.20 \quad \pm 0.21 \quad \pm 0.20$

$\pm 0.0058 \pm 0.0123 \pm 0.0056$

$\pm 0.15 \quad \pm 0.31 \quad \pm 0.14$

$\pm 0.0047 \pm 0.0055 \pm 0.0050$

$\pm 0.12 \quad \pm 0.14$

$\pm 0.13$

$\pm 0.0042 \pm 0.0128$

Total D

$\bar{x}_{b}$, mol $\bar{x}$

$\sigma$

RSD, $\%$

$\begin{array}{lll}6.028 & 6.022 \quad 6.026\end{array}$

$\pm 0.0074 \quad \pm 0.0069 \quad \pm 0.0076$

$+0.54+0.87$

$+0.59$

$-0.87$

$-0.94$

$-0.79$

$+0.20$

$\pm 0.1$

\pm 0.33
+0.18

Component

Total mol 7

Average of 6

Cylinder 7

GAZAB

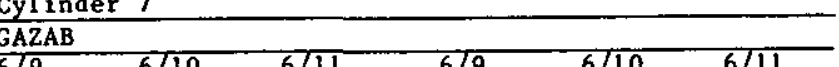

$\begin{array}{lll}6.050 & 6.063 \quad 6.048\end{array}$

6.024

6.027

6.030

6.044

$\pm 0.0026 \quad \pm 0.0133 \quad \pm 0.0129$

0.0049

$+0.02$

$\pm 0.0037$

$6.047-6.04$
0.0037

$\pm 0.40 \quad \pm 0.61 \quad \pm 0.37$

Cylinder 8

GAZAB

$6 / 9$

8

$+0.07$

$+0.30$

$\pm 0.0061 \pm 0.0150$

${ }^{5} \mathrm{He}$

$\bar{x}_{b}$, mol $z$

$$
3.92
$$

3.927

3.935

3.926

3.930

$6 / 10$

$6 / 11$

\section{MAT}

AT 250 HDT

RSD, $\%$

$\% \Delta$ Theo

$\pm 0.23 \pm 0.08 \quad \pm 0.11$

$\pm 0.0071 \quad \pm 0.0038 \quad \pm 0.0039$

$\pm 0.18$

$\pm 0.10 \pm 0.10$

$\begin{array}{lll}3.917 & 3.935 & 3.923\end{array}$

$+0.01$

$+0.28$

$+0.05$

$\pm 0.25$

$\pm 0.0039 \pm 0.0032$

Total D

$\bar{x}_{b}$, mol $x$

0

RSD, $z$

$\begin{array}{llll}6.067 & 6.059 & 6.065\end{array}$

$\begin{array}{lll}6.034 & 6.042 \quad 6.031\end{array}$

$+0.15$

$\pm 0.10$

$\pm 0.08$

$\pm 0.0069 \pm 0.0051 \pm 0.0084$

$\pm 0.0063 \pm 0.0050 \quad \pm 0.0033$

$\pm 0.10 \quad \pm 0.08 \quad \pm 0.05$

$\pm 0.0116 \quad \pm 0.0062 \pm 0.0084$

6.054

$6.049 \quad 6.053$

0.053

$\pm 0.19$

$\pm 0.10$

$\pm 0.14$

$\pm 0.0101$

$\pm 0.0050$

$\pm 0.11$

$\pm 0.46$

$\pm 0.38$

$\pm 0.45$

$\pm 0.0075 \quad \pm 0.0071 \quad \pm 0.0131$

$\pm 0.12 \pm 0.12 \quad \pm 0.22$

$+0.68+0.55+0.65$

* All analyses made with liquid $N_{2}$ in traps. 


\section{TABLE 24}

Mound Mixture No. 2 - Average of June Analyses

\begin{tabular}{|c|c|c|c|c|c|c|c|c|}
\hline & \multicolumn{2}{|c|}{ Cylinder 5} & \multicolumn{2}{|c|}{ Cylinder 6} & \multicolumn{2}{|c|}{ Cyl inder 7} & \multicolumn{2}{|c|}{ Cyl inder 8} \\
\hline & GAZAB & $\overline{\mathrm{MAT}}$ & $\widehat{G A Z A B}$ & MAT & GAZAB & MAT & GAZAB & MAT \\
\hline${ }^{3} \mathrm{He}$, avg., mol \% & 3.892 & 3.950 & 3.890 & 3.933 & 3.913 & 3.929 & 3.925 & 3.925 \\
\hline$\% \Delta$ Theo & -0.82 & +0.66 & -0.87 & +0.24 & -0.27 & +0.14 & +0.03 & +0.03 \\
\hline Total D, a & 6. & 6.0 & 6.027 & 6.044 & 6.064 & 6.036 & 6.052 & 6.017 \\
\hline$\% \Delta \cdot$ Theo & -0.01 & +0.46 & +0.02 & +0.30 & +0.63 & +0.16 & +0.43 & +0.15 \\
\hline
\end{tabular}


TABLE 25

Mound Mixture No. 2 - Analyzed July 1982*

\begin{tabular}{|c|c|c|c|c|c|c|c|c|c|c|c|c|}
\hline \multirow{3}{*}{$\begin{array}{l}\text { Component } \\
\text { Total mol \% } \\
\text { Avg of } 6 \\
\end{array}$} & \multicolumn{6}{|c|}{ Cyl inder 5} & \multicolumn{6}{|c|}{ Cyl inder 6} \\
\hline & \multicolumn{4}{|c|}{ GAZAB } & \multicolumn{2}{|c|}{ MAT 250} & \multicolumn{4}{|l|}{$\overline{\mathrm{GAZAB}}$} & \multicolumn{2}{|c|}{ MAT 250} \\
\hline & $7 / 13$ & $7 / 14$ & $7 / 15$ & $7 / 16$ & $7 / 22$ & $7 / 23$ & $7 / 13$ & $7 / 14$ & $7 / 15$ & $7 / 16$ & $7 / 22$ & $7 / 23$ \\
\hline \multicolumn{13}{|l|}{${ }^{5} \mathrm{He}$} \\
\hline $\bar{x}_{b}, \operatorname{mol} \%$ & 3.904 & 3.904 & 3.904 & 3.905 & 3.923 & 3.925 & 3.900 & 3.895 & 3.890 & 3.901 & 3.915 & 3.917 \\
\hline RSD, \% & .07 & .08 & .08 & .09 & .12 & .08 & .17 & .07 & .08 & .05 & .13 & .11 \\
\hline$\% \Delta$ Theo & -.51 & -.51 & -.51 & -.48 & -.02 & +.03 & -.61 & -.74 & -.87 & -.59 & -.23 & +.18 \\
\hline \multicolumn{13}{|l|}{ Total $D^{\star \star}$} \\
\hline $\bar{x}_{b}$, mol $\%$ & 6.031 & 6.037 & 6.043 & 6.043 & 6.031 & 6.049 & 6.036 & 6.037 & 6.042 & 6.046 & 6.035 & 6.050 \\
\hline RSD, \% & .09 & .04 & .03 & .06 & .04 & .05 & .12 & .12 & .09 & .07 & .02 & .05 \\
\hline$\% \Delta$ Theo & +.08 & +.18 & +.28 & +.28 & +.08 & +.38 & +.16 & +.18 & +.26 & +.33 & +.14 & +.40 \\
\hline \multicolumn{13}{|l|}{${ }^{s} \mathrm{He}^{* *}$} \\
\hline $\bar{x}_{b}$, mol $\%$ & 3.908 & 3.904 & 3.902 & 3.909 & 3.928 & 3.930 & 3.916 & 3.907 & 3.899 & 3.909 & 3.955 & 3.926 \\
\hline RSD, \% & .11 & .13 & .04 & .09 & .14 & .09 & .06 & .14 & .16 & .09 & .10 & .07 \\
\hline$\% \Delta$ Theo & -.42 & -.51 & -.56 & -.38 & +.10 & +.14 & -.19 & -.43 & -.64 & -.38 & +.02 & +.05 \\
\hline \multicolumn{13}{|l|}{ Total $\mathrm{D}^{* *}$} \\
\hline $\bar{x}_{b}$, mol \% & 6.055 & 6.046 & 6.058 & 6.055 & 6.052 & 6.067 & 6.042 & 6.037 & 6.035 & 6.037 & 6.032 & 6.041 \\
\hline RSD, $\%$ & .04 & .11 & .08 & .07 & .08 & .04 & .04 & .07 & .03 & .06 & .05 & .11 \\
\hline$\% \Delta$ Theo & +.48 & +.33 & -.53 & +.48 & +.42 & +.68 & +.26 & +.18 & +.15 & +.18 & +.10 & +.26 \\
\hline
\end{tabular}

* Each value (7) is the average of 6 analyses in mol \%.

** Liquid $\mathrm{N}_{2}$ was used in both instruments for all analyses. 
TABLE 26

Mound Mixture No. 2 - Average of July Analyses

\begin{tabular}{|c|c|c|c|c|c|c|c|c|}
\hline Component & \multicolumn{2}{|c|}{ Cylinder 5} & \multicolumn{2}{|c|}{ Cylinder 6} & \multicolumn{2}{|c|}{ Cylinder 7} & \multicolumn{2}{|c|}{ Cylinder 8} \\
\hline Total mol $\%$ & GAZAB & MAT 250 & GAZAB & MAT 250 & GAZAB & MAT 250 & GAZAB & MAT 250 \\
\hline Avg. ${ }^{3} \mathrm{He}$ & 3.904 & 3.924 & 3.896 & 3.916 & 3.906 & 3.929 & 3.908 & 3.926 \\
\hline$\% \Delta$ Theo & -.51 & 0 & -.71 & -.20 & -.46 & +.13 & -.41 & +.05 \\
\hline Total avg. D & 6.038 & 6.040 & 6.040 & 6.042 & 6.054 & 6.060 & 6.038 & 6.036 \\
\hline$\% \Delta$ Theo & +.20 & +.23 & +.23 & +.26 & +.46 & +.56 & +.20 & +.17 \\
\hline
\end{tabular}

The tests with the Mound mixtures confirm that despite identical pure gas calibration techniques, there is a consistent bias in ${ }^{3} \mathrm{He}$ determinations between the GAZAB and the MAT $250 \mathrm{HDT}$. At the 4 mol \% level, ${ }^{3} \mathrm{He}$ analyses with the GAZAB are about $0.5 \%$ (relative) below analyses made with the MAT 250 HDT. The reason for the bias is not known at this time.

The June data (Table 22) show that the gas in all four cylinders of Mixture No. 1 is identical. The data for Mixture No. 2 (Table 24) are inconclusive. However, the July data (Table 26) show that the total $\mathrm{D}$ content in cylinder 7 is about $0.2 \%$ (relative) greater than that in the other three cylinders.

Storage of Pure HD

On August 18, 1978, the SRP Production Department loaded $\sim 250$ liters of pure HD $(>99.95 \% \mathrm{HD})$ into various vessels. This was done to:

- aid in the determination of the

$$
\frac{\mathrm{D}^{+}}{\mathrm{HD}} \text { cracking pattern }
$$

- determine the long-term stability of HD in various types of vessels

- meet future requests for high purity HD and $\mathrm{HD}$ mixtures from other DOE sites

- supply HD for the testing of the GAZAB mass spectrometer. 
Nineteen months later (March 1980) the HD was analyzed on MS-15, a cycloidal focusing mass spectrometer in Building 232-H. Four years after loading, it was analyzed with the GAZAB and MAT 250 HDT mass spectrometers. The results of these analyses are summarized in Table 27. They show that in passivated vessels, there is essentially no portium ingrowth and the re-equilibration rate $\left(\mathrm{HD} \neq \mathrm{H}_{2}+\mathrm{D}_{2}\right.$ ) is very low. The data also indicate that the re-equilibration rate in untreated vessels is some function of the volume-to-surface ratio; the re-equilibration rate in the 50liter vessels being substantially lower than that in the $500 \mathrm{~cm}^{3}$ vessels.

TABLE 27

HD Analysis (Loaded 8/18/78 - >99.957 HD)

Analysis March 1980 Mol \% (MS No. 15-232H)

\begin{tabular}{llll}
\hline 5-Liter Passivated & $50-$ Liter & 50-Liter & Whitey Cylinder 500 cc \\
Vessel-Ion Devices & PC No. 1C & PC No. 1B & SRP Mobilled Vessel \\
\hline
\end{tabular}

$\begin{array}{rrrrrr}\mathrm{H}_{2} & 0.17 & 0.63 & 1.21 & 9.70 & 0.93 \\ \mathrm{HD} & 99.77 & 98.87 & 97.72 & 81.46 & 98.64 \\ \mathrm{D}_{2} & 0.05 & 0.49 & 1.06 & 8.84 & 0.41\end{array}$

Analysis July 1982

\begin{tabular}{|c|c|c|c|}
\hline $\begin{array}{l}\text { 5-Liter Passivated } \\
\text { Vessel-Ion Devices }\end{array}$ & $\begin{array}{l}\text { 50-Liter } \\
\text { PC No. } 1\end{array}$ & $\begin{array}{l}\text { 50-Liter } \\
\text { PC No. } 1 \text { B }\end{array}$ & $\begin{array}{l}\text { Whitey Cylinder } 500 \mathrm{cc} \\
\text { Mound Lab-Filled Vessel }\end{array}$ \\
\hline MAT $250^{\star}$ & MAT $250^{*}$ & MAT 250* & \\
\hline
\end{tabular}

$\begin{array}{llllllll}\mathrm{H}_{2} & 0.084 & 0.096 & 1.19 & 1.20 & 2.67 & 2.69 & 26.2\end{array}$

$\begin{array}{llllllll}\text { HD } & 99.83 & 99.81 & 97.63 & 97.60 & 94.66 & 94.63 & 47.6\end{array}$

$\begin{array}{llllllll}\mathrm{D}_{2} & 0.077 & 0.096 & 1.18 & 1.20 & 2.67 & 2.69 & 26.2\end{array}$

*alculations of $\mathrm{H}_{2}$ based on GAZAB analyses which indicate $\mathrm{H}_{2}=\mathrm{D}_{2}$. GAZAB resolves $\mathrm{D}^{+}$and $\mathrm{H}_{2}$. MAT 250 cannot resolve $\mathrm{D}^{+}$and $\mathrm{H}_{2}$. 


\section{HD Cracking Pattern}

As shown in Table 28 , tests with high purity HD on the MAT 250 $\mathrm{HDT}$ and GAZAB mass spectrometers showed that the cracking fraction

$$
\frac{\mathrm{D}^{+}}{\mathrm{HD}^{+}}
$$

is $\sim 75 \%$ of the cracking fraction

$$
\frac{\mathrm{D}^{+}}{\mathrm{D}_{2}^{+}}
$$

routinely measured in pure $D_{2}$ gas calibrations.

Thus, the historical assumption of equimolar contributions

$$
\frac{\mathrm{D}^{+}}{\mathrm{HD}^{+}}=50 \% \text { of } \frac{\mathrm{D}^{+}}{\mathrm{D}_{2}^{+}}
$$

was shown to be incorrect. This assumption was necessary because neither ultra high purity HD nor high resolution mass spectrometers were available before now. The importance of high resolution is indicated by the change in the $\mathrm{D}^{+} / \mathrm{HD}^{+}$value measured with the MAT 250 HDT (resolution $\sim 600$ ) as a function of HD concentration. With the higher resolution of the $\operatorname{GAZAB}(\sim 1200)$, the $\mathrm{D}^{+} / \mathrm{HD}^{+}$value remains constant.

The GAZAB mass spectrometer was used for a variety of tests with DT standards. Multiple calibrations were made with pure $\mathrm{D}_{2}$, pure $\mathrm{T}_{2}$, and $\mathrm{T}-500$ ( $50 \mathrm{~mol} \% \mathrm{D}-50 \mathrm{~mol} \% \mathrm{~T}$ ) standard to obtain comparative sensitivities. The data in Table 29 show sensitivity biases between pure $\mathrm{D}_{2}$ and $\mathrm{D}_{2}$ in the mixture, and between pure $\mathrm{T}_{2}$ and $T_{2}$ in the mixture. The fact that the biases have opposite signs suggests a slight error in the theoretical values for the $\mathrm{T}-500$ standard. It is not known why the $\mathrm{T}_{2}$ bias is double the size of the $\mathrm{D}_{2}$ bias.

In each of the $D_{2}$ and $T_{2}$ pure gas analyses 1 isted in Table 29, the $\frac{\mathrm{D}^{+}}{\mathrm{D}_{2}^{+}}$and $\frac{\mathrm{T}^{+}}{\mathrm{T}_{2}^{+}}$ratios, respectively were measured. The average values obtained were:

$$
\begin{aligned}
& \frac{\mathrm{D}^{+}}{\mathrm{D}_{2}^{+}}=0.00384 \\
& \frac{\mathrm{T}^{+}}{\mathrm{T}_{2}^{+}}=0.00289
\end{aligned}
$$


TABLE 28

Summary of HD Cracking Pattern Data (7/22/82)

$\frac{\text { Sample* }}{99.8 \% \mathrm{HD}} \frac{\frac{\mathrm{MAT}}{\mathrm{H}^{+}}}{\frac{\mathrm{HD}^{+}}{0.00493}} \frac{\frac{\mathrm{DDT}}{\mathrm{D}^{+}}}{0.00654} \frac{\frac{\mathrm{D}^{+} / \mathrm{HD}^{+}}{\mathrm{D}^{+} / \mathrm{D}^{+}}}{75.4 \%} \frac{2}{75}$

$\begin{array}{lll}\frac{\mathrm{H}^{+}}{\mathrm{HD}^{+}} & \frac{\mathrm{D}^{+}}{\mathrm{D}_{2}^{+}} & \frac{\mathrm{D}^{+} / \mathrm{HD}^{+}}{\mathrm{D}^{+} / \mathrm{D}^{+}} \times 100 \\ 0.00493 & \frac{2}{0.00654} & \frac{2}{75.4 \%}\end{array}$

Vesse

GAZAB

\begin{tabular}{|c|c|c|}
\hline$\underline{D}^{+}$ & & $\frac{\mathrm{D}^{+} / \mathrm{HD}^{+}}{{ }^{+}} \times 100$ \\
\hline $\overrightarrow{\mathrm{HD}}^{+}$ & $\mathrm{D}_{2}^{+}$ & $\mathrm{D}^{+} / \mathrm{D}_{2}^{+}$ \\
\hline .00302 & 0.00386 & $78.2 \%$ \\
\hline
\end{tabular}

$97.6 \% \mathrm{HD}$

0.00450

0.00659

$68.3 \%$

0.00294

0.00384

$76.6 \%$

0.00296

0.00382

$77.5 \%$

$94.6 \% \mathrm{HD}$

0.0040

0.00643

$62.2 \%$

Conditions

Ion source temperature $<150^{\circ} \mathrm{C}$

Resolution 600

Electron energy $85 \mathrm{eV}$

Anode to ion source $\mathrm{V}+42 \mathrm{~V}$

$10 \mathrm{kV} 3.6 \mathrm{~A}$ cathode

$0.2 \mathrm{~mA}$ emission (trap current)

\section{Conditions}

Ion source temperature $180^{\circ} \mathrm{C}$

Resolution 1200

Electron energy $77 \mathrm{eV}$

Anode to ion source $\mathrm{V} \sim 59 \mathrm{~V}$

Trap current $50 \mu \mathrm{A}$

Total emission $0.62 \mathrm{~mA}$

Block current $0.38 \mathrm{~mA}$

repeller $+3.2 \mathrm{~V}$

* Isotopic analyzes of these samples are given in Table 10. 
TABLE 29

GAZAB Sensitivities, $\mathrm{mV} / \mu$

Pure Standard T-500 (50\% D $-50 \% \mathrm{~T})$

Pure gas

Vessel QM 非 WAP 非 $\mathrm{QM}$ \#2 2 WAP $\# 2$ QM \#2 WAP 非

Species

$$
\text { D.2 }
$$

$\mathrm{D}_{2}$

D.

DT

DT

$\mathrm{T}_{2}$

T.

$\mathrm{T}_{2}$

$$
158.64 \quad 158.43
$$

$158.35 \quad 157.33$

157.36

155.34

155.30

154.22

$$
158.87 \quad 158.81
$$

158.54

157.4

157.34

$155.43 \quad 155.27$

154.43

$159.01 \quad 158.44$

158.4

157.34

157.00

$\begin{array}{llll}155.22 & 155.21 & 154.53\end{array}$

$158.74 \quad 158.51$

$158.42 \quad 157.34$

157.22

155.04

155.19154 .56

$\begin{array}{lllllllll}158.81 & 158.46 & 158.52 & 157.34 & 157.32 & 155.17 & 155.22 & 154.47\end{array}$

$\begin{array}{llllllll}158.88 & 158.46 & 158.62 & 157.23 & 157.35 & 155.22 & 155.14 & 154.35\end{array}$

$\begin{array}{lllllllll}159.09 & 158.63 & 158.53 & 157.41 & 157.30 & 155.19 & 155.05 & 154.42\end{array}$

$\begin{array}{lllllllll}158.79 & 158.54 & 158.50 & 157.30 & 157.26 & 155.05 & 154.98 & 154.16\end{array}$

$\begin{array}{lllllllll}\text { Avg . sens. } & 158.85 & 158.50 & 158.52 & 157.34 & 157.27 & 155.21 & 155.17 & 154.39\end{array}$

RSD

$\pm 0.09 \% \quad \pm 0.04 \% \quad \pm 0.09 \% \quad \pm 0.04 \% \quad \pm 0.08 \% \quad \pm 0.08 \% \quad \pm 0.07 \% \quad \pm 0.09 \%$

$\Delta$ sensitivity

(between vessel)

(relative)

$\triangle \mathrm{QM}$ 非 - WAP 非

$0.01 \%$

$-0.22 \% \quad-0.21 \%$

$\Delta$ sensitivity*
$($ mix - pure)

$\Delta$ sensitivity
$(\operatorname{mix}-$ pure)

* (Sens. Mix - Sens. Pure) 
Multiple runs were made on each vessel containing DT standards $\mathrm{T}-0702$ and $\mathrm{T}-930$ to determine if there were any differences between vessels. The GAZAB was calibrated with standard $T-500$ for all of these runs. The results in Table 30 indicate that the difference in the total $\mathrm{T}(\mathrm{T}-0702)$ and total $\mathrm{D}(\mathrm{T}-930)$ are less than $.05 \%$ relative. This data and the comparison data in Table 29 for the vessels containing DT standard T-500 show that both the Quantum Mechanics vessels and the Western Air Products vessels are well passivated. Neither type affects the composition of the stored st andards.

Multiple analyses of standards $\mathrm{T}-0700, \mathrm{~T}-0702$, and $\mathrm{T}-930$ were made over a six week period. The results (Tables 31,32 , and 33 ) show that analyses with the GAZAB are generally within $0.25 \%$ (relative) of the theoretical values.

The ability of the GAZAB to distinguish between two samples of nearly the same composition was tested by comparing the data for standards $T-0702$ and $T-0700$. As shown in Table 34, the GAZAB reliably detected and measured the $\sim 0.4 \%$ relative difference between the two standards.

Norman Parson, GEND, reported that their MAT 251 HDT continues to operate very well. The instrument is set up to operate routinely at a resolution of 1300 . T. Mehrhoff, GEND, modified the MAT low resolution ( 600$)$ software to operate the instrument at high resolution. As shown in Table 35 , the instrument is precise within $0.3 \%$ (relative $95 \%$ confidence 1 imits) and accurate within $0.5 \%$ (relative) for the major components. Reproducible nonlinear effects in the DT measurements were observed in some of the data. Gross differences in sample inlet pressures between individual analyses of standards $12-\mathrm{T}-200$ and $2-\mathrm{L}$ caused variations in the measured DT values. The differences caused the $0.36 \%$ and $0.63 \%$ precisions shown for the total $D /$ total $T$ ratio measurements for these standards. When the DT values were corrected for the pressure effect, the precision values for the total D/total $T$ ratio determination fell to $0.28 \%$ and $0.25 \%$, respectively. 
TABLE 30

GAZAB Tests to Determine DT Differences Between Vessels*

\begin{tabular}{|c|c|c|c|c|c|c|}
\hline $\begin{array}{l}\text { T-930 } \\
\text { QM 非3 } \\
\text { Total D\% }\end{array}$ & $\begin{array}{l}10 / 18 / 82 \\
\text { QM 非 } \\
\text { Total D\% }\end{array}$ & $\begin{array}{l}\mathrm{T}-930 \\
\text { QM 非 } 3 \\
\text { Total D\% }\end{array}$ & $\begin{array}{l}10 / 21 / 82 \\
\text { QM 非 } \\
\text { Total D\% }\end{array}$ & $\begin{array}{l}\mathrm{T}-0702 \\
\text { WAP 非 } \\
\text { Total T\% }\end{array}$ & $\begin{array}{l}10 / 19 / \\
\text { WAP \#4 } \\
\text { Total } \\
\end{array}$ & $\begin{array}{l}82 \\
+ \\
T \% \\
\end{array}$ \\
\hline 7.050 & 7.050 & 7.032 & 7.040 & 6.874 & 6.873 & \\
\hline 7.046 & 7.052 & 7.034 & 7.040 & 6.874 & 6.874 & \\
\hline 7.052 & 7.054 & 7.036 & 7.037 & 6.873 & 6.870 & \\
\hline 7.048 & 7.050 & 7.036 & 7.043 & 6.865 & 6.866 & \\
\hline 7.048 & 7.049 & 7.040 & 7.036 & 6.872 & 6.872 & \\
\hline 7.046 & & 7.036 & $\underline{7.036}$ & 6.870 & 6.872 & \\
\hline $7.048 \pm 0.002$ & $7.051 \pm 0.002$ & $7.036 \pm 0.003$ & $7.039 \pm 0.003$ & 6.868 & 6.866 & \\
\hline \multirow[t]{2}{*}{$\mathrm{RSD} \pm 0.03 \%$} & $\pm 0.03 \%$ & $\mathrm{RSD} \pm 0.04 \%$ & $\pm 0.04 \%$ & 6.870 & 6.862 & \\
\hline & & & & 6.872 & 6.871 & \\
\hline \multirow[t]{3}{*}{$\triangle Q M$ Q 非-QM 非 } & $=0.04 \% \mathrm{rel}$ & $\triangle \mathrm{QM} \# 3-\mathrm{QM}$ \#4 & $=0.04 \%$ & 6.875 & & \\
\hline & & & & $6.871 \pm 0.003$ & 6.870 & \pm 0.00 \\
\hline & & & & $\begin{array}{l}\mathrm{RSD} \pm 0.04 \% \\
\triangle \mathrm{WAP} \equiv 3-\text { WAP }\end{array}$ & $\begin{array}{l} \pm 0.06 \% \\
\# 4=0\end{array}$ & $0.01 \%$ \\
\hline
\end{tabular}

* QM - vessels fabricated by Quantum Mechanics.

WAP - vessels fabricated by Western Air Products. 


\section{TABLE 31}

Analysis of Standard Mixture SRP T-0700 by GAZAB

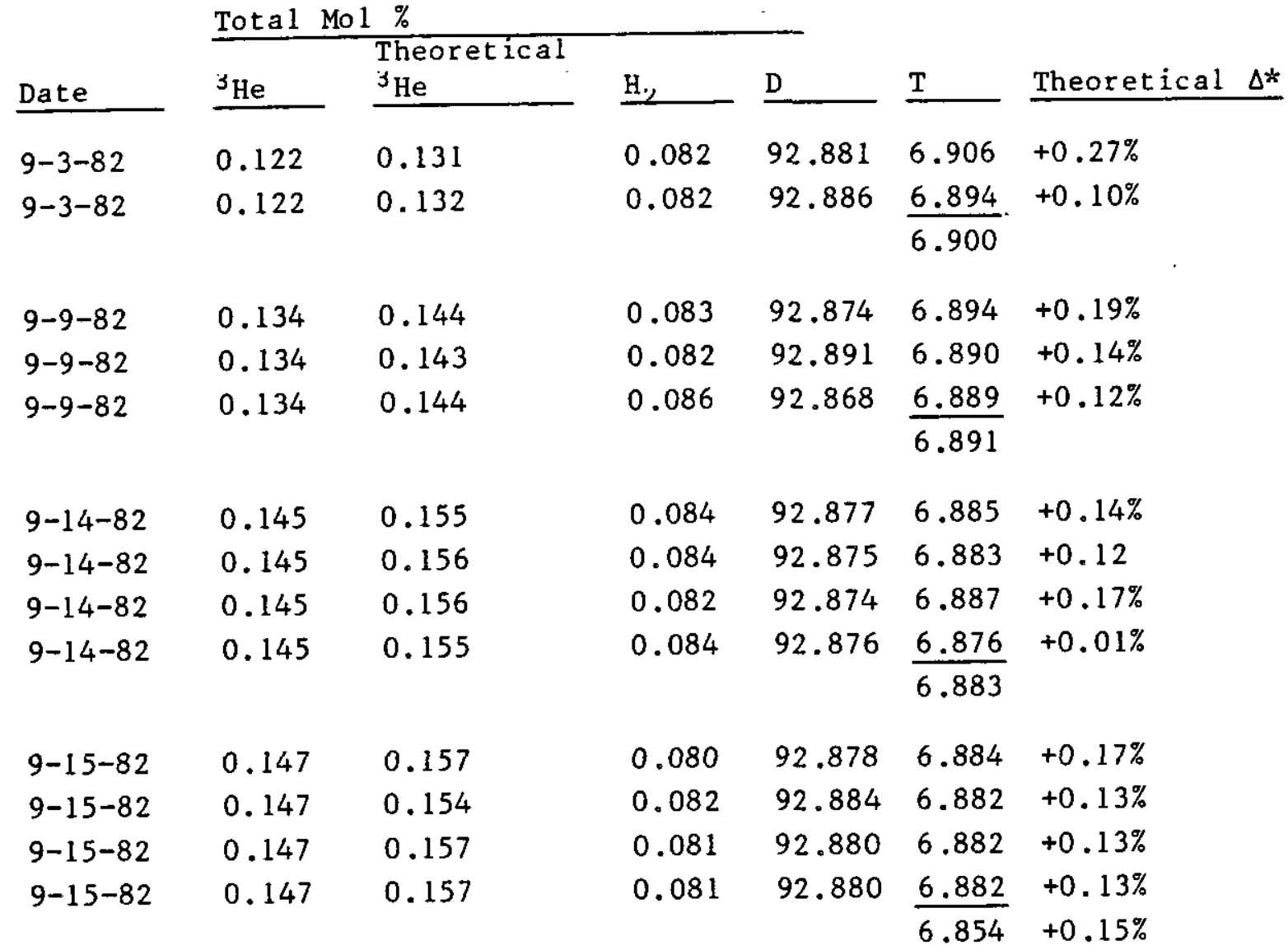

Difference from theoretical $\mathrm{T}$ value. 
TABLE 32

Analysis of Standard Mixture SRP T-0702 by GAZAB

Total Mol \%

\begin{tabular}{|c|c|c|c|c|c|c|c|}
\hline Date & ${ }^{3} \mathrm{He}$ & $\begin{array}{l}\text { Theoretical } \\
{ }^{\mathrm{He}}\end{array}$ & $\underline{\mathrm{H}_{2}}$ & $\underline{D}$ & $\mathrm{~T}$ & $\Delta \mathrm{T}-0700 * *$ & Theoretical $\Delta^{*}$ \\
\hline $9-3-82$ & 0.150 & 0.139 & 0.090 & 92.830 & 6.930 & $+0.45 \%$ & $+0.23 \%$ \\
\hline \multirow[t]{2}{*}{$9-3-82$} & 0.150 & 0.139 & 0.090 & 92.825 & 6.932 & - & $+0.26 \%$ \\
\hline & & & & & 6.931 & & \\
\hline $9-9-82$ & 0.162 & 0.152 & 0.091 & 92.874 & 6.894 & & $+0.19 \%$ \\
\hline $9-9-82$ & 0.157 & 0.152 & 0.090 & 92.891 & 6.890 & & $+0.14 \%$ \\
\hline $9-9-82$ & 0.157 & 0.152 & 0.090 & 92.868 & 6.924 & & $+0.12 \%$ \\
\hline \multirow[t]{2}{*}{$9-9-82$} & 0.161 & 0.152 & 0.091 & 92.826 & 6.917 & & $+0.15 \%$ \\
\hline & & & & & 6.918 & $+0.39 \%$ & \\
\hline $9-14-82$ & 0.174 & 0.162 & 0.091 & 92.822 & 6.909 & & $+0.11 \%$ \\
\hline $9-14-82$ & 0.172 & 0.162 & 0.091 & 92.828 & 6.910 & & +0.13 \\
\hline $9-14-82$ & 0.172 & 0.162 & 0.090 & 92.823 & 6.910 & & $+0.13 \%$ \\
\hline \multirow[t]{2}{*}{$9-14-82$} & 0.172 & 0.162 & 0.090 & 92.826 & 6.909 & & $+0.11 \%$ \\
\hline & & & & & 6.910 & $+0.40 \%$ & \\
\hline $9-15-82$ & 0.175 & 0.165 & 0.086 & 92.827 & 6.907 & & $+0.10 \%$ \\
\hline $9-15-82$ & 0.176 & 0.165 & 0.087 & 92.827 & 6.907 & & $+0.10 \%$ \\
\hline $9-15-82$ & 0.174 & 0.165 & 0.086 & 92.826 & 6.910 & & $+0.15 \%$ \\
\hline \multirow[t]{2}{*}{$9-15-82$} & 0.176 & 0.165 & 0.087 & 92.825 & 6.910 & & $+0.15 \%$ \\
\hline & & & & & 6.908 & $+0.37 \%$ & \\
\hline $10-13-82$ & 0.236 & 0.224 & 0.090 & 92.792 & 6.884 & & $+0.23 \%$ \\
\hline $10-13-82$ & 0.234 & 0.224 & 0.090 & 92.798 & 6.882 & & $+0.20 \%$ \\
\hline $10-13-82$ & 0.232 & 0.224 & 0.091 & 92.805 & 6.878 & & $+0.14 \%$ \\
\hline \multirow[t]{2}{*}{$10-13-82$} & 0.234 & 0.224 & 0.089 & 92.799 & 6.882 & & $+0.20 \%$ \\
\hline & & & & & 6.882 & $+0.41 \%$ & $\because$ \\
\hline $10-19-82$ & $10 r$ uns & & Each v & ssel & 6.871 & & $\frac{+0.14 \%}{+0.16 \%}$ \\
\hline
\end{tabular}

* Average vesse 1 WAP $\# 3$ - WAP $\$ 4$.

* Theoretical $\Delta 0.44 \%$ relative between $\mathrm{T}-0700$ and $\mathrm{T}-0702$.

$\dagger \Delta=$ difference from theoretical $\mathrm{T}$ value. 


\section{TABLE 33}

Analysis of Standard Mixture SRP T-930 by GAZAB

Total Mol \%

\begin{tabular}{|c|c|c|c|c|c|c|c|}
\hline Date* & ${ }^{3} \mathrm{He}$ & $\begin{array}{l}\text { Theoretical } \\
{ }^{3} \mathrm{He} \\
\end{array}$ & $\underline{\mathrm{H}_{2}}$ & D & $\underline{T}$ & $\Delta$ & Theoretical \\
\hline $9-3-82$ & 1.490 & 1.498 & 0.55 & 7.084 & 91.378 & $D_{2}$ & $+0.12 \%$ \\
\hline $9-3-82$ & 1.484 & 1.498 & & 7.082 & & & $+0.09 \%$ \\
\hline $9-9-82$ & 1.674 & 1.665 & & 7.094 & & & $+0.35 \%$ \\
\hline $9-9-82$ & 1.679 & 1.665 & & 7.095 & & & $+0.36 \%$ \\
\hline $9-9-82$ & 1.688 & 1.665 & & 7.109 & & & $+0.26 \%$ \\
\hline $9-9-82$ & 1.684 & 1.665 & & 7.096 & & & $+0.37 \%$ \\
\hline $9-14-82$ & 1.817 & 1.804 & & 7.080 & & & $+0.22 \%$ \\
\hline $9-14-82$ & 1.815 & 1.804 & & 7.078 & & & +0.19 \\
\hline $9-14-82$ & 1.819 & 1.804 & & 7.083 & & & $+0.26 \%$ \\
\hline $9-14-82$ & 1.820 & 1.804 & & 7.079 & & & $+0.20 \%$ \\
\hline $9-15-82$ & 1.850 & 1.832 & & 7.080 & & & $+0.23 \%$ \\
\hline $9-15-82$ & 1.851 & 1.832 & & 7.084 & & & $+0.28 \%$ \\
\hline $9-15-82$ & 1.849 & 1.832 & & 7.082 & & & $+0.25 \%$ \\
\hline $9-15-82$ & 1.852 & 1.832 & & 7.080 & & & $+0.23 \%$ \\
\hline $10-13-82$ & 2.626 & 2.604 & & 7.053 & & & $+0.24 \%$ \\
\hline $10-13-82$ & 2.622 & 2.604 & & 7.054 & & & $+0.26 \%$ \\
\hline $10-13-82$ & 2.631 & 2.604 & & 7.060 & & & $+0.34 \%$ \\
\hline $10-13-82$ & 2.638 & 2.604 & & 7.058 & & & $+0.31 \%$ \\
\hline $10-18-82$ & 2.764 & 2.742 & & 7.050 & avg. 12 & runs & $+0.27 \%$ \\
\hline $10-21-82$ & 2.847 & 2.824 & & 7.038 & avg. $\begin{array}{c}12 \\
\text { Aver }\end{array}$ & $\begin{array}{l}\text { runs } \\
\text { age }\end{array}$ & $\frac{+0.14 \%}{+0.26 \%}$ \\
\hline
\end{tabular}

* Average vessel QM 非 - QM 非. 
TABLE 34

Detection of Small Differences

\begin{tabular}{|c|c|c|c|c|}
\hline Date & $\frac{\text { Total T, }}{\mathrm{T}-0702}$ & $\frac{\text { Mol } \%}{T-0700}$ & $\frac{\Delta \mathrm{T}, \text { Mol } \%}{(\mathrm{~T}-0702)-(\mathrm{T}-0700)}$ & $\Delta \mathrm{T}, \operatorname{Re} 1 \%$ \\
\hline $9 / 3 / 82$ & 6.931 & 6.900 & 0.031 & $0.45 \%$ \\
\hline $9 / 9 / 82$ & 6.918 & 6.891 & 0.027 & $0.39 \%$ \\
\hline $9 / 14 / 82$ & 6.910 & 6.883 & 0.027 & $0.39 \%$ \\
\hline $9 / 15 / 82$ & 6.908 & 6.883 & 0.025 & $0.36 \%$ \\
\hline \multirow[t]{3}{*}{$10 / 13 / 82$} & 6.882 & 6.854 & 0.028 & $0.41 \%$ \\
\hline & & $\bar{\Delta}$ & 0.028 & $0.40 \% \pm 0.04$ (RSD) \\
\hline & Theoreti & cal & 0.031 & $0.44 \%$ \\
\hline
\end{tabular}


TABLE 35

\begin{tabular}{|c|c|c|c|c|}
\hline Standard & Total H & Total D & Total $T$ & D/T Precision** \\
\hline \multirow{2}{*}{$\begin{array}{ll}\text { ST } & 330 \\
& \text { Precision** }\end{array}$} & $35.49 \mathrm{~mol} \%$ & $35.44 \mathrm{~mol} \%$ & $29.07 \mathrm{~mol} \%$ & \multirow{3}{*}{$0.27 \%$} \\
\hline & $\pm 0.22 \%$ & $\pm 0.12 \%$ & $\pm 0.24 \%$ & \\
\hline $\operatorname{Re} 1$ bias $†$ & $\pm 0.17 \%$ & $0.00 \%$ & $-0.07 \%$ & \\
\hline $3-M R=1274-02$ & 0.28 & 60.11 & 39.61 & \multirow[t]{3}{*}{$0.17 \%$} \\
\hline Precision & $\pm 5 \%$ & $\pm 0.09 \%$ & $\pm 0.14 \%$ & \\
\hline Rel bias & $+100 \%$ & $+0.12 \%$ & $-0.50 \%$ & \\
\hline \multirow[t]{3}{*}{$12-\mathrm{T}-900$} & 0.07 & 11.16 & 88.77 & \multirow[t]{4}{*}{$0.35 \%$} \\
\hline & $\pm 37 \%$ & $\pm 0.36 \%$ & $\pm 0.05 \%$ & \\
\hline & & $( \pm 0.28 \%)+\dagger$ & & \\
\hline & $+133 \%$ & $+2.2 \%$ & $-0.30 \%$ & \\
\hline $2-L$ & 0.32 & 92.77 & 6.91 & \multirow{2}{*}{0.63} \\
\hline \multirow[t]{2}{*}{ Precision } & $\pm 0.9 \%$ & $\pm 0.04 \%$ & $\pm 0.63 \%$ & \\
\hline & & & $( \pm 0.35 \%) \dagger \dagger$ & \multirow[t]{2}{*}{$0.25 \%+\dagger$} \\
\hline Rel bias & $+220 \%$ & $-0.26 \%$ & $+0.29 \%$ & \\
\hline $10-11-T-300$ & 0.05 & 72.00 & 29.75 & \multirow[t]{3}{*}{$0.21 \%$} \\
\hline Precision & $\pm 15 \%$ & $\pm 0.08 \%$ & $\pm 0.19 \%$ & \\
\hline Rel bias & $-150 \%$ & $+0.17 \%$ & $-0.30 \%$ & \\
\hline \multicolumn{5}{|c|}{$\begin{array}{l}\text { * GEND data courtesy of } \mathrm{N} \text {. H. Parsons } \\
\text { ** Precision }=\text { relative } 95 \% \text { confidence limits for a single determination } \\
+ \text { Relative bias }=\frac{\text { (observed mol } \% \text { - theoretical mol } \% \text { ) }}{\text { theoretical mol } \%} \times 100\end{array}$} \\
\hline
\end{tabular}




\section{REFERENCES}

1. W. M. Jones. "Thermodynamic Functions for Tritium Deuteride. The Dissociation of Tritium Particles. Equilibrium Among the Isotopic Hydrogen Molecules." J. Chem. Phys. 17, 1062 (1949).

2. R. Schott and G. Beau. "Quantitative Analysis of Hydrogen Isotopes by Mass Spectrometry." Method. Phys. Anal. 7, 165 (1971).

3. P. Chastagner. Mass Spectrometer for Accurate Hydrogen Isotopic Analyses. USDOE Report DP-1492, E. I. du Pont de Nemours \& Co., Savannah River Laboratory, Aiken, SC (1978).

4. R. B. Ferguson and P. Chastagner. "High Resolution Mass Spectrometer for Accurate Analysis of Mixtures of Hydrogen and Helium Isotopes." Int. J. Mass Spectrom. Ion Phys. 24, 403 (1977). 
APPENDIX I

DOE MASS SPECTROMETER TECHNICAL GROUP

James W. Guthrie - Coordinator Sandia National Laboratories Division 1551

P.O. Box 5800

Albuquerque, NM 87185

Robert L. Carpenter

Rockwell International

Atomics International Division

P.O. Box 464

Golden, Co 80401

Phillippe Chastagner

E. I. du Pont de Nemours \& Co. Savannah River Laboratory

Aiken, SC 29808

R. E. Ellefson

Monsanto Research Corp.

Mound Facility

P.O. Box 32

Miamisburg, OH 45342

James C. Franklin

Y-12 Plant

Union Carbide Corporation

P.O. BoX Y

Oak Ridge, TN 37830

William D. Harman

Y-12 Plant

Union Carbide Corporation

P.O. BoX Y

Oak Ridge, TN 37830

W. Bascom Hess

E. I. du Pont de Nemours \& Co.

Savannah River Plant

Aiken, SC 29808
Edward D. Loughran, WX-2

University of California

Los Alamos National Laboratory

P.0. Box 1663

Los Alamos, NM 87544

Lester C. Myers

Mason \& Hanger-Silas Mason Co., Inc.

Pantex Plant

P.0. Box 647

Amarillo, TX 79144

Norman H. Parsons

General Electric Co.

Neutron Devices Dept.

P.O. Box 11508

St. Petersburg, FL 33733

Robert H. Sherman, Q10

Los Alamos National Laboratory

P.0. Box 1663

Mail Stop 764

Los Alamos, NM 87544

Ronald K. Stump, $L-358$

University of California

Lawrence Livermore National Lab.

P.O. Box 808

Livermore, CA 94550

Karen Greulich

Sandia National Laboratories

Division 8443

P.0. Box 969

Livermore, CA 94550 


\section{A. GENERAL DESCRIPTION}

1. The instrument should have an overall mass range of at least $\mathrm{m} / \mathrm{e} 1-600$. The resolution should be 2000 at mass 4 and the abundance sensitivity for the $\mathrm{H}_{2}{ }^{+}-\mathrm{D}^{+}$doublet should be at least $.40,000$. It should be easily adjustable to a stable resolution of at least 3000 at mass 28 .

2. After a pure gas standardization, the instrument should have an overall capability of determining the total amount of an $\mathrm{H}$-isotope present at the $6 \%$ level in a 2 std cc sample of a mixture (regardless of isotopic species) and a $15: 1$ ratio of two major components (e.g., total $\mathrm{D} \approx 90 \%$ and a total $\mathrm{H} \approx 5 \%$ ) according to the tests described in the Performance Tests (c.l.k.). The normal sample analysis rate should not be less than six samples per hour.

3. The mass spectrometer should be constructed entirely of metal with metal-gasketed joints (except as specified) and be bakeable to at least $250^{\circ} \mathrm{C}$. Standard UHV joints compatible with Varian and Ultek joints are performed.

4. The high voltage distribution system will be designed to operate continuously at altitudes of up to 7600 feet above sea level.

\section{B. DETAILED SPECIFICATIONS}

1. Sample Inlet System. The main purpose of this inlet system is for demonstrating the performance specifications. The inlet system will be all stainless steel and will be bakeable to at least $150^{\circ} \mathrm{C}$. In normal operation the inlet system will be maintained at a temperature of about $40^{\circ} \mathrm{C}$ and will be held constant within $\pm 0.1^{\circ} \mathrm{C}$. It will consist of a sample inlet volume equipped with a 0-200 torr bourdon tube gage, (or equivalent), an expansion volume (reservoir) a molecular leak connected to the ionization chamber of the source, a bypass valve around the molecular leak, an acceptable capacitance type manometer such as the MKS $145 \mathrm{AH}-1$ (whose chamber is included in the temperature controlled system), a bypass valve around the capacitance manometer, an ionization pump to maintain the reference side of the capacitance manometer at a pressure 
$<1 \times 10^{-7}$ torr, a polyphenyl ether diffusion pump with water, air, freon, or thermoelectrically cooled baffles, molecular seive, optically dense foreline trap, or an adequate forepump and an isolation valve between the forepump and diffusion pump. The inlet system will essentially be as shown in the attached sketch.

The conductance of the gold foil molecular leak (easily interchangeable) will be less than $0.2 \mathrm{cc} / \mathrm{sec}$ for nitrogen gas.

All valves will be constructed to provide minimum surface area in contact with the sample and for ease of maintenance. When possible, the valves will be mounted with their seats facing the active volume as shown in the sketch.

No device that allows mercury to contact the sample gas may be used.

2. Ion Source. The ion source is the key element in the mass spectrometric analysis of mixtures of the H-isotopes.

a. The ion source will be a heated, electron bombardment, short focal length, high-brightness type.

b. The accelerating voltage will be at least $8,000 \mathrm{~V}$.

c. The source materials must be chosen to minimize memory and to facilitate cleaning and maintenance.

Nichrome $\mathrm{V}$ is the preferred material for the metal parts and aluminum oxide is preferred for the insulators.

d. The filaments will be self-aligning.

The source will function correctly with either tungsten or rhenium filament material. (See Item 6.a.).

e. The ion source region will be differentially pumped with respect to the analyzer.

f. An adequate isolation valve is required between the ion source housing and the analyzer to permit the source to be vented for filament changing and repair without venting the analyzer.

g. Z axis focusing plates will be provided after the ion source exit slit plate to optimize transmission from the ion source through the analyzer. 
h. The ion source temperature will be variable from ambient temperature (with the filament on) to at least $250^{\circ} \mathrm{C}$ and will be regulated within $\pm 0.2^{\circ} \mathrm{C}$.

i. The ionizing voltage will be precisely adjustable over a range of at least 10 to $150 \mathrm{~V}$.

j. The ionizing current will be trap regulated and will be adjustable over a range of at least 10 to $300 \mu \mathrm{A}$.

k. The ion source controls will be simple and the settings must be precisely reproducible.

1. The ion source exit slit(s), if any, will be externally adjustable (precisely) without breaking the vacuum.

3. Analyzer. The analyzer must have high transmission and sharp focus for good resolution and abundance sensitivity. The magnet should be a low-impedance high-current electromagnet.

The analyzer will be all metal and will be bakeable to at least $150^{\circ} \mathrm{C}$.

Any realignment of the analyzer magnet (if moved during the bakeout procedure) must be simple and precise.

4. Ion Collector(s)

a. The principal ion collector will be a Faraday cage type with a reliable, effective secondary electron suppression system.

b. The collector slit will be adjustable (precisely) from outside the vacuum system over a range of about $500 \mu \mathrm{m}$ to less than $2 \mu \mathrm{m}$.

c. The collector slit or the ion beam will be rotatable (precisely) from outside the vacuum system.

d. An electron multiplier ion detector will be provided.

e. A total ion monitor collector will be provided.

5. Vacuum System

a. Pressure Measurement

Ionization gages will be located in the high vacuum pumping lines to monitor the pressure in all parts of the system that are equipped with diffusion pumps and they must not 
contribute to background spectra in the m/e 2 to $44 \mathrm{range}$. Pirani gages will be provided in all fore pressure and roughing lines.

Isolation valves will be used between diffusion pumps and forepumps.

b. Source Housing

The ion source housing will be maintained at a pressure less than $1 \times 10^{-7}$ torr at all times during operation. It will be pumped by a diffusion pump with polyphenyl ether fluid and will have a liquid nitrogen trap with a minimum holding time of 12 hours. A viton-sealed and gasketed isolation valve will be provided between the $\mathrm{LN}_{2}$ trap and the source housing. An isolation valve will be used between the diffusion pump and the forepump. Differential pumping is required between the source housing and the analyzer to prevent degradation of the pressure in the analyzer.

c. Analyzer

The pressure in the analyzer will be maintained less than $2 \times 10^{-8}$ torr at all times. The analyzer will be pumped between the source housing and the magnetic analyzer and between the magnetic analyzer and the intermediate slit and between the intermediate slit and the electrostatic analyzer. Polyphenyl ether filled diffusion pumps with adequate trapping and isolation valves between diffusion pumps and forepumps will be used.

d. Mechanical Pumps

The mechanical forepumps will be quiet running, have readily available parts, and require minimum maintenance. The forepumps will be isolated by adequate foreline traps to prevent the forepump oil from backstreaming into the system. These pumps will also be equipped with automatic safety valves to isolate them during power failures or whenever isolation is desired.

e. The sample inlet system will have a separate pumping system similar to the source housing pumping system.

f. Protection System

An adequate protection system will be provided to protect all components in the event of failure of power, water (or other collants), or vacuum. 
6. Electronics

All electronic supplies and controls will be of all-solid state design.

a. Emission Regulator

The emission regulator will regulate the trap current of the electron bombardment ion source within $\pm 0.05 \%$. The trap current range will be at least 10 to $300 \mu \mathrm{A}$ with precise settings and readout. The ionizing potential will be precisely adjustable over the range of at least 10 to $150 \mathrm{~V}$ and will be stable within $\pm 0.1 \mathrm{~V}$. The regulator will operate satisfactorily with all normally used filament materials including, but not limited to, tungsten and rhenium.

b. High Voltage Supply

The high voltage supply to the ESA supply will be precisely adjustable over a minimum range of 500 to $10,000 \mathrm{~V}$ and will be stable within $\pm 0.002 \%$ ( $20 \mathrm{~min}$.$) at 8 \mathrm{kV}$ accelerating voltage. Manual and repetitive sweep modes at several different sweep speeds will be provided. The unit will be capable of being controlled by a computer (analog signals $10 \mathrm{~V}$ maximum). The supply and all associated high voltage wiring and control circuitry will be suitable for continuous operation at altitudes 7,600 feet above sea level.

c. Magnet Power Supply and Control

The magnet power supply and control unit will be stable within $\pm 0.0005 \%$ ( $2 \mathrm{~min}$. at $\mathrm{m} / \mathrm{e} 2$ and above). The unit will be precisely field controlled with a Hall probe. It will be resetable within $\pm 20 \mathrm{~m}$ gauss. Manual and bidirectional sweep modes at several different sweep speeds will be capable of being controlled by a computer (analog signals $10 \mathrm{~V}$ maximum).

d. Amplifier

The amplifier will have a dynamic range of at least $5 \times 10^{5}: 1$, a response time of 0.3 seconds or less, a noise level less than $2 \times 10^{-15} \mathrm{~A}$, and be linear within $0.1 \%$ over the entire range (with a $1 \times 10$-inch ohm resistor). The unit will have two outputs; one for a recorder, and the other for a DVM or a computer. 


\section{PERFORMANCE TESTS}

The instrument will be tested with hydrogen and helium and mixtures of their isotopes to demonstrate satisfactory low mass performance. Testing will be limited to the nonradioactive isotopes. The Faraday cage collector will be used for all of the testing except where the electron multiplier is specified.

The instrument will be tested for satisfactory high mass performance with nitrogen and other inorganic gases either singly or in mixtures.

\section{Performance Tests with Hydrogen and Helium Isotopes}

a. The source will be adjusted with pure $D_{2}$ and pure $H_{2}$ for a resolution of at least 2000 ( $10 \%$ valley definition) with flat-topped peaks and this setting will be used for all of the performance testing (hydrogen and helium). No manual readjustment will be necessary over the $\mathrm{m} / \mathrm{e}=2-44$ mass range (see $\mathrm{N}_{2}$ sensitivity test below).

When the instrument is calibrated with pure $\mathrm{D}_{2}$ gas, the $\mathrm{H}_{2}$ and $\mathrm{HD}$ sensitivities* should agree with the $\mathrm{D}_{2}$ sensitivity within $0.5 \%$ without manual readjustment to the ion source. Sensitivities will not require redetermination more than once every eight hours.

When the ion source is adjusted for optimum performance with the $\mathrm{H}$ isotopes, the sensitivity for $\mathrm{N}_{2}$ will not be more than $20 \%$ less during automatic scans than when the ion source is adjusted for optimum performance with $\mathrm{N}_{2}$ gas.

b. Absolute sensitivity of the instrument will be tested with pure $\mathrm{D}_{2}$ gas flowing into the ion source. The ion intensity measured at the Faraday cage ion collector for $\mathrm{D}_{2}{ }^{+}$will be not less than $3 \times 10^{-1}$ A when the $D_{2}$ gas flow into the ion source is $2.5 \times 10^{-5} \mathrm{~atm}-\mathrm{cc} / \mathrm{sec}$.

c. The abundance sensitivity will be at least 40,000 for the $\mathrm{H}_{2}{ }^{+}-\mathrm{D}^{+}$doublet at mass 2 and for the $\mathrm{HT}^{+}-\mathrm{D}_{2}{ }^{+}$doublet at mass 4 .

The abundance sensitivity at mass 2 will be demonstrated with appropriate $\mathrm{D}_{2}-\mathrm{H}_{2}$ mixtures at a pressure that produces a $1 \times 10^{-10} \mathrm{~A} \mathrm{H}_{2}^{+}$ion beam at the ion collector. The height of the tail of the $\mathrm{H}_{2}{ }^{+}$ion peak under the $\mathrm{D}^{+}$ion peak will not be more than one part in 40,000 of the height of the $\mathrm{H}_{2}^{+}$ion peak. With the same sample, at the same time, the height of the tail of the $\mathrm{D}_{2}{ }^{+}$ion peak at the

* Sensitivity here (and elsewhere when not qualified) means output current per $\because$ pressure in the inlet system. 
calculated peak $\mathrm{HT}^{+}$mass position will not be more than one part in 40,000 of the height of the $\mathrm{D}_{2}{ }^{+}$ion peak.

d. The absence of memory will be demonstrated by introducing a sample of pure $D_{2}$ into the system at a pressure that yields a mass 4 ion beam of $1 \times 10^{-10} \mathrm{~A}$. The sample will then be pumped out for ten minutes. At the end of the ten minute period, an equal pressure of pure $\mathrm{H}_{2}$ will be put into the system. The peak at mass 4 will not be larger than

$3 \times 10^{-15}$ A (30 ppm of the previous $\mathrm{D}_{2}{ }^{+}$ion peak) and the $\mathrm{HD}^{+}$ion peak at mass 3 will be no larger than that attributable to the pure $\mathrm{H}_{2}$ gas.

e. The background of the instrument will be determined by pumping out the inlet system and the ion source overnight so the pressure in the ion source housing is $2 \times 10^{-8}$ torr or less, and measuring the residual ion peaks in the mass 2-44 range with the inlet system valved off. A series of 10 analyses, such as those required for the precision and accuracy test, will be made and the ion source and sample system will be pumped out for a period of ten minutes, and the background will again be measured. No background ion peak will show an increase under these conditions of more than 100 ppm of the major peak when a sample from the series of 10 is flowing into the ion source.

f. The absence of gas interference will be demonstrated by flowing pure $\mathrm{D}_{2}$ gas into the ion source at a rate of approximately $1 \times 10^{-5}$ atm-cc/sec. along with an Ar leak of similar proportions. The gas flows will be obtained from Sandia standard leaks. The $\mathrm{D}_{2}{ }^{+}$ion current will be monitored for another ten minute period. The $\mathrm{D}_{2}{ }^{+}$ion outputs for the two periods will agree within $0.1 \%$.

g. Trimer formation will be measured by observing the $\mathrm{D}_{3}+$ mass position during the abundance sensitivity test. The trimer formation at mass 6 should be less than $0.005 \%$ of the $\mathrm{D}_{2}{ }^{+}$ ion peak.

h. Linearity will be measured by determining the sensitivity for pure $\mathrm{D}_{2}$ (also for $\mathrm{N}_{2}, \mathrm{O}_{2}$, and $\mathrm{Xe}$ ) over a pressure range of 15 to $100 \mu$ in the inlet system. All of the sensitivities will agree within $\pm 0.15 \%$.

i. Satisfactory sensitivity for trace impurities will be demonstrated by measuring the ${ }^{4} \mathrm{He}$ content of air in a sample of not more than $100 \mu$ behind the standard leak using the electron multiplier ion detector. 
j. The absence of gas equilibration will be demonstrated by monitoring the mass $3 \mathrm{HD}^{+}$peak while a freshly-mixed $50 \% \mathrm{H}_{2}-50 \% \mathrm{D}_{2}$ sample is flowing into the ion source. There should not be any observable increase in the $\mathrm{HD}^{+}$ peak. The height of the $\mathrm{HD}^{+}$peak should not increase more than 100 ppm of the total signal.

k. Precision and Accuracy

The precision and accuracy will be demonstrated by analyzing two mixtures supplied by the contractor, consisting of a nominal $90.0 \mathrm{~mol} \% \mathrm{D}, 6.0 \mathrm{~mol} \% \mathrm{H}$, and $4.0 \mathrm{~mol} \%{ }^{3} \mathrm{He}$ and $6.0 \mathrm{~mol} \% \mathrm{D}, 90.0 \mathrm{~mol} \% \mathrm{H}$ and $4.0 \mathrm{~mol} \%{ }^{3} \mathrm{He}$, respectively. The $H$ and $D$ will be at or near equilibrium. The instrument will be calibrated with pure gases, and ten consecutive analyses of each standard mixture will be made at a rate of at least six analyses per hour (six separate introductions of sample gas into the inlet system). The major component's ion beam intensity (from the mixtures and calibra$t$ ion gases) will be made at a rate of at least six analyses per hour (six separate introductions of sample gas into the inlet system). The major component's ion beam intensity (from the mixtures and calibration gases) will be at least $5 \times 10^{-11} \mathrm{~A}$ at the collector. Sixteen hours or more later, the instrument will be recalibrated with the pure gases and another set of ten analyses of each standard mixture will be made. The total H, D, and ${ }^{3} \mathrm{He}$ contents will be calculated for each analysis. The following steps will be done:

1. For each set of ten analyses the sample mean and standard deviation will be calculated for each component. The mean for each set is given by:

$$
\bar{x}_{j}=\frac{\sum_{i=1}^{n} x_{j i}}{n} \quad j=1,2
$$

where $\vec{x}_{j}$ is the sample mean of the $j$ th set. $x_{j i}$ are the individual measures of the component and $n$ is the number of observations (10). The standard deviation is given by:

$$
s_{J}=\sqrt{\frac{\sum_{i=1}^{n} x_{j i}-\bar{x}_{j}^{2}}{n-1}}
$$

where $s_{j}$ is the sample standard deviation of the $j^{\text {th }}$ set. 
2. Each of the sets of 10 analyses will be tested for outlying observations.

$$
\frac{\left|x_{e x j}-\bar{x}_{j}\right|}{s_{j}}>2.29
$$

Where $x_{\text {ex }}$ is the extreme observation of the $j^{\text {th }}$ set (high or low), the observation will be discarded.

In discarding an observation, the entire analysis will be discarded. Not more than one "outlier" will be allowed in each set of 10 analyses.

If an observation is discarded in a set, a new sample mean and standard deviation will be calculated based upon the remaining nine observations.

3. The remaining data will be pooled to give a mean and standard deviation for the test. The pooled mean is:

$$
\bar{x}_{p}=\frac{n_{1} \bar{x}_{2}+n_{2} \bar{x}_{2}}{n_{1}+n_{2}}
$$

where $\bar{x}_{p}$ is the pooled mean, $n_{1}$ and $n_{2}$ are the number of observations remaining ( 9 or 10 ) after possible outlier discarding and $\overline{\mathrm{X}}_{1}$ and $\overline{\mathrm{X}}_{2}$ are the sample means again after possible discarding.

The pooled standard deviation is:

$$
s_{p}=\sqrt{\frac{\left(n_{1}-1\right) s_{1}^{2}+\left(n_{2}-1\right) s_{2}^{2}}{n_{1}+n_{2}{ }^{-2}}}
$$

where $s_{p}$ is the pooled standard deviation and $s_{1}$ and $s_{2}$ are the sample standard deviations after possible discarding of out liers.

4. An upper confidence for the population standard deviation will be calculated by:

$$
\mathrm{U}=\mathrm{K} \mathrm{s}_{\mathrm{p}}
$$

where $U$ is the upper bound for the population standard deviation and $k$ is a value from the following table: 


$\begin{array}{cc}\mathrm{n}_{1}+\mathrm{n}_{2} & \mathrm{~K} \\ 20 & 4.153 \\ 19 & 4.200 \\ 18 & 4.253\end{array}$

The ratio $U / \bar{X}_{\mathrm{P}}$ must be less than or equal to the relative precision limits given in Table II-1. Thus, for example, in mixture No. $1, \mathrm{U} / \overline{\mathrm{X}}_{\mathrm{p}}<.002$ or $0.20 \%$ for total $\mathrm{H}$.

TABLE II-1

\begin{tabular}{|c|c|c|c|}
\hline & Component & $\begin{array}{l}\text { Nominal } \\
\text { Concentration }\end{array}$ & $\begin{array}{l}\text { Maximum Precision } \\
\text { Limit (Relative) }\end{array}$ \\
\hline \multirow[t]{3}{*}{ Mixture No. 1} & Total H & $6.0 \mathrm{~mol} \%$ & $\pm 0.20 \%( \pm 0.012 \mathrm{~mol} \%)$ \\
\hline & Total D & $90.0 \mathrm{~mol} \%$ & $\pm 0.04 \%( \pm 0.036 \mathrm{~mol} \%)$ \\
\hline & ${ }^{3} \mathrm{He}$ & $4.0 \mathrm{~mol} \%$ & $\pm 0.40 \%( \pm 0.016 \mathrm{~mol} \%)$ \\
\hline \multirow[t]{3}{*}{ Mixture No. 2} & Total H & $90.0 \mathrm{~mol} \%$ & $\pm 0.04 \%( \pm 0.036 \mathrm{~mol} \%)$ \\
\hline & Total D & $6.0 \mathrm{~mol} \%$ & $\pm 0.20 \%( \pm 0.012 \mathrm{~mol} \%)$ \\
\hline & ${ }^{3} \mathrm{He}$ & $4.0 \mathrm{~mol} \%$ & $\pm 0.40 \% \quad( \pm 0.016 \mathrm{~mol} \%)$ \\
\hline
\end{tabular}

5. Using the values, as supplied by the contractor for the mixtures, the sample means for each component must satisfy the following:

$$
\frac{\left|\bar{x}_{j}-K C\right|}{K C}<.005 \quad j=1,2
$$

where KC is the specified concentrations for the components.

In addition, for each component the following must also be satisfied:

$$
\frac{\left|\bar{x}_{1}-\bar{x}_{2}\right|}{\bar{x}_{p}}<.005
$$




\begin{tabular}{|c|c|c|}
\hline Total D & 90.0 & $\operatorname{mol} \%$ \\
\hline Total H & 6.0 & mol \\
\hline${ }^{3} \mathrm{He}$ & 4.0 & mol \% \\
\hline $\mathrm{D}_{2}$ & 84.4 & moli \\
\hline $\mathrm{HD}$ & 11.13 & mol \\
\hline $\mathrm{H}_{2}$ & 0.45 & mol \\
\hline
\end{tabular}

Approximate equilibriun distribution of test mixture No. 2

Total D

6.0 mol \%

Total H

90.0 nol \%

${ }^{3} \mathrm{He}$

$4.0 \mathrm{~mol} \%$

$\mathrm{D}_{2}$

$0.45 \mathrm{~mol} \%$

HD

$11.13 \mathrm{~mol} \mathrm{\%}$

$\mathrm{H}_{2}$

84.4 mol \%

\section{Higher Mass Performance Tests}

a. The source will be adjusted with a nominal $50 \% \mathrm{~N}_{2}, 50 \%$ co gas mixture for a resolution of at least 3000 ( $10 \%$ valley definition) at mass 28 with an $\mathrm{N}_{2}{ }^{+}$ion beam intensity of at least $1 \times 10^{-10} \mathrm{~A}$ at the collector. This setting will be used for all of the higher mass performance testing.

b. The abundance sensitivity will be demonstrated with normal Xe gas at a pressure in the inlet system that produces a $3 \times 10^{-11} \mathrm{~A}$ or larger ${ }^{134} \mathrm{Xe}$ ion intensity at the collector. The combined contribution of ${ }^{132} \mathrm{Xe}$ and ${ }^{134} \mathrm{Xe}$ at the mass 133 position will not be greater than one part in $10^{6}$ of the height of the ${ }^{134} \mathrm{Xe}$ ion peak and the combined contribution of ${ }^{134} \mathrm{Xe}$ and ${ }^{136} \mathrm{Xe}$ at the mass 135 position will not be greater than one part in $10^{6}$ of the height of the ${ }^{134} \mathrm{Xe}$ ion peak.

c. The precision and accuracy will be demonstrated by analyzing 10 successive samples of pure natural Xe gas at a rate of at least four analyses per hour (four separate introductions of $\mathrm{Xe}$ gas into the inlet system). The data will be treated as in Section C.1.K (above) and the values obtained will be equal to or less than the values in Table II-2. 
TABLE II-2 Maximum Precision Average from Known

Maximum Deviation of Abundance, Relative, \%

Isotope Abundance, mol, \% Limits, Relative, \%

$\pm 1$

$124 \mathrm{Xe}$

0.096

$\pm 1.0$

$\pm 1$

${ }^{126} \mathrm{Xe}$

0.090

$\pm 1.0$

$\pm 0.5$

${ }^{128} \mathrm{Xe}$

1.919

$\pm 0.25$

$\pm 0.3$

$130 \mathrm{Xe}$

26.44

$\pm 0.12$

$\pm 0.4$

$131 \mathrm{Xe}$

4.08

$\pm 0.20$

$\pm 0.3$

$132 \mathrm{Xe}$

21.18

$\pm 0.13$

$\pm 0.3$

${ }^{134} \mathrm{Xe}$

$\pm 0.12$

$\pm 0.3$

${ }^{136} \mathrm{Xe}$

8.87

$\pm 0.17$

$\pm 0.4$ 


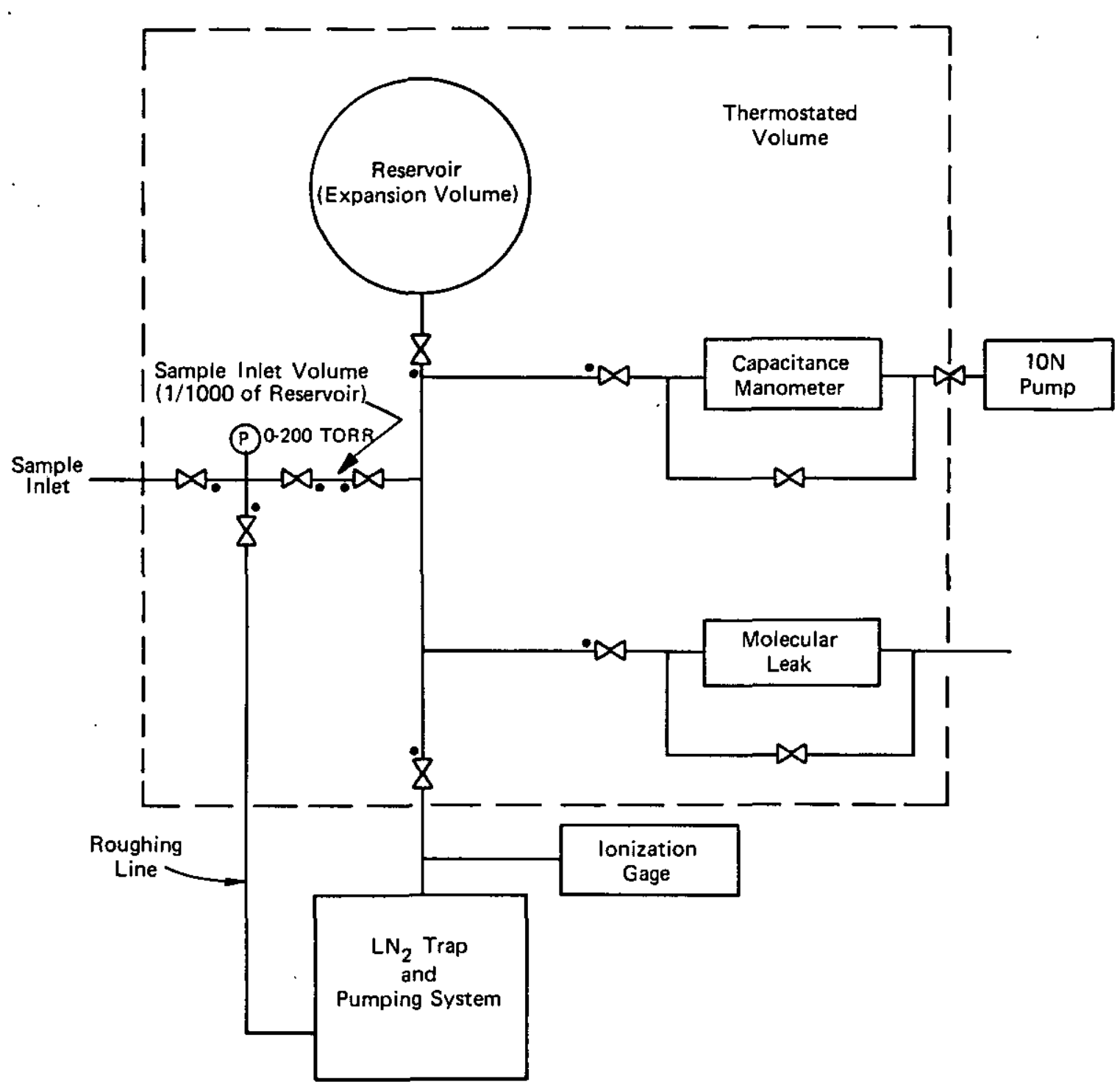

FIGURE II-1. Sketch of Sample Inlet System 
APPENDIX III

MEMORANDUM (JANUARY 6, 1981) FROM J. W. GUTHRIE (SNLA) TO

G. L. THOMPSON (SNLA PURCHASING) 


\section{Sandia Laboratories}

date: January 6,1981

Albuguerque. New Mexico

Livermore. Calitornia

to: G. L. Thompson, 3713

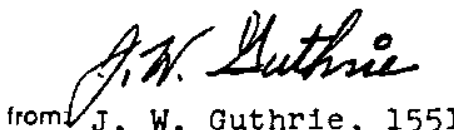

Coordinator, DOE Mass Spectrometer Development Program

subject: Contract 13-9152 with VG Isotopes Ltd., England via The Kearns Group, Galthersburg, Maryland

Evaluation by DOE's Savannah River Facility of the latest (December 1980) test information from VG Isotopes, Ltd. has resulted in the following recommendations concerning contract $13-9152$.

1. Waive the right to again witness specification tests in England (witnessed by W. B. Hess, SRP In April and octobs 1980).

2. Authorize shipment of the mass spectrometer system to the Savannah River Fac1l1ty as per contract 13-9152. (Reference mWX dated $1-6-81$ to $G$. L. Thompson and J. W. Guthrie, SNLA, from J. Beatty and $W . B$. Hess, SRP).

3. Specify March 1,1981 as the date for comnletion of installation and acceptance testing at the Savannah River Facility.

4. Proceed at the Savannah River Facility w1th final acceptance tests using specification SLA-XMS-8-79-SR dated November 1, 1979 (as per contract 13-9152) with the following specification changes as authorized by the Savannah River Fac1lity. (Reference, TWX dated 12-18-80 to G. L. Thompson and J.W. Guthrie, SNLA, from $J$. Beatty and $W . B$. Hess, SPP).

a. Item C.1.d (page 9)

The absence of memory will be demonstrated by introducing a sample of nure $n_{2}$ (from the inlet system) into the MS at a pressure that yields a mass 4 ion beam of $1 \times 10^{-10} \mathrm{~A}$. The $D_{2}$ flow w111 be stonped (close inlet valve) and replaced by an equal flow of pure $H_{2}$ (from the flow standard) for io minutes. After the ten rifulte period the peak at mass 4 will not te larper than $3 \times 1 n^{-15} \mathrm{~A}$ (30 pom of the previous $\mathrm{D}_{2}{ }^{+}$ion peak) and the $\mathrm{HN}^{+}$ion peak at mass 3 will be no larger than that attributable to the pure $\mathrm{II}_{2}$ gas. 
b. Item C.1.e (page 10)

The backpround of the instrument $w 11$ be determined by pumping out the inlet system and the ion source overnight so the pressure in the ion source housing is $2 \times 10^{-3}$ torr or less and measuring the residual ion peaks ill the mass $2-44$ range with the inlet system valved off. A series of 10 analyses, such as those required for the precision and accuracy test, will be made and the ion source and sample system will be pumped out for a period of ten minutes, and the background will again be measured. No background ion peak (excluding waters) will show an increase under these conditions of more than $100 \mathrm{ppm}$ of the major peak when a sample from the series of 10 is flowing into the lon source.

c. Item C.1.1 (page 11)

The absence of gas equilibration will be demonstrated by monitoring the mass $3 \mathrm{HD}^{+}$peak from $\mathrm{D}_{2}$ (inlet system) and $\mathrm{H}_{2}$ (rlow standard) flowing into the ion source. The HD $^{+}$peak will not exceed 600 ppm more than that attributable from the $\mathrm{H}_{2}$ and $\mathrm{D}_{2}$ gases.

d. Item C.2.a (page 17)

The tests in C.2.b and C.2.c will be run at the same. resolution as the hydrogen tests in C.l.

e. Item C.2.b (page 17)

The abundance sensitivity will be demonstrated with normal Xe gas at a pressure in the inlet system that produces a $3 \times 10^{-11} \mathrm{~A}$ or larger $134 \mathrm{Xe}$ ion intensity at the collector. The comined contribution of $132 \mathrm{xe}$ and 134 xe at the mass 133 position wili not te greater than 1 part in $10^{4}$ of the height of the $134 \mathrm{xe}$ ion peak and the combined contribution. of $134 \%$ and $136 \%$ at the mass 135 position will not be greater than 1 part in $10^{4}$ of the height of the ${ }^{134} \mathrm{xe}$ Ion peak.

f. Item C.2.c (page 17)

The precision and accuracy will be demonstrated by analyzing 10 successive samples of pure natural Xe gas at a rate of at least 4 analyses per hour. For the set of 10 analyses the sample mean and standard deviation will be calculated for each $\mathrm{Xe}$ isotope. The data will be treated as in Section $C$, pages 13 and 14 (Items 1 and 2). The $f$ sigma (Table II for $f$ values) precision and accuracy (mean for the set) obtained will be equal to or less than the values in Table II. 
TABLE II

\begin{tabular}{|c|c|}
\hline Isotope & $\begin{array}{c}\text { Natural_Abundance } \\
(\mathrm{mol} \%)\end{array}$ \\
\hline${ }^{124} \mathrm{Xe}$ & 0.096 \\
\hline${ }^{126}$ Xe & 0.090 \\
\hline${ }^{128} \mathrm{Xe}$ & 1.919 \\
\hline${ }^{129} \mathrm{Xe}$ & 26.44 \\
\hline${ }^{130} \mathrm{Xe}$ & 4.08 \\
\hline${ }^{131} \mathrm{xe}$ & 21.18 \\
\hline${ }^{132} \mathrm{xe}$ & 26.89 \\
\hline $134 \mathrm{Xe}$ & 10.44 \\
\hline${ }^{136} \mathrm{xe}$ & 8.87 \\
\hline
\end{tabular}

$\begin{gathered}\text { Maximum Precision } \\ \text { Ifits } \\ \text { (Relative) }\end{gathered}$
$\pm 1.0 \%$
$\pm 1.0 \%$
$\pm 0.25 \%$
$\pm 0.12 \%$
$\pm 0.20 \%$
$\pm 0.13 \%$
$\pm 0.12 \%$
$\pm 0.17 \%$
$\pm 0.18 \%$

Maximum Deviation

of Average from Known Abundance (Relative)

$\pm 1 \%$

$\pm 1 \%$

$\pm 0.5 \%$

$\pm 0.3 \%$

$\pm 0.4 \%$

$\pm 0.3 \%$

$\pm 0.3 \%$

$\pm 0.3 \%$

$\pm 0.4 \%$

\section{Values of $f$ for $P=0.05$}

Degrees of Freedom

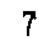

8

9

10

11

12 i values

2. 365

2. 306

2.262

2.228

2.201

2.179 
APPENDIX IV

ACCEPTANCE TESTS OF THE MSTG GAZAB, FEBRUARY 1981

IV-1 
interest:-

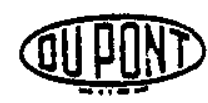

E. I. DU PONt de Nemours \& COMPany

ATOMIC ENERGY DIVISION

Savannam River Plamt

AIKET. SOUTH CAMOLINA 3980

Merch 4, 1981

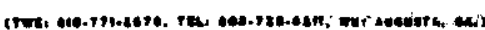

J. W. Guthrie, Coordinator

DOE Mass Spectrometer Development Group

Sandia National Laboratorles, Albuquerque

Albuquerque, No

\section{ACCEPTANCE OF THE GAZAB MASS SPECTROMETER}

The vG Instruments, Inc. GAZAB Mass Spectrometer was delivered to

Savannah River Laboratory February 2, 1981. Instailation of the

GAZAB has now been completed, having met, without exception, all

requirements of the specification SLA-XMS-8-79-SR as amended

December, 1980 and as required by the Sandia Contract 13-9152.

All contract materials have been delivered with the following exceptions:

1) Remaining flow and mixture standards (presently located at Rennedy Airport, New York)

2) Remaining portions of the 8 sets of operating and service manuals and appropriate drawings.

Attached is a copy of the VG Instrments Customer Acceptance Paper.

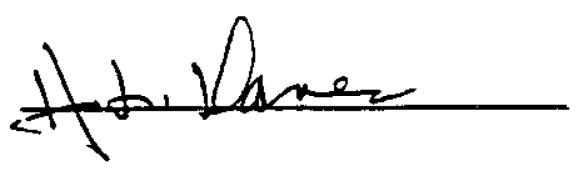

$3 / 4 / 81$

$M B N$ Nen

SRP Representatives

E. I. du Pont 


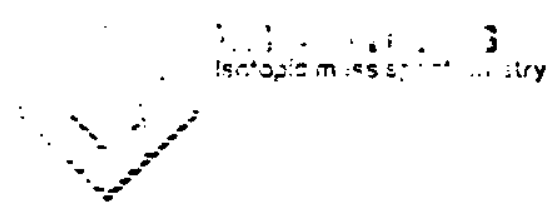

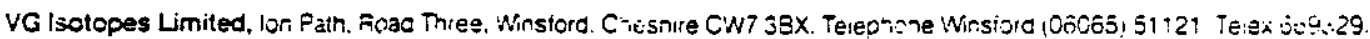

CUSTOMER ACCEPTANCE

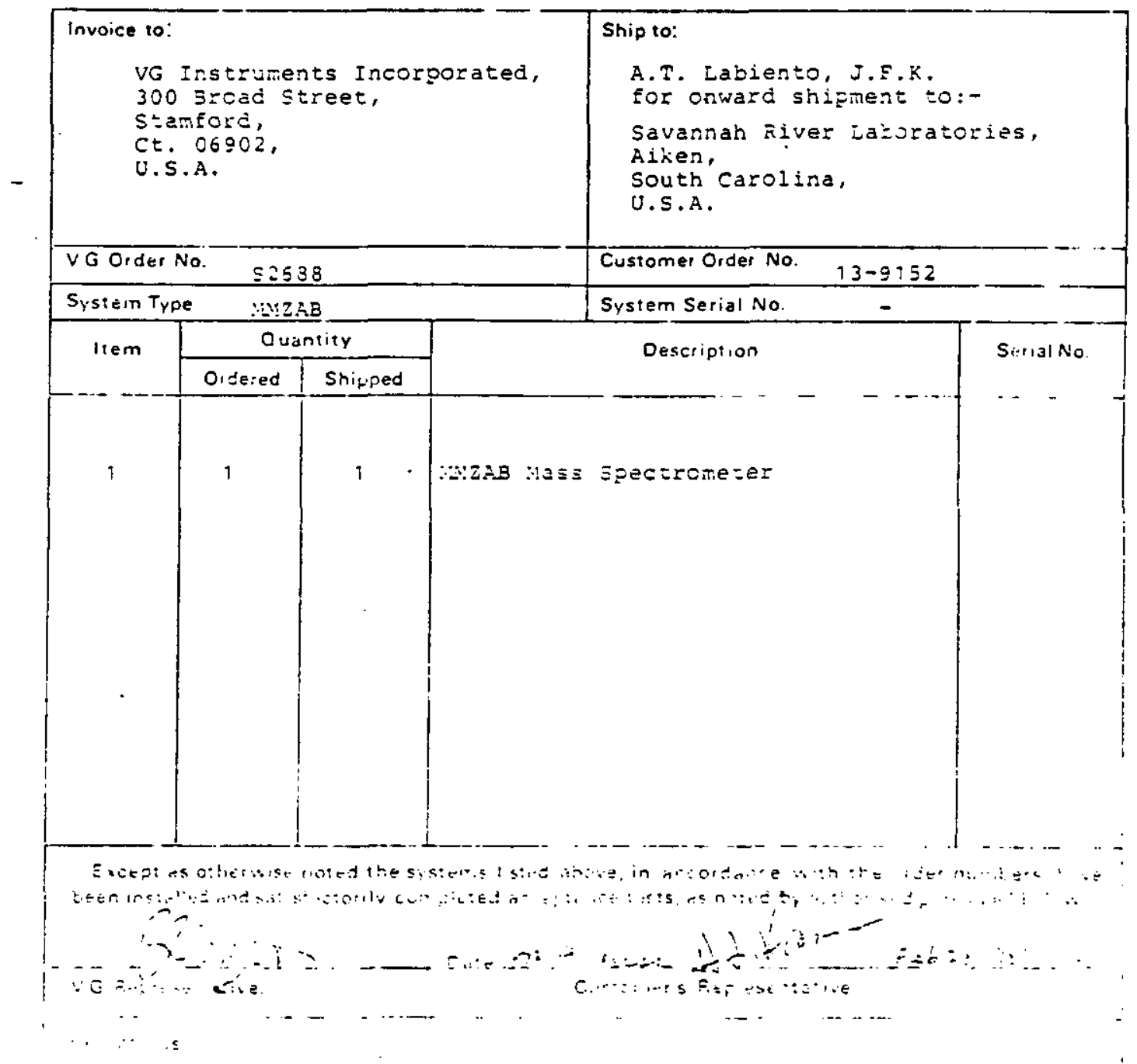

\section{BEST AVALABLE COPY}




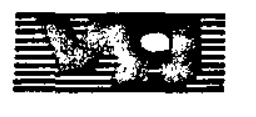

\section{MICROMASS 践g8 \\ VG-Isotopes Limited}

\section{GAZAB \\ PERPORMANCE \\ DATA}

\section{February 1981}

E. I. du Pont de Nemours \& Co. Savannah River Laboratory

Aiken. S. C. 29801 
GAZAB CHECKOUT

MASS OISCRIMIKATION - ABSOLUTE SENSITIVITY

Sensitivity $10^{11} \Omega$

$\mathrm{H}_{2} \quad$ Purity $99.97 \%$

$111.02 \mathrm{mv} / \mu$

HD Purity $99.7 \%$

$111.06 \mathrm{mv} / \mathrm{\mu}$

$\mathrm{D}_{2} \quad$ Purity $99.3 \%$

$110.92 \mathrm{mv} / \mu$

$$
\text { IV }-5
$$




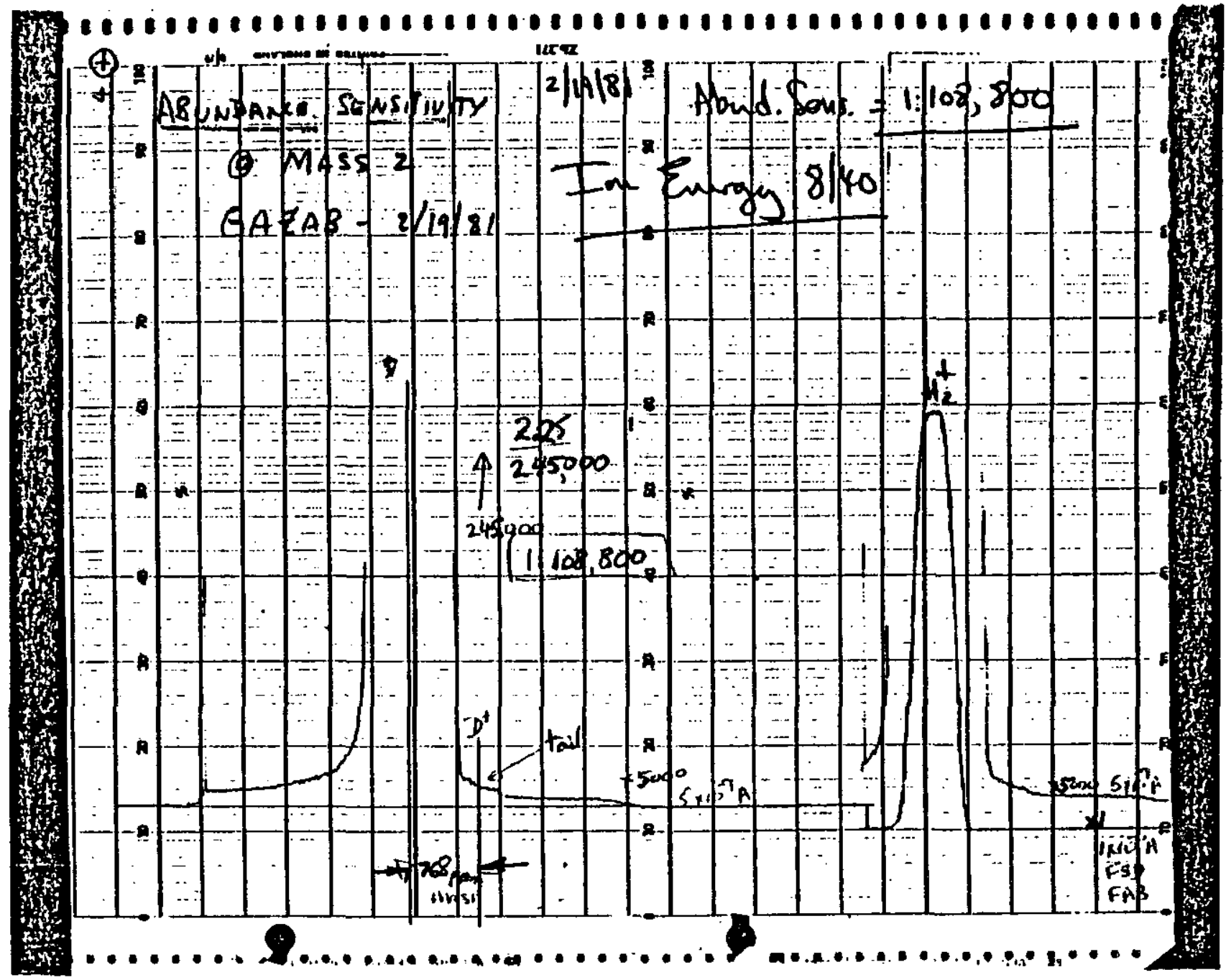




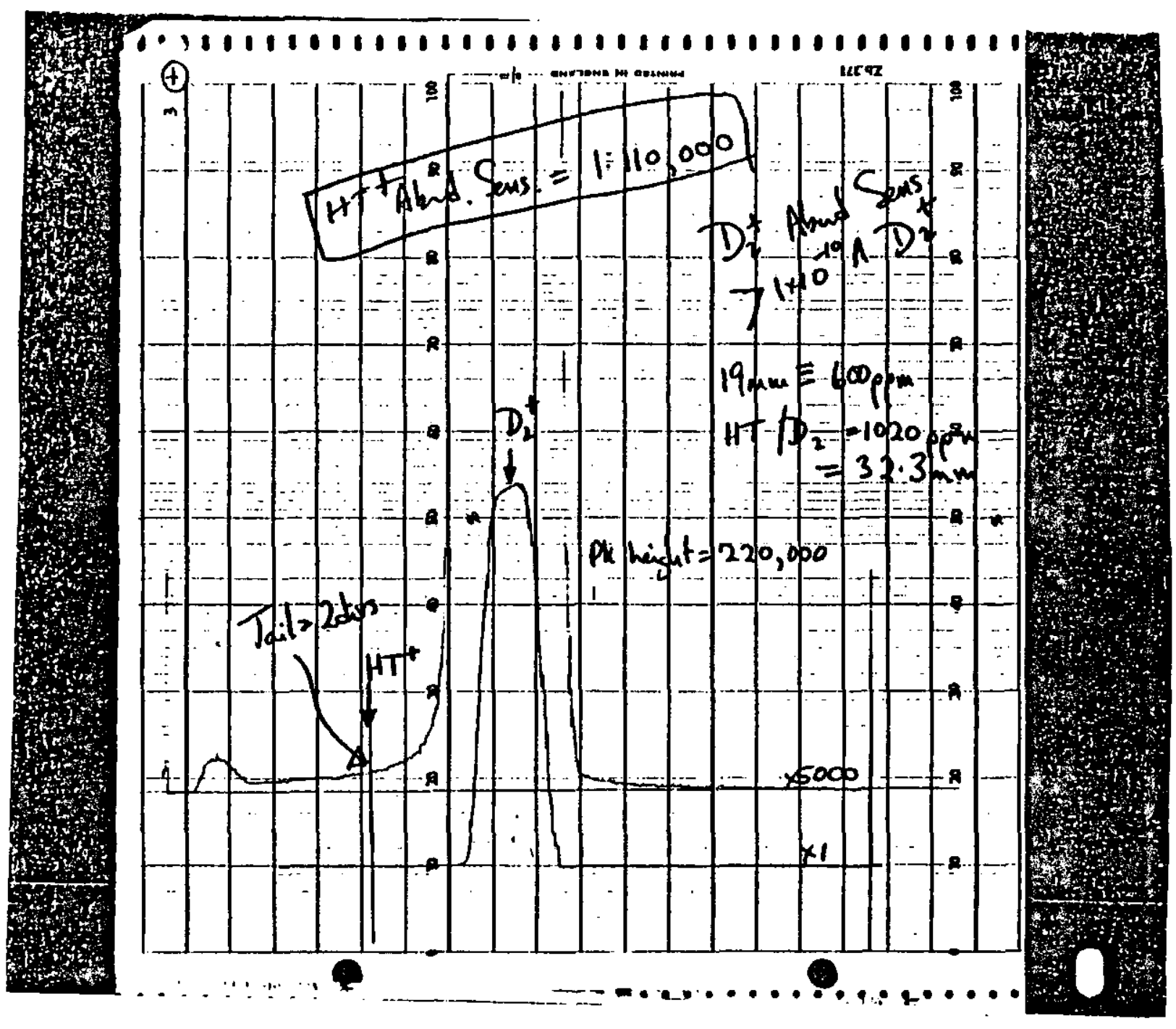


Memag.

De fon tided.

D) $D_{2}$ bled in fromistl. bech $6.5 \times 10^{\circ} A$. for 4 mins.

2) Stapped flow fo 10 mins. a premped surea to $7 \times 10^{-9}$ Tom.

3) Ploced 65 mun $\mathrm{H}_{2}$ in resenvir ad allowed to flow into

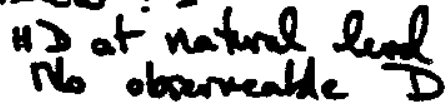
uning Fondons detrowas

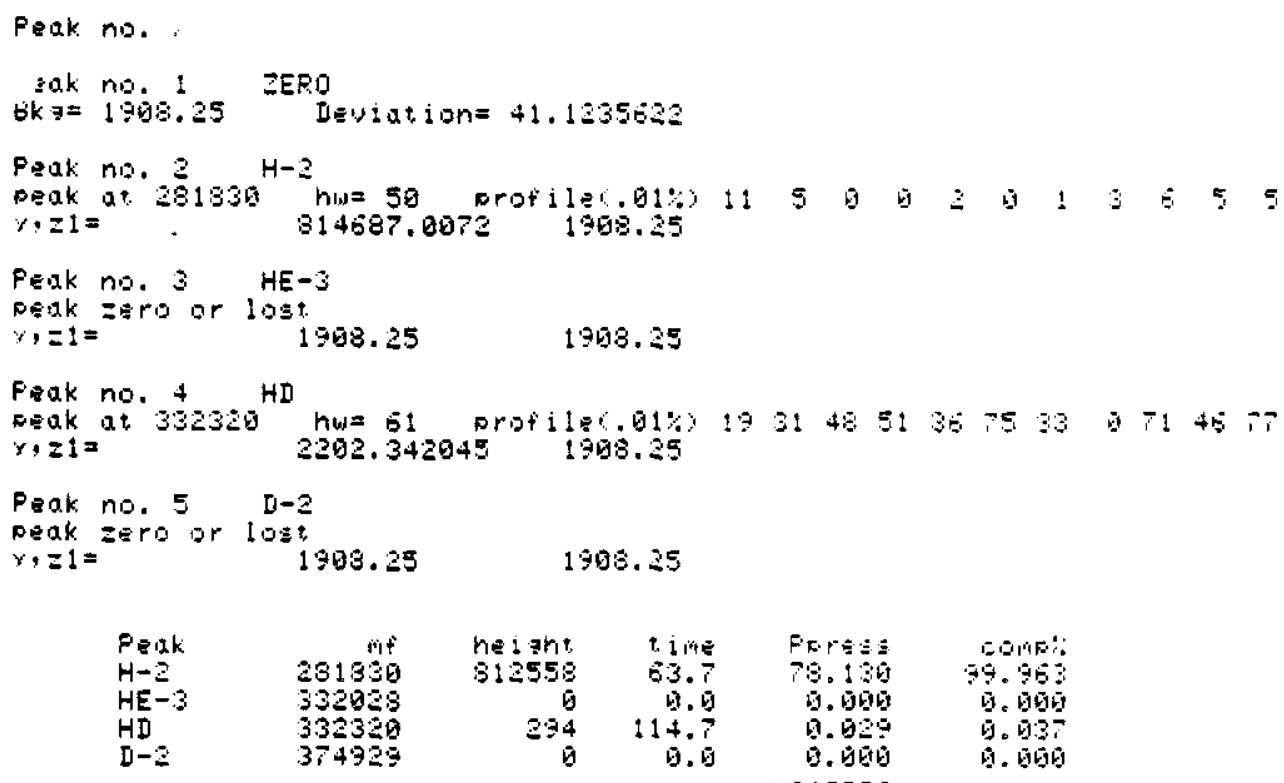

IV-8 
$8 \oplus$

Menns

1) $D_{2}$ leat with rultipliar $1.92 \times 10^{-7} \mathrm{~A}$. For 2 mins.

2) Coud CRT7Vdure and pumped source for 10 mins.

3) After $10 \mathrm{~min} D_{2}$ im currat on meltipliarwes

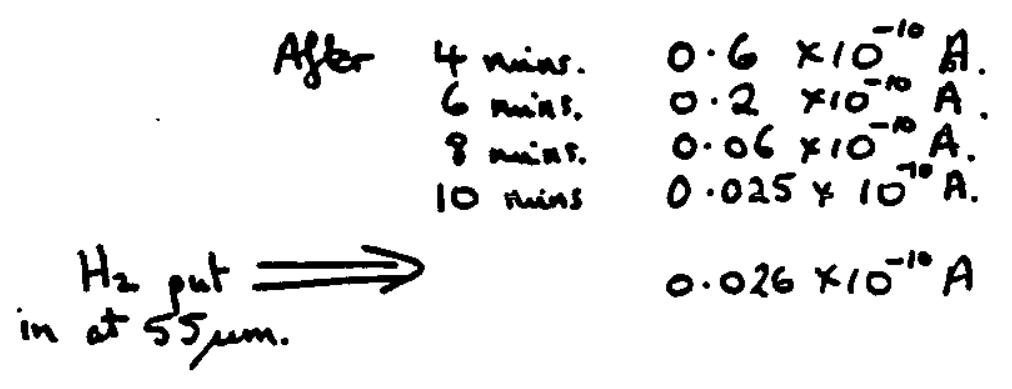

Menery mans 4 curent $=2.6 \times 10^{-12}$ Anp. $D_{2}^{+}$beem $=1.92 \times 10^{-7}$.

MenryimPPm $\quad \frac{2.6 \times 10^{-12}}{1.92 \times 10^{-7}} \times 10^{6}=\frac{2.6 \times 10^{-6}}{1.92 \times 10^{-7}}$

$$
=13.5 \mathrm{ppm} \text { of } D_{2} \text { signal }
$$

spec. is 30 ppm of $D_{2}$ signal. 


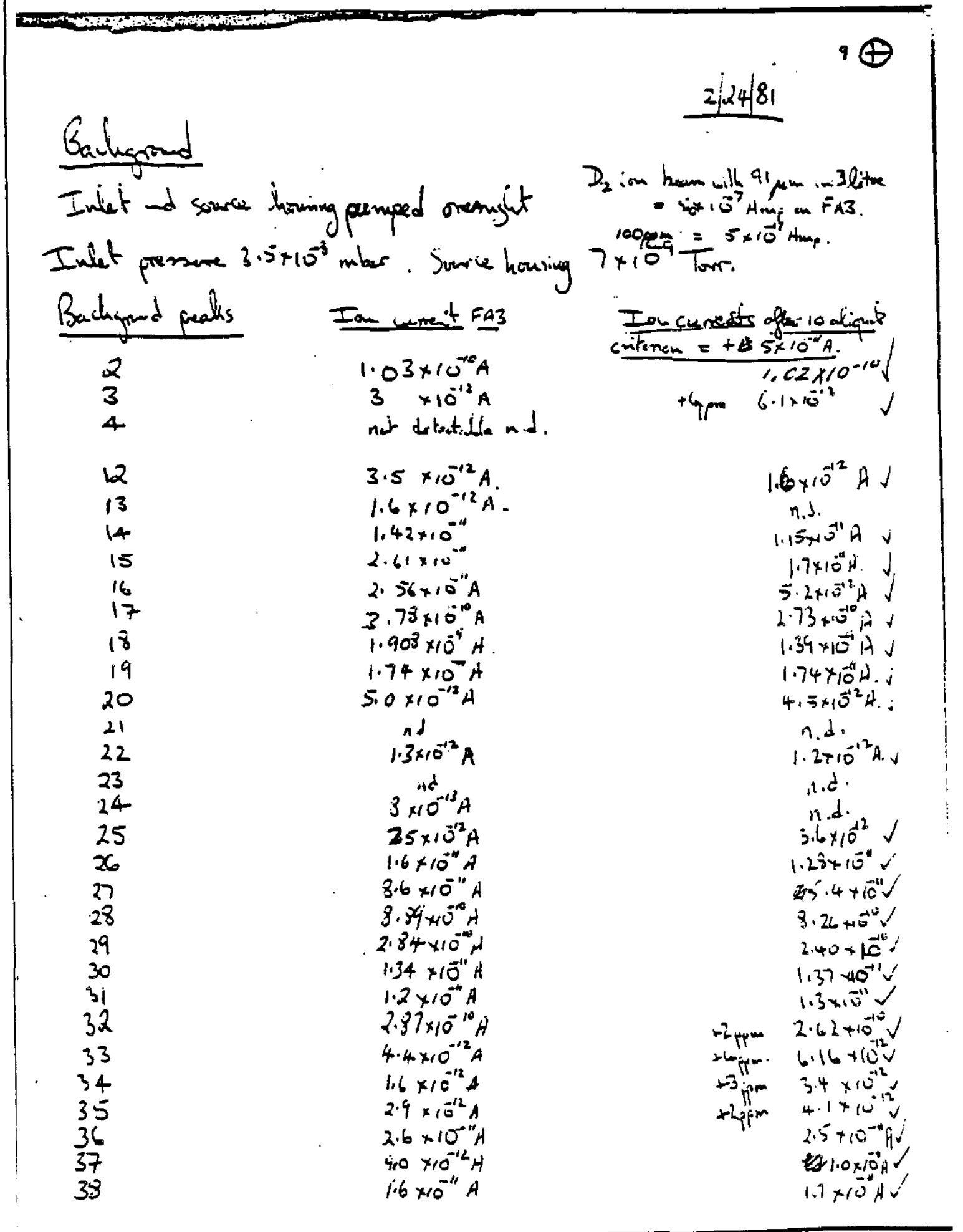




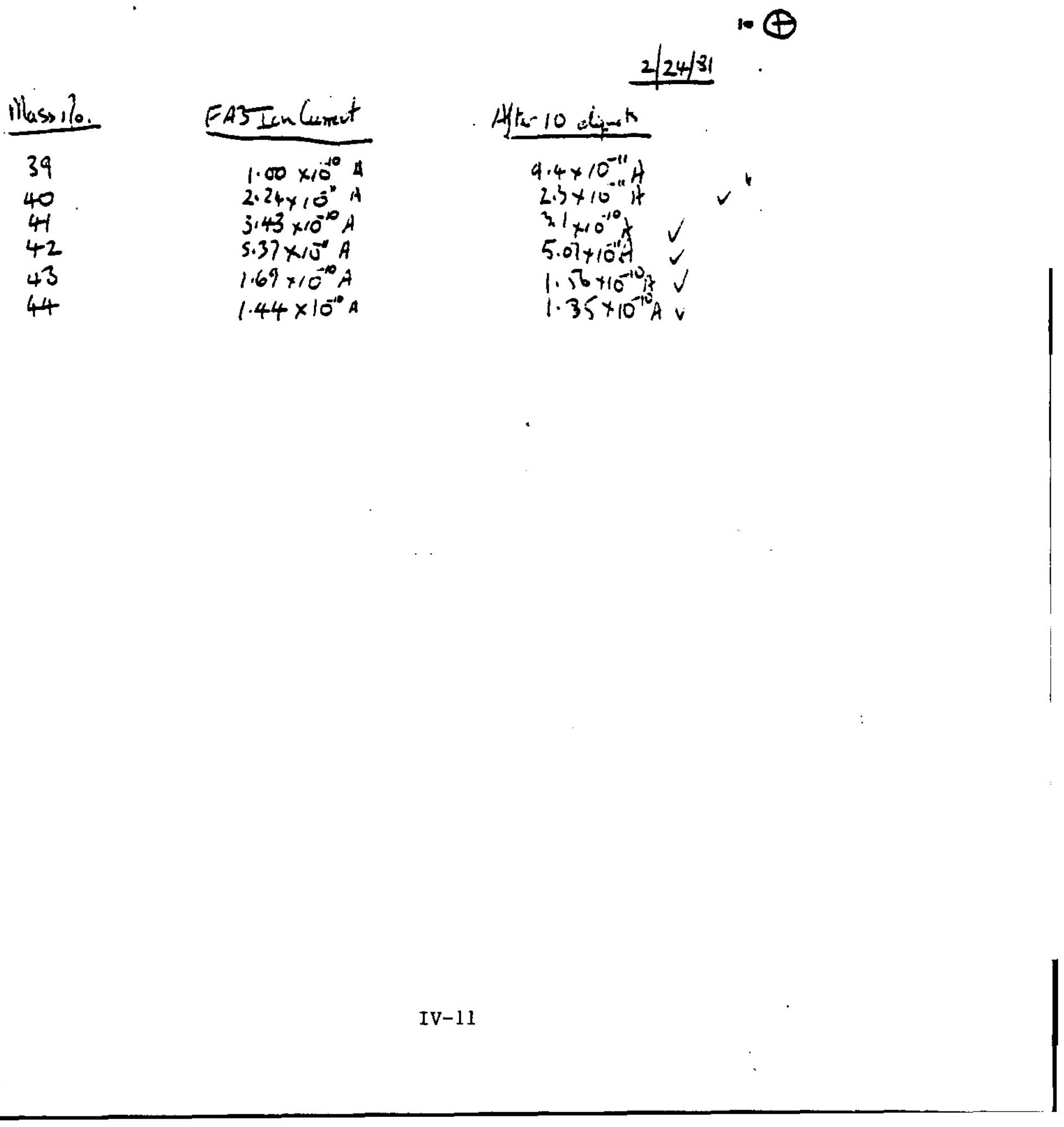




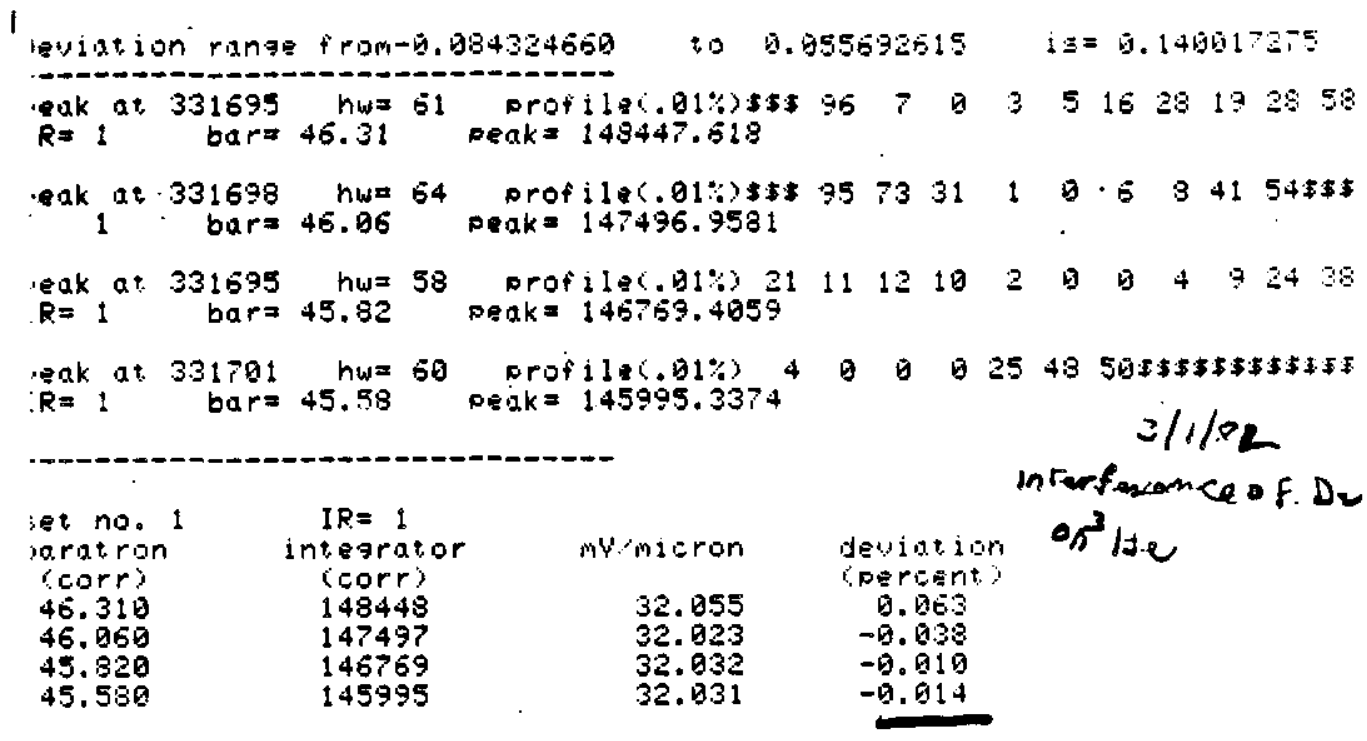

$\operatorname{mean}=32,0359721$

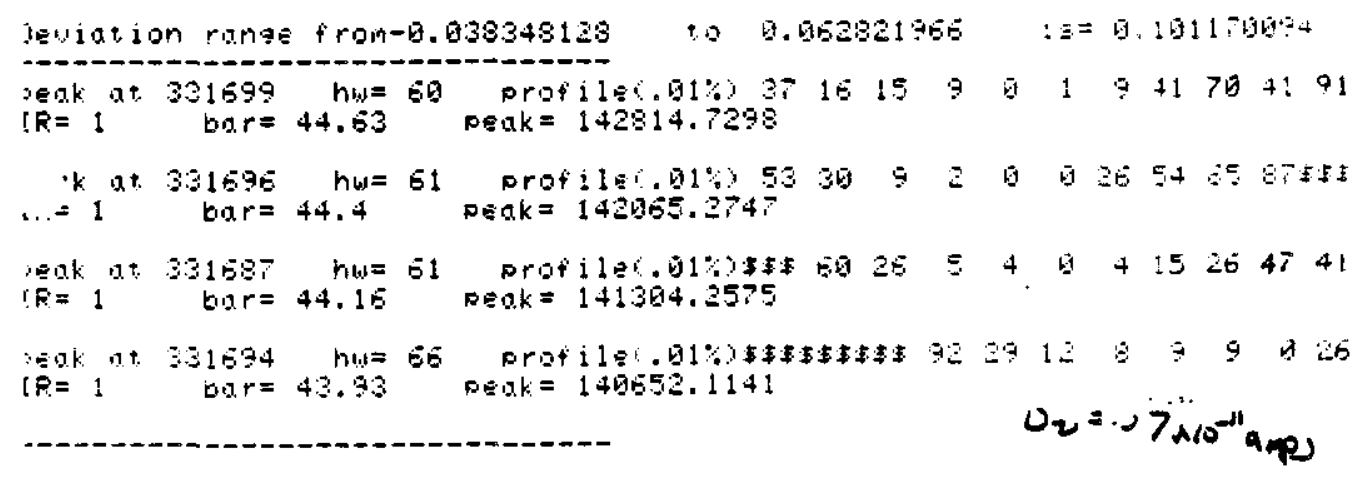

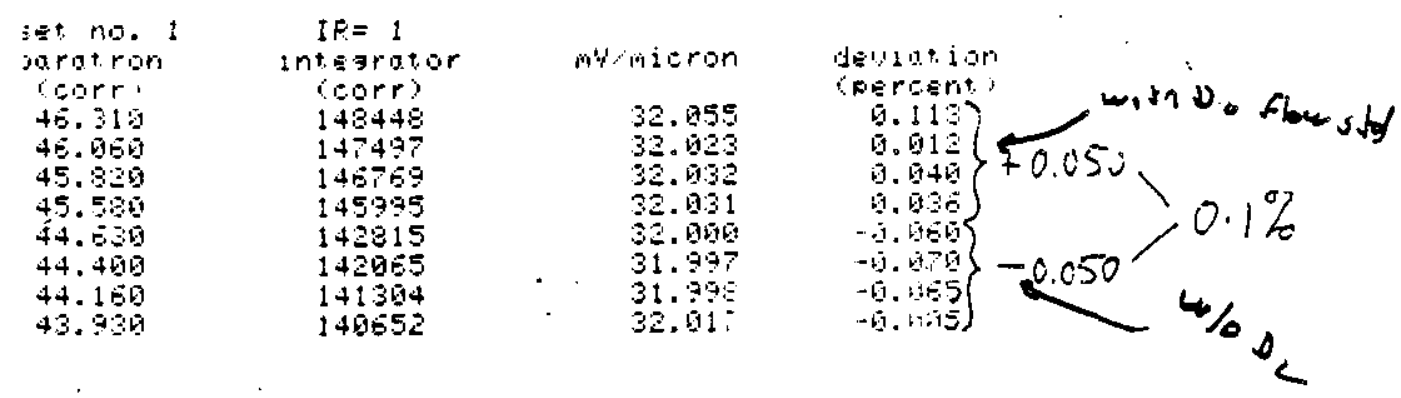

mean= 32.619025

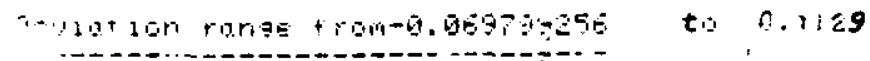


Interference Argar on D2.

Repeller optimum, D Fous optimani

Repeller + 0.5 relts (indiatés m matas), DFocus 10.900

Argon im curvent $1.16 \times 10^{-10}$ Amp.

$D$ Four $10 \mid 9000^{(1,30 \mathrm{pm})}$ Interference $+0.5 \%$ (tva with $D_{2}$ cully)

$D$ Fous $10 / 1000$

$D$ Fous $10 / 950$

$-0.8 \%$ (-ve wiv $D_{2}=d_{y}$ )

$D$ Fotur 101900 (Repeat of $1.30 \mathrm{pm})$ at $3.11 \mathrm{pm}+0.5 \%$ (tw witt $D_{2}$ mly)

DFom $10 / 925 \quad 3,24 \mathrm{~cm}$.

\begin{tabular}{ll|l} 
DFous 10 & 925 Repeat 336 \\
DFous 10 & 925 & 3,56
\end{tabular} $+0.2 \%$ (tre wing 20.4 ).

$-0.1 \%(-m,-)$
$-0.1 \%(-v e)$ 


\section{GAS INTERFERTNOE}

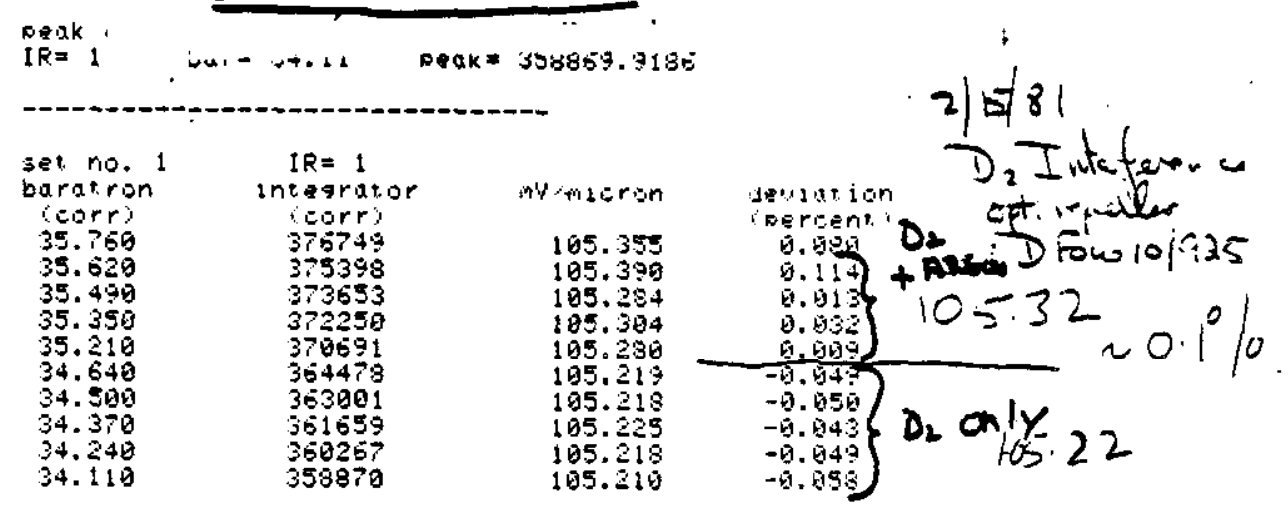

Mean= 105.2702554
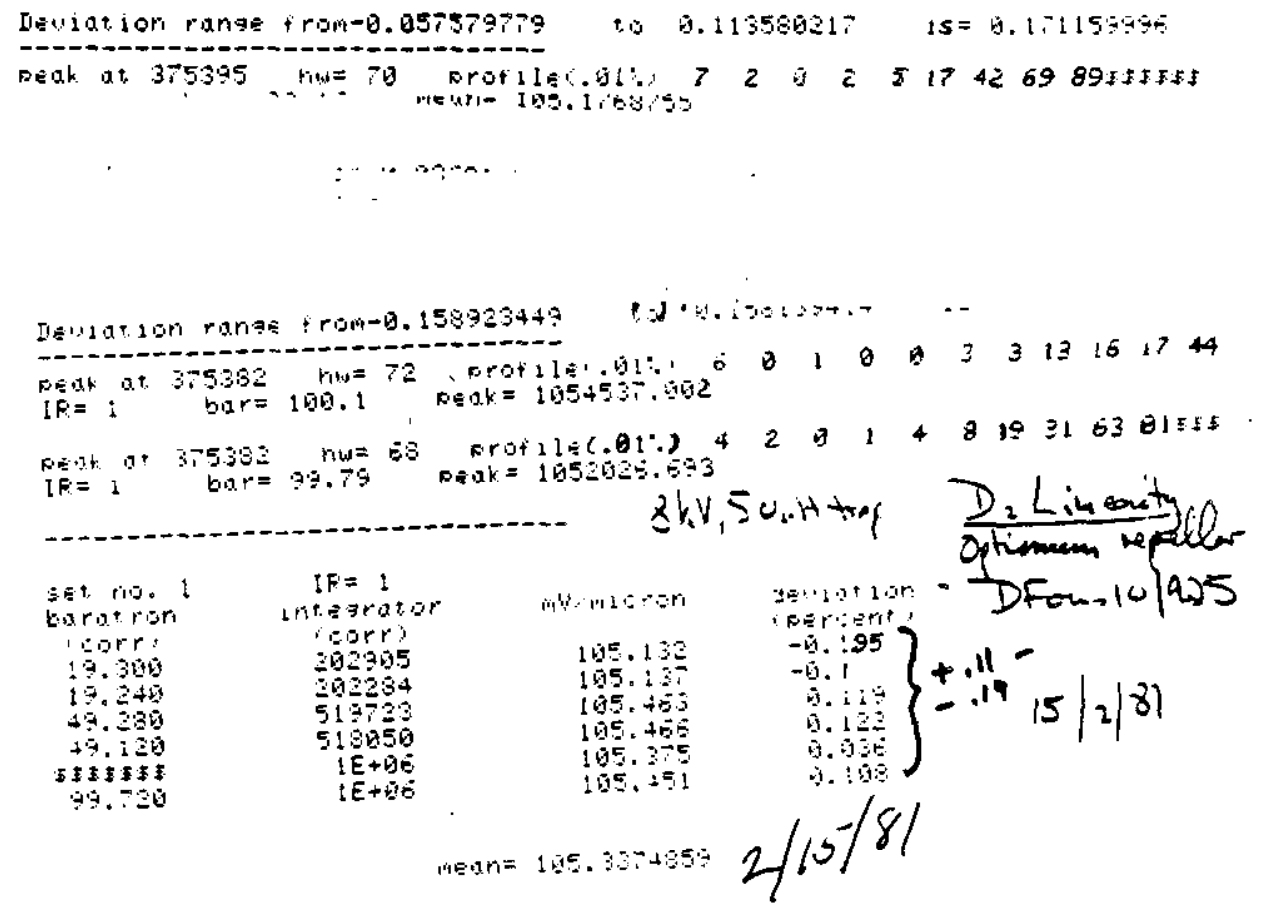


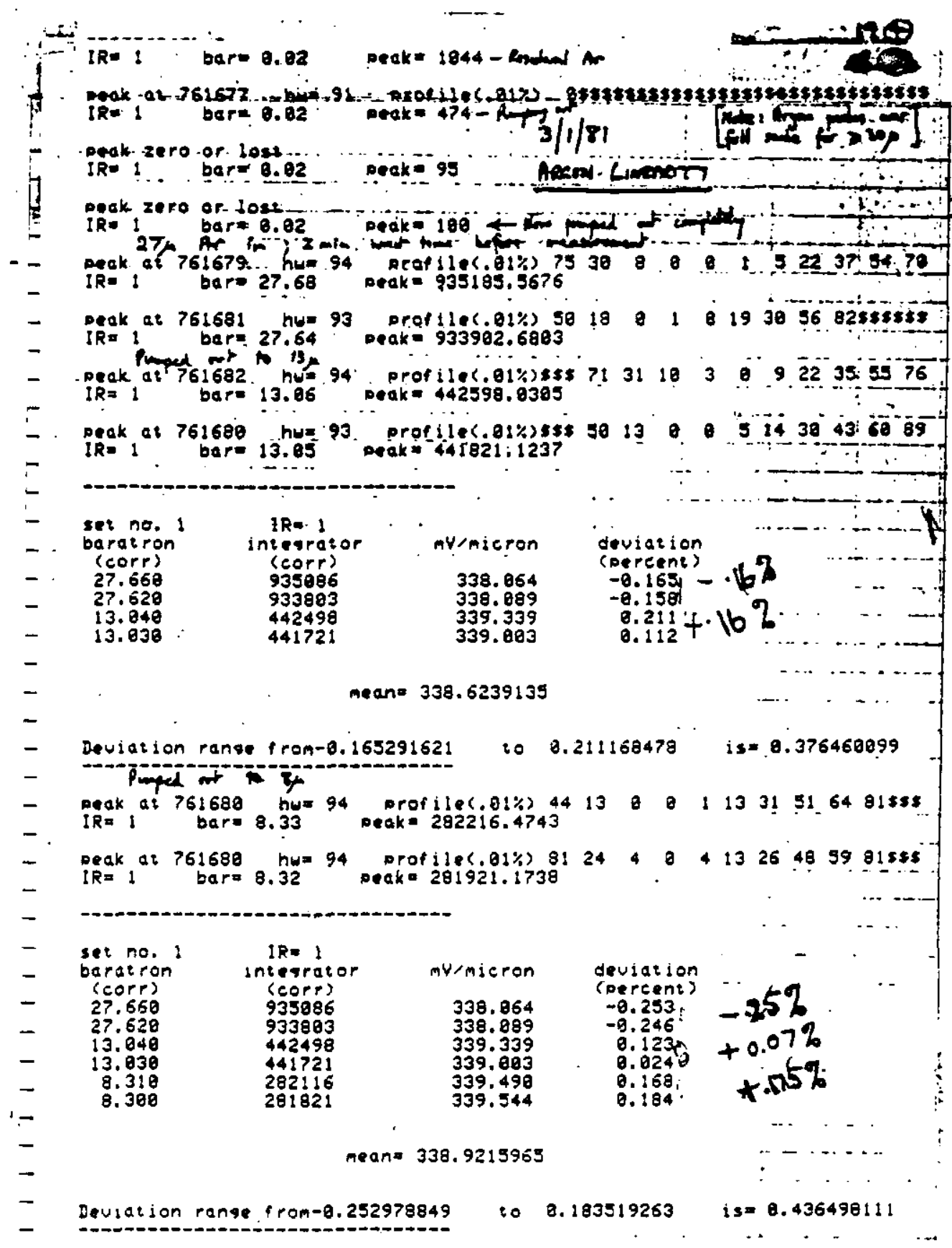




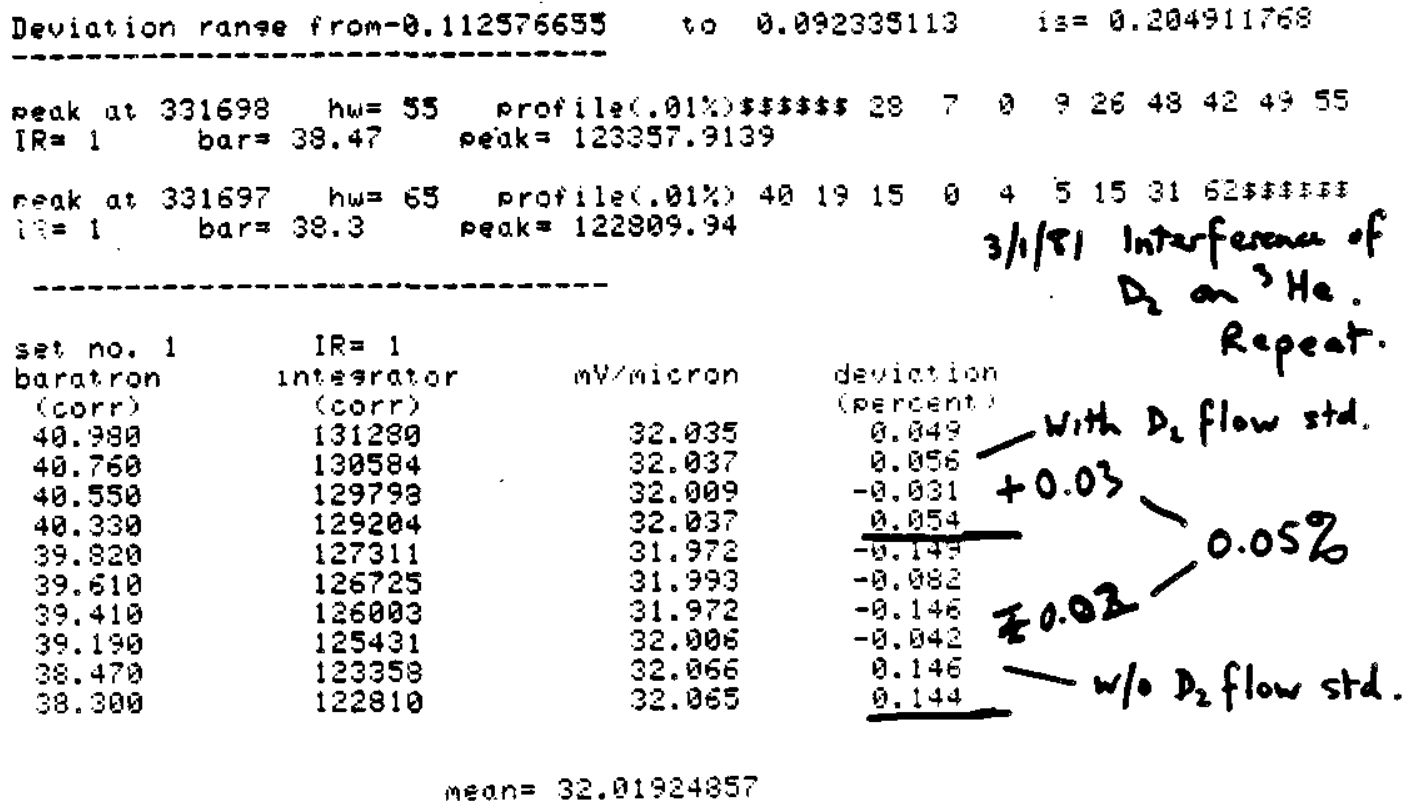

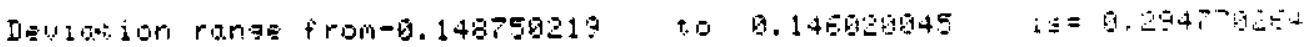




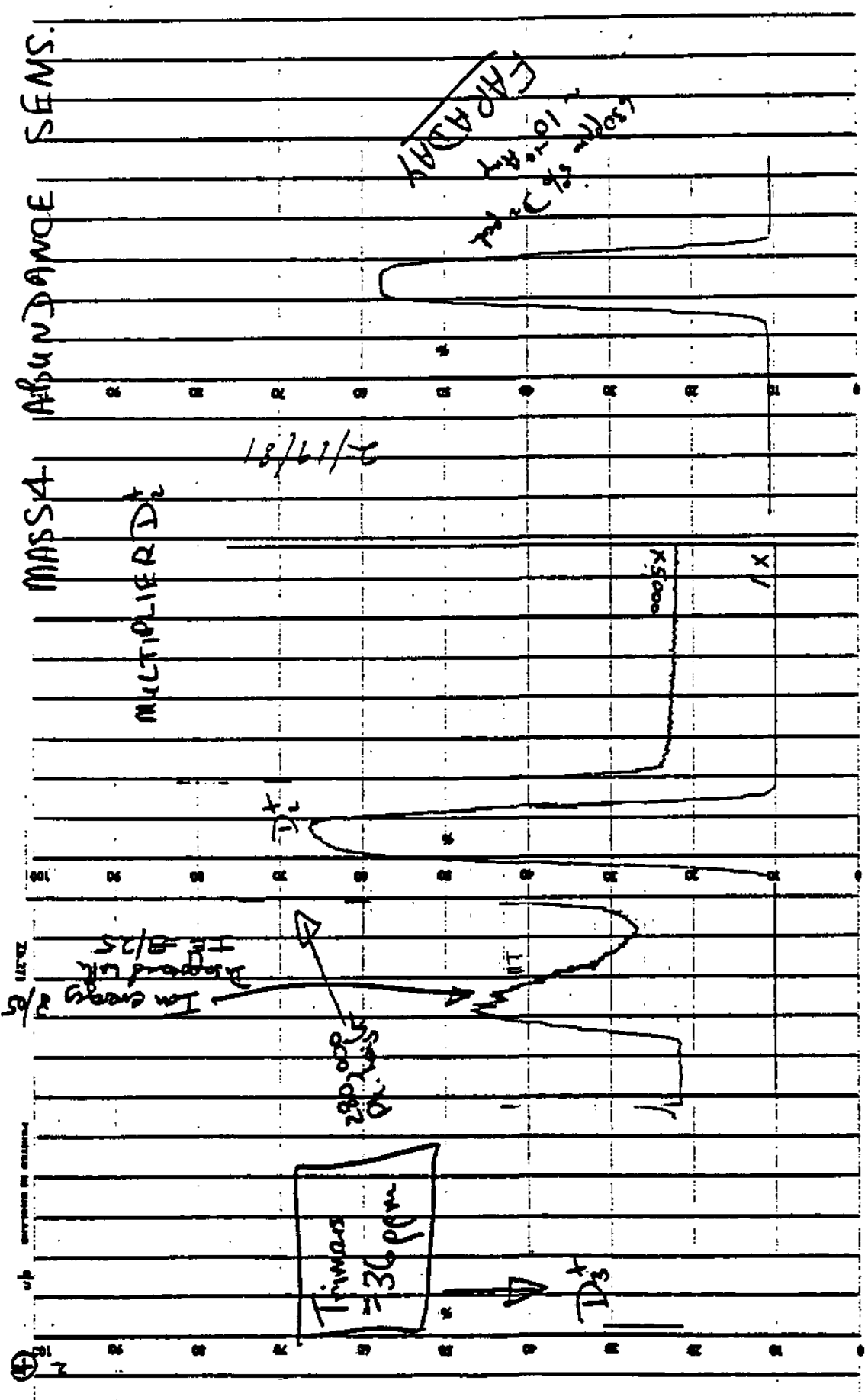


Equilibation

$\mathrm{H}_{2}$ sens. $105.88 \mathrm{mg} / \mathrm{mm}$.
260181

HDland

$0.045 \%$

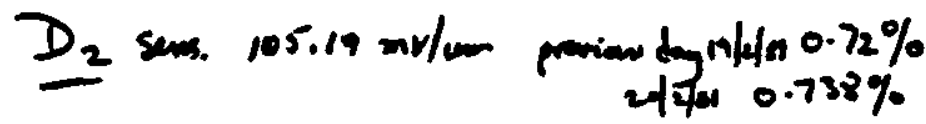

- Andor $49.919 \% \mathrm{H}_{2}$

$$
49.670 \% D_{2}
$$

$11.30 \mathrm{a} \cdot \mathrm{m}$.

$H_{2}$ pk plifted daw in mass by 2100 digits HD moned dam by sodig.

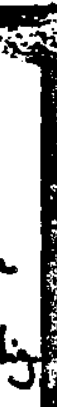

Expected HD lend is $0.384 \%$

$$
\begin{aligned}
\text { excens } & =0.411-0.384=0.027 \% \\
& =\frac{270 \mathrm{ppm} \times \mathrm{s}}{S P E C}=600 \mathrm{pPM}
\end{aligned}
$$

IV -18 
Prak no. 3 HE-3

hus 12 profiled.01:) 204469 o $557599359053 \quad 3$ $x+21=$

$1922.875873 \quad 1290.35$

Peak no. 4 HD

Deak a 332261 hu= 59 profiles.01\%) $592075+130$ o 312566311 $y, z 1=\quad 2106.600408$ 1990.25

Peak no. 5 D-2

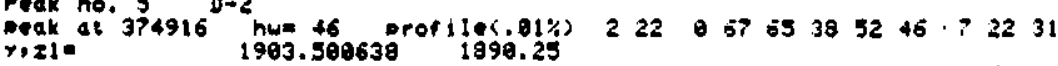

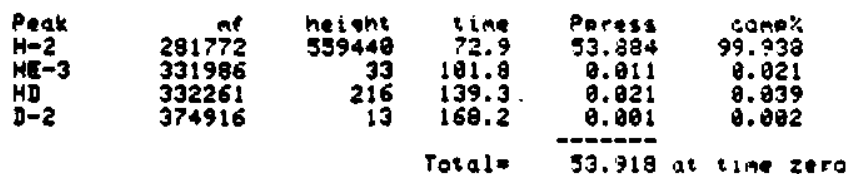

CLOSURE- 1.064029260

Baratrone 57.37 at time zero (zero corrected) Baratron 57.37 at 2 ime zero cero corrected

Bareiron zerou 0.09

Pressurea 98.86

Peak ne. 1 ZERO

8kv1 1887.75 Deviasion: 11.59446329

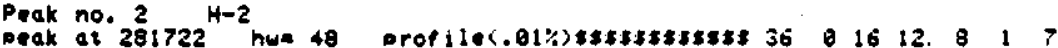
$Y, z 1=$ $4278.977599 \quad 1897.75$

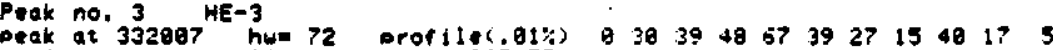

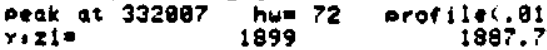

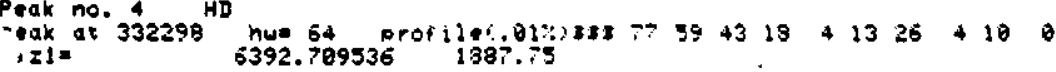

Prax no, $5 \mathrm{D}-2$

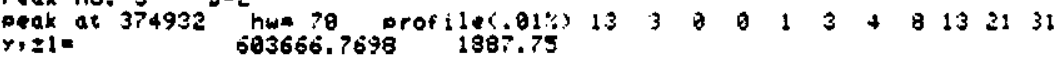

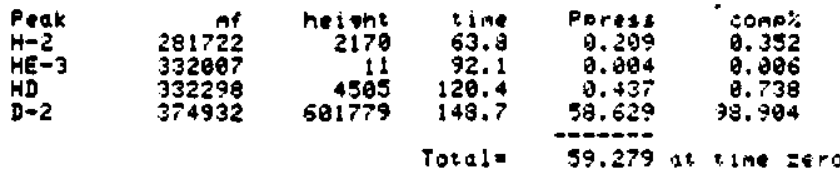

CLOSURE= 9.991421564

8aratron= 59.77 at time zero (zero corrected)

measurede $\$ 9.28$ correspondine :0 time zero

factor= $1.00744 \quad 34=10519.50520$

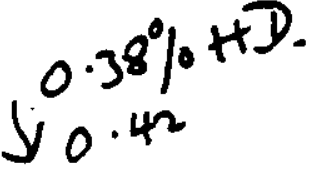

Poak no. 1 EERO

Deviarione 21.63111794

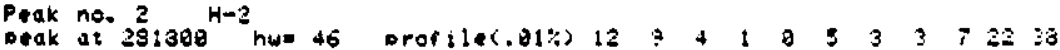

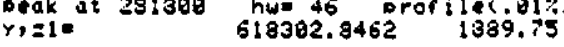

Peak no. 3 HE-3

peak zero or lost

$Y, 21=$ 1889.75 1889.75

Peak no. 4 HD

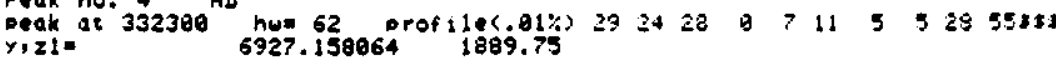

Peak no. 5 D-2

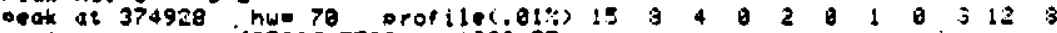
$z 1=\quad \$ 87806.7,23 \quad 1889.75$

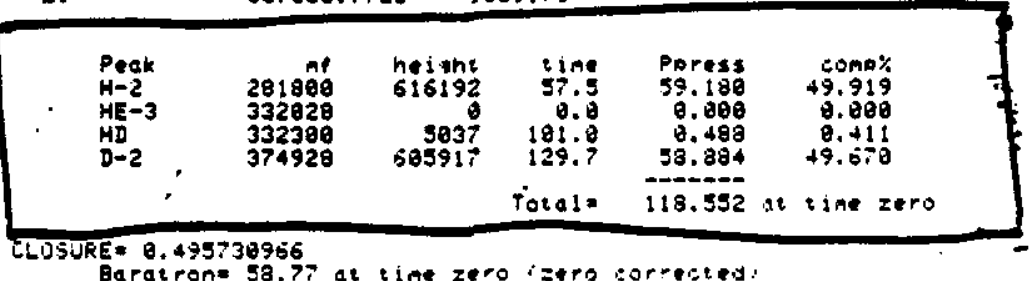

Bapatron= 58.77 at tint zero istpo corpeteted

Mensuredesssses corpesponaint io tine $z+$ ro

IV -19 


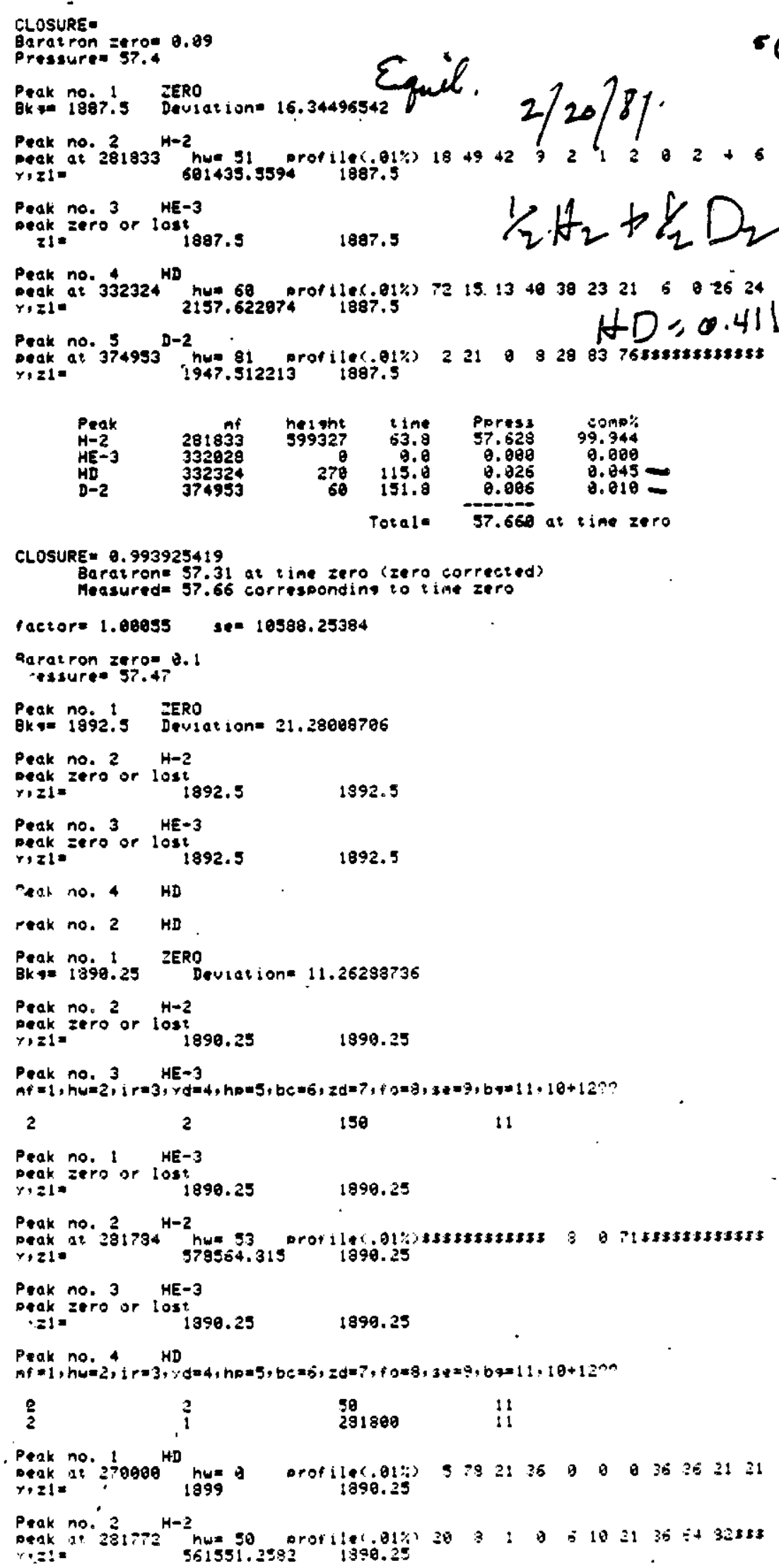

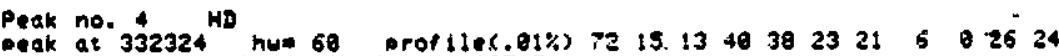
$Y, Z 1=02157.622074 \quad 1887,5$

Peak no. 5 D-2 fDD 0.41

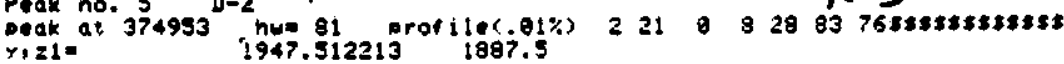

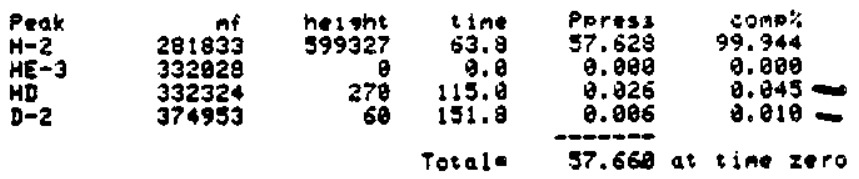

CLOSURE= 0.993925419

Barairone 57.31 at time zero (zero corrected)

Measured $=57.66$ corresponding to timt zero

factor= $1.08055 \quad s e=10388.25384$

Aaparon zero= 2.1

tsisuree 57.47

Peak no. I EERO

OK $=1992.5$ Deviation= 31.28009706

Peak no. $2 \mathrm{H}-2$

Deak zero or lost

rizi= $1892.5 \quad 1392.5$

Peak no. 3 HE-3

beak =ero or lost

$r, x_{1}=1892.5 \quad 1892.5$

net. no. 4 HD

reak no. 2 HD

Peak no. 1 ZERO

Bky= 1399.25 Deviation= 11.26298736

Prak no. $2 \quad \mathrm{H}-2$

peak zero or lost

Yiz1= $1890.25 \quad 1890.25$

Peak no. 3 HE-3

$m f=1, h w=2, i r=3, y d=4, h p=5, b c=6, z d=7, f, 2=8,34=9, b+11,18+129 ?$

2

150

Peak no. 1 HE-3

Deak zero or lost

Y, 1810 1890.25 1990.25

Peak no. $2{ }^{2} \mathrm{H}^{-2}$ hwe 33 protilec.

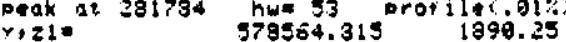

Prak no. 3 HE-3

park zero or lost

$21=$ 1990.25 1899.25

Peak no. 4 ND

mf $=1, h w=2$, i $r=3, \because d=4, h p=5, b c=5, z d=7, f o=8,34=4, b q=11,1 \theta+12 m a$

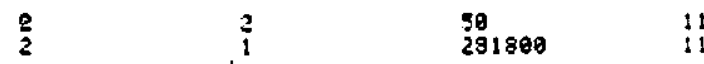

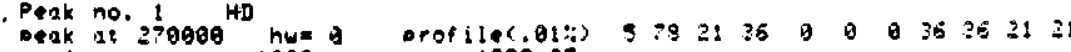

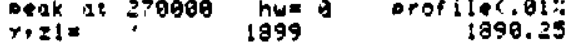

Peak no. $2{ }^{\mathrm{H}-2}$ o protilet

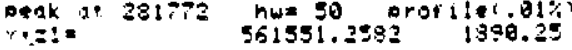




\section{$15 \oplus$ \\ $2 / 21 / 81$}

Mixd gl. \#3 Andyon alibotim $4.30 \mathrm{p.m.}$ Onigind Inent technique

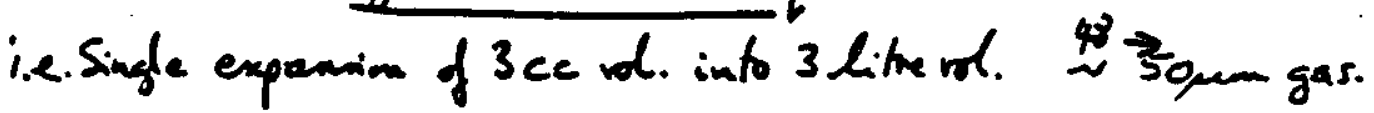
$\mathrm{H}_{2}{ }^{3} \mathrm{He}$ HD $\mathrm{D}_{2}$ Totel H TetlD dasure

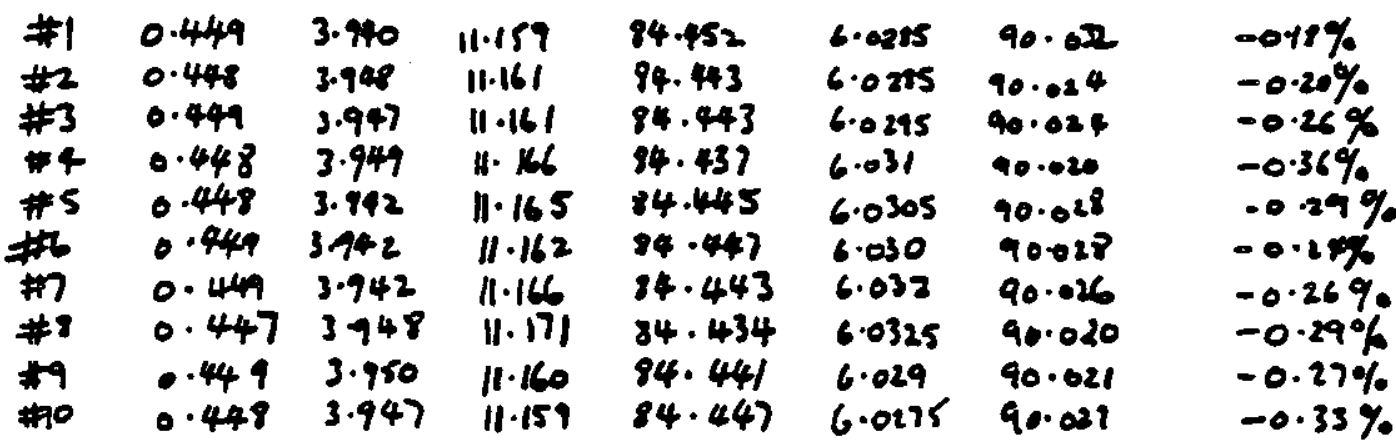

\begin{tabular}{|c|c|c|}
\hline $\begin{array}{l}4.25 \% \\
\text { spec. }\end{array}$ & $\begin{array}{l}0 . \overline{38} \\
0.40\end{array}$ & $\begin{array}{l}0.11 \% \\
0.20\end{array}$ \\
\hline
\end{tabular}

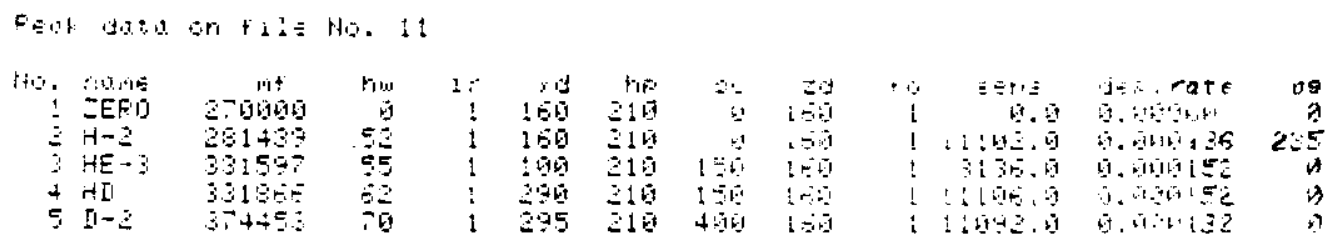

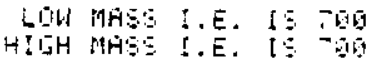




\section{Trep 50, $8 \mathrm{KV} \quad 10.56 \mathrm{Am} \quad 2 / 28 / 81$ Filament 2.1

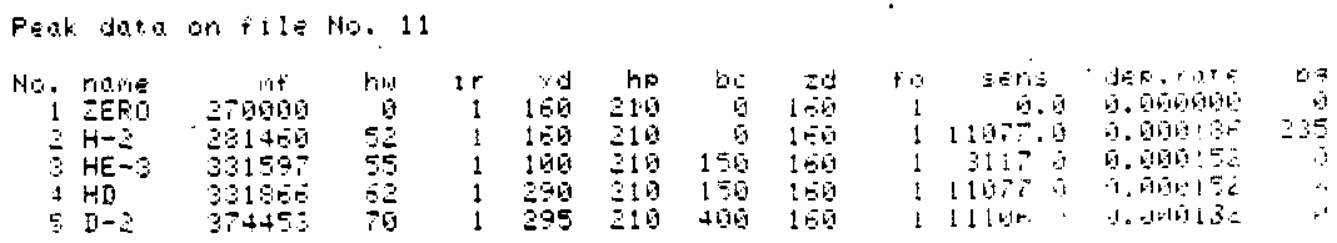

LOW MASS I.E. IS 79日

HILH MHSS I.E. IS $\frac{7600}{860}$

mass DiserM. O.K.

$\operatorname{mix} * 1$ cyl 3

$\mathrm{H}_{2} \mathrm{H}=3 \mathrm{HO} \mathrm{D}_{2}$

$11.453 \quad 3.966 \quad 11.88684 .395$

2.453

3.452

4.454

5.451

6.453

7.452

8.453

9.452

$10.45^{\circ} 2$

$3.76 /$

3.96

3.961

3.964

11.18884 .397

11.19484 .388

11.18884 .397

3.963

$11.193 \quad 84.391$

$11.186 \quad 84.399$

3.96211 .187 \&.37

$3.962 \quad 11.19084 .344$

$\begin{array}{llll}3.963 & 11.190 \quad 84.395\end{array}$

3.961

$11.197 \quad 84.390$

* note - aceuracy-a nominal blended at SRP and verified that are in error.

man
4.20
Spec.

16

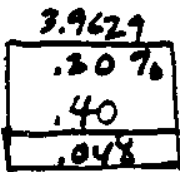

$M 1 x * 1$ Pooled Data.

Pooled \pm .30

Spec.
Sraakd III00 AM

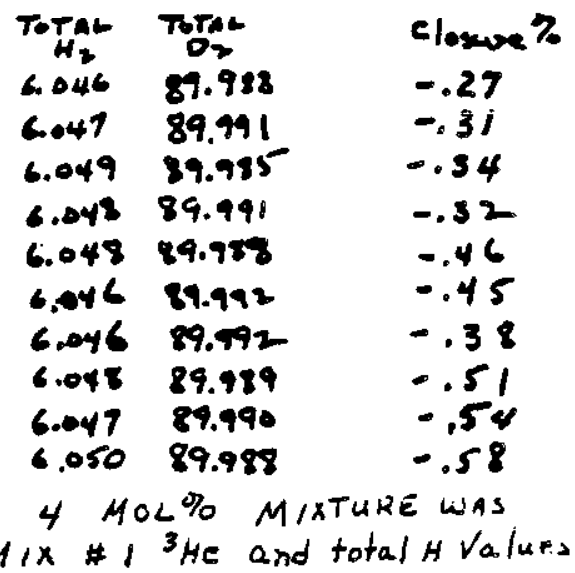

6.0475

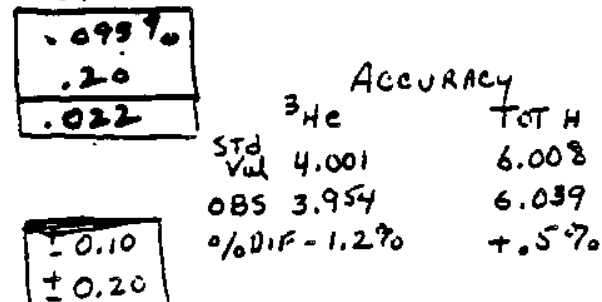


edratron $=$ erog 0.08

Poessurt= 53.01

pilak no. 1

8 log 93.5

ZERO

Diniation= 30.0515126

Mix $1 \mathrm{cy} / \mathrm{m}=3$

(Typical scans)

$P$ fiox no. $2 \mathrm{H}-2$

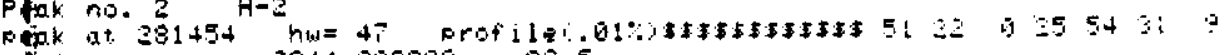
$r z 1=$ 2944.283988 93.5

Pejak no. 3 HE-3

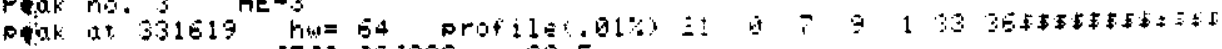

- $1=$

Pit no. 4 HD

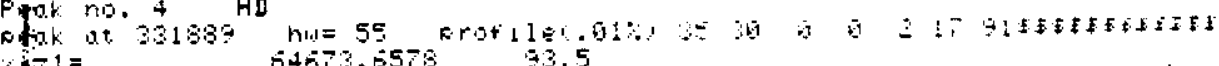
in $=$

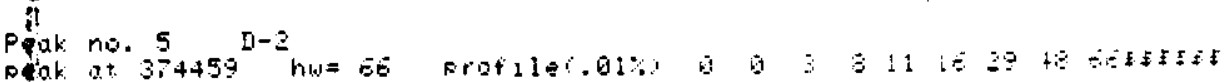

$4=1=\quad 48552.1195 \quad 33.5$

:

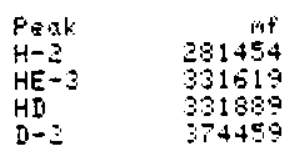$$
\text { he i } 3 r \text { t }
$$

1
1
10.9

C. 65

9.290

$5,1 \%$

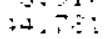

$1+3.9$

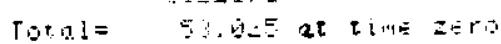

!

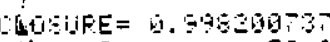

Earneron= S2.43 ne tine -

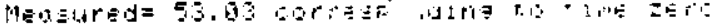

E.).

Fresarea $=51,54$

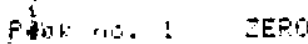

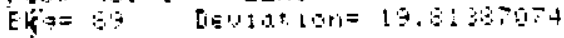

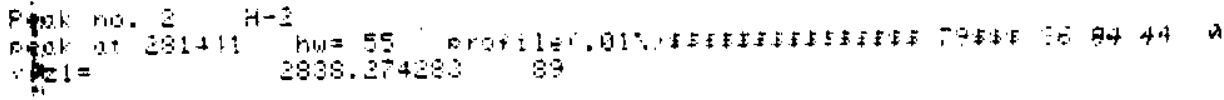
20.5140 .0

Font no. 3 HE-3

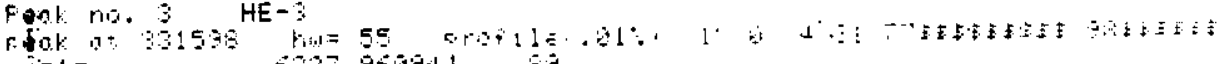
$\because=1=$ $627.9604+28$

Fine ring 4 HI

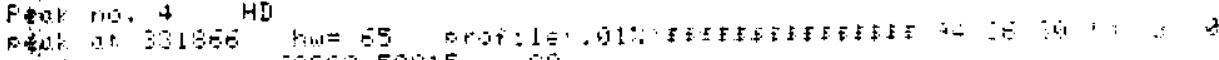
$\because: 1=$

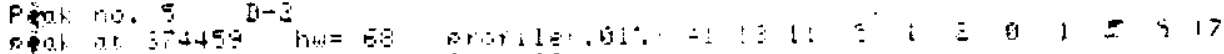

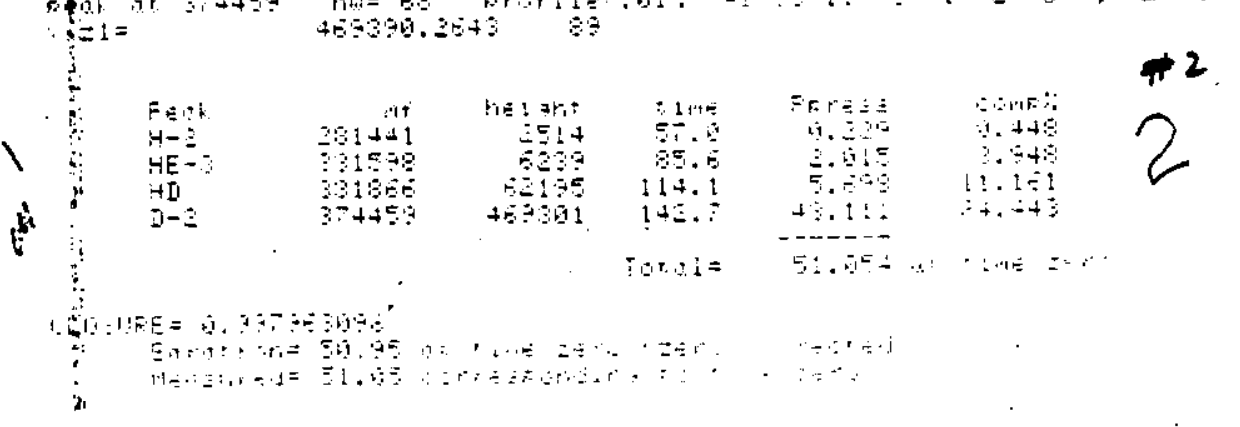




$$
\text { PRECISION + ACEVRACY DaTA }
$$

$2 / 27 / 81$ contut. 2/27/81 $7.30 \mathrm{pm}-8.30 \mathrm{pa}$.

Mix \#2 $C_{y} \neq 7$. Started $\sim 7.15$ p.m. using 4.30p-celibration Onginal labet Techaipe

1.e. single expansion of 3ee vil. mb 3 litre res.

$$
\mathrm{H}_{2} \text { 3He HD } \mathrm{D}_{2} \text { Total } H^{\circ} \text { Totel D }
$$

Closure

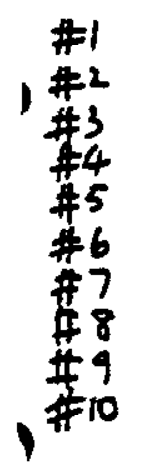

Meen

4.2.

Spec

SD

\begin{abstract}
$84.483 \quad 3.908$
\end{abstract}
$74.412 \quad 3.910$

$84.482 \quad 3.714$

$84.479 \quad 3.915$

$84.472 \quad 3.908$

$84.487 \quad 3.910$

$84.482 \quad 3709$

$84.480 \quad 3.908$

$84.498 \quad 3.910$

$84.470 \quad 3713$

3.911
0.28
0.40

0.002593

\section{$11.153 \quad 0.456 \quad 90.060$}

$11.143 \quad 0.456 \quad 90.063$

11. 148

H.149

II. 154

11.148

11.152

- 11.155

- 11.136

... 11.158

\subsection{0 .056}

$0.456 \quad 90.053$

0.455

0.455

0.457

0456

0.456

0.458

90.059

90.061

90.058

90.058

90.066

10.049

6.0325

6.0275

6.0310

6.0305

6.0320

6.0290

6.0330

6.0335

*6.0240*

$* 6.0370 *$

$-0.08 \%$

$-0.08 \%$

$-0.10 \%$

$-0.13 \%$

$+0.03 \%$

$-0.12 \%$

$-0.12 \%$

$-0.23 \%$

$-0.23 \%$

$-0.19 \%$

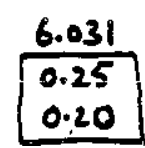

0.003576 


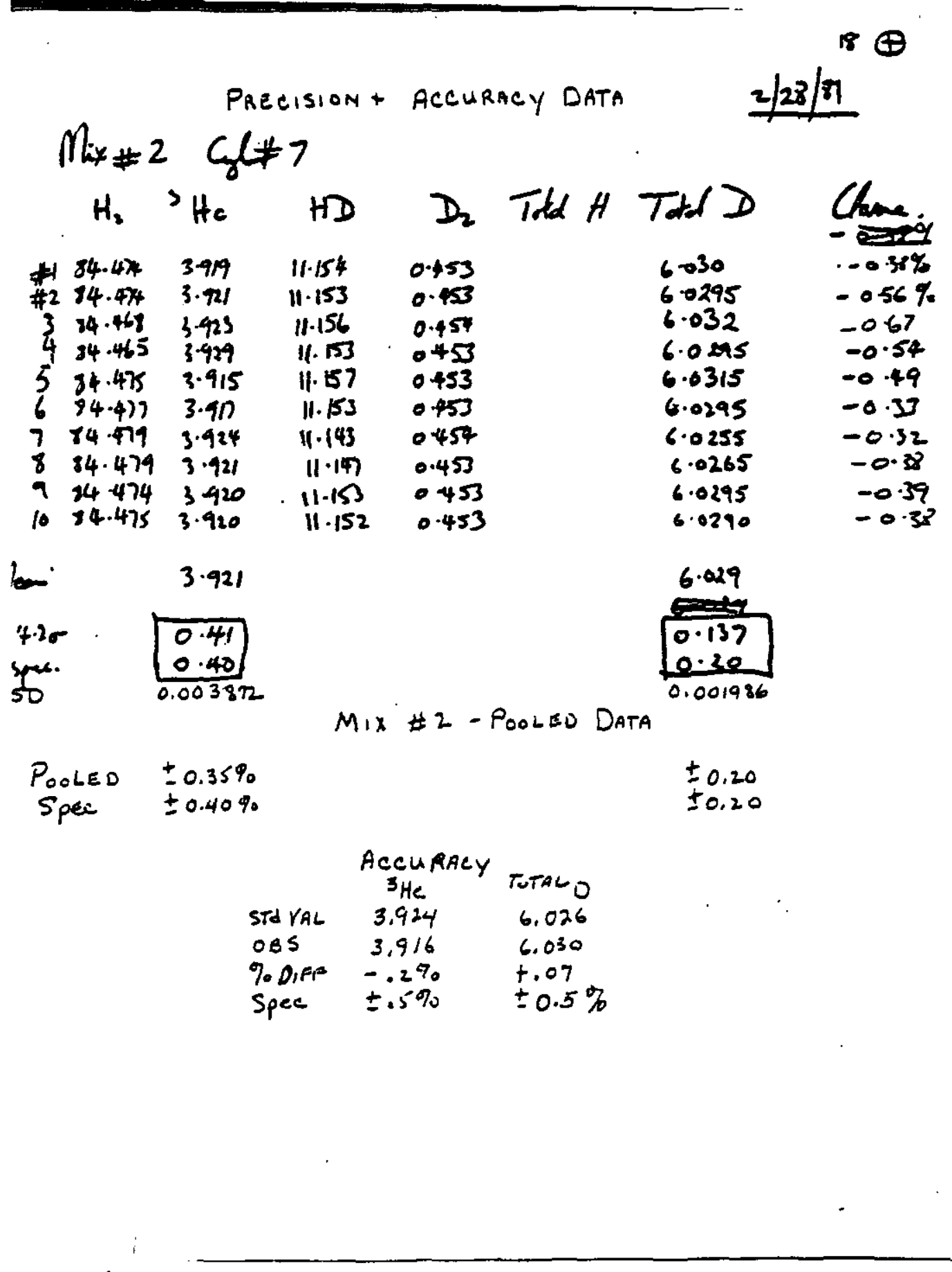


Eariatisn zero=

I Fressure $=\$ 5.62$

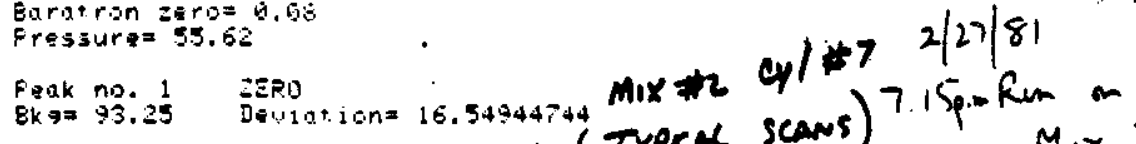

(Typical scans) $M, 1 \times 2$

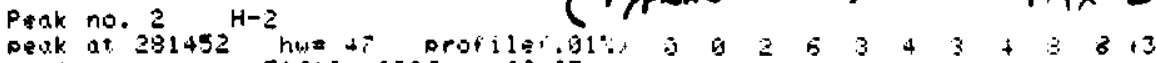

$y, z 1=0.5151 .51 .0026 \quad 93.25$

Peak no. 3 HE-3

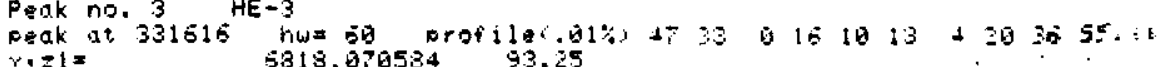

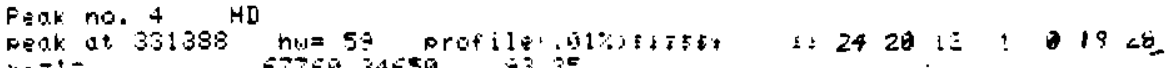

।

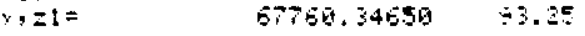

Fink io. 5 . 50,0

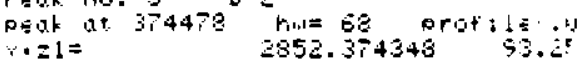

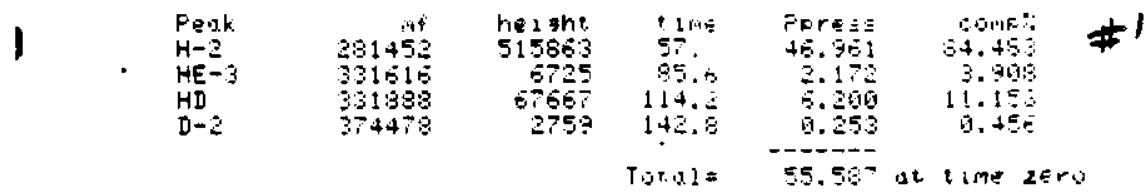

LLDSUFE = $0.999150+36$

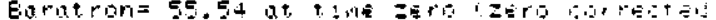

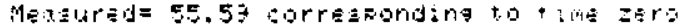

1

Earueran =aro=

Fresidre $=53.8$

Fat no. 1 EERO

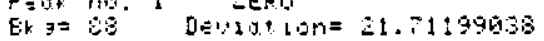

Fagl nis $\bar{z} \quad \mathrm{H}-\mathrm{z}$

: Fenk d $\therefore=1=$

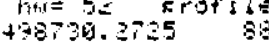

PEAR rij. 3 HE-3

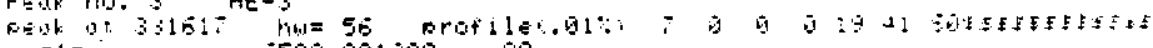
$\cdot=1=\quad 5584.001237$

Feor no. i in

1

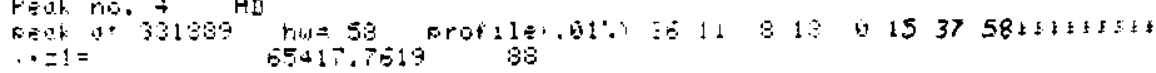

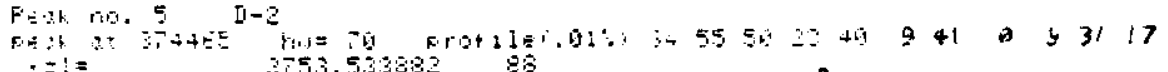

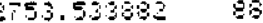

$\neq 2$

1

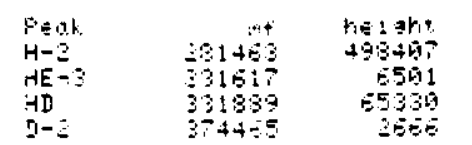

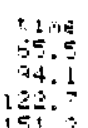

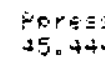

$2 .+10$

5.93

9. 345

$\operatorname{Tin+1}=$

S2.795 ar Tne zoris

I

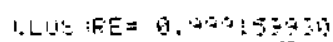

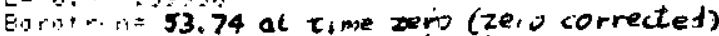

ile 1 I.14 $1.1=53.79$ sorrapounding to time zero 
eak deta on file No. 13

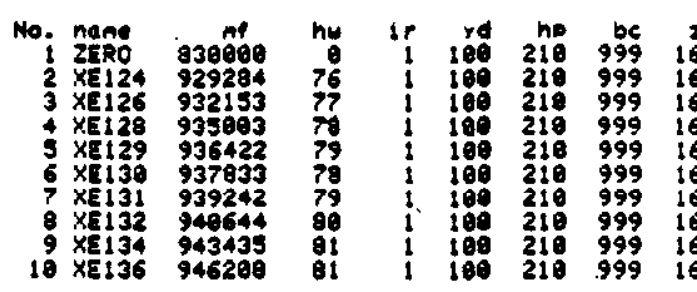

HION MASS T.E. IS 790

Baraeron zeros 0.12

Baratron zeroe B.is

Pressure*

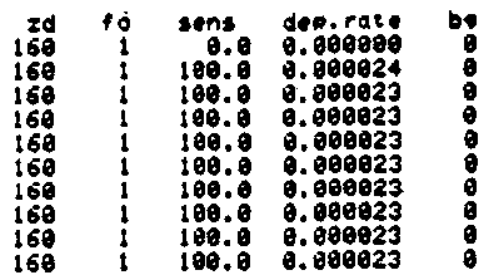

Xe Andyin

1st. Alingt + Manm.

Tressuren

Pressures 42.44

Peak no. 1 ZERO

Bkq0 109.25 Deuiationm 21.87909376

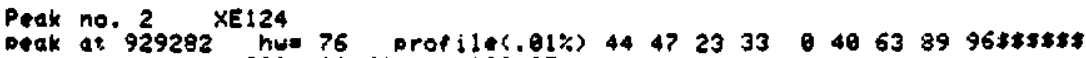
2901.281682 109.25

Peak no. $3 \quad X E 126$

peak at 932151 hy= 76 orofite(.01\%) 5447.223914003354963538

Peak no. 4 XE128

poak at 935001 hu= 79 profile(.01\%) i6 40,00031937 6353sss

$Y, z=1$ 57335.35053 109.35

Peak no. 5 XE129

Deak at 936421 hwe 29 proitlec.01 435 is 38 it 710319 t2 75

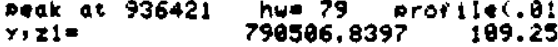

Peak no. $5 \quad X E 130$

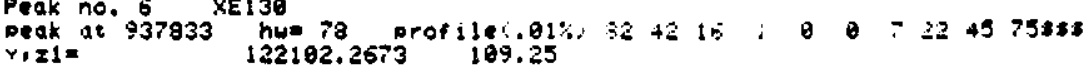

Peak no. 7 XE131

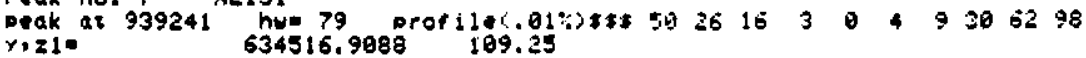

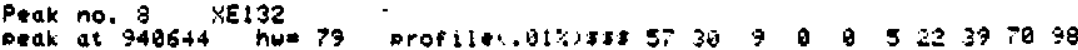

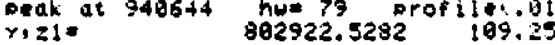

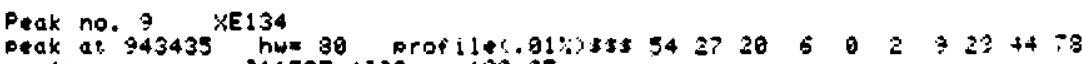

$x, z 1=0311597,4009$ 109.2E

Peak no. 10 ike136

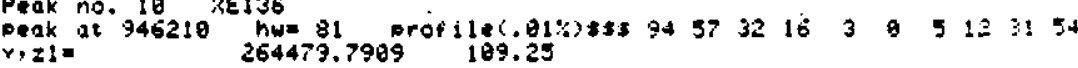

\begin{tabular}{|c|c|c|c|c|c|}
\hline 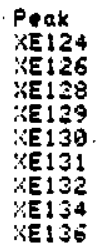 & $\begin{array}{r}m f \\
929282 \\
932151 \\
935091 \\
936421 \\
937833 \\
939241 \\
340644 \\
943435 \\
946210\end{array}$ & $\begin{array}{r}\text { heithe } \\
3872 \\
2678 \\
57426 \\
790390 \\
121993 \\
634488 \\
302813 \\
311488 \\
364371\end{array}$ & 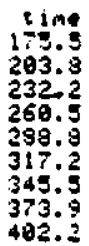 & $\begin{array}{r}\text { Poress } \\
33.340 \\
36.909 \\
577.369 \\
7951.806 \\
1228.089 \\
5390.491 \\
3091.395 \\
31+1.457 \\
2667.799\end{array}$ & $\begin{array}{r}\text { Come: } \\
0.0958 \\
0.0894 \\
1.9179 \\
26.4139 \\
4.0794 \\
21.2975 \\
26.8792 \\
10.4951 \\
8.8617\end{array}$ \\
\hline
\end{tabular}

CLOSURE: $\therefore .4047 T E-03$

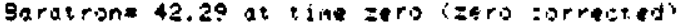

Meduredesessst corresponding to : ine =ero 


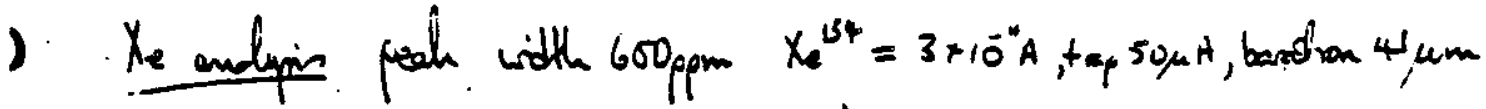
Changed line 500 in 11 las $3($ Rog. 9) to gine lingar wait for gas to

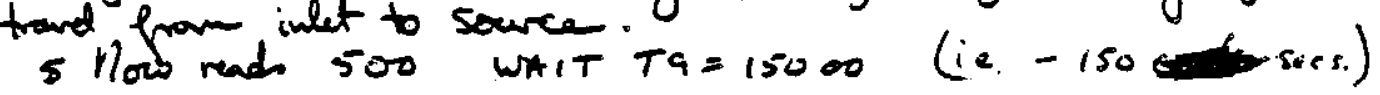

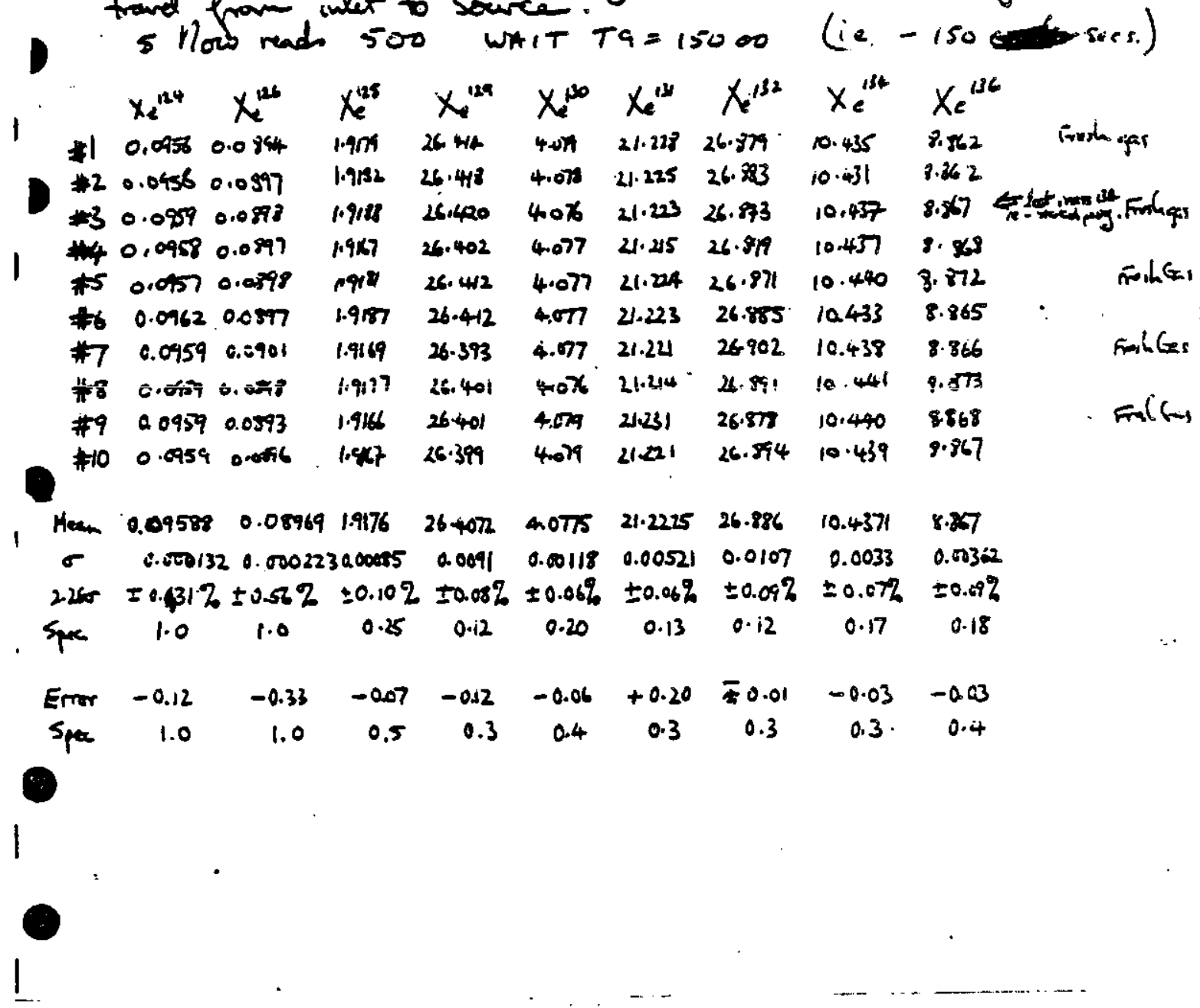


$13 \oplus$

Xe Abundance Sensitivity

$$
\frac{2 / 24 / 81}{6.55 \rho \cdot m} .
$$

See attached Ped plots firm mass 132 thru mass 138 Under maximum gain of $\times 10,000$ relative to $x /$ plot $\left(X_{e} e^{134}\right.$ ph. height of 34.5 dives.) , background at $\sim$ Mass 133 is $\sim 1$ div. related to 345,000 dive. for $X_{e}^{134}\left(3 \times 10^{-14} \mathrm{~A}, 40 \mathrm{\mu m}\right.$ min inlet)

$\therefore$ Abound. Sens. (Mass 133) $=1: 345,000 \sim 3 \mathrm{ecm}$

$$
\text { (Mass 135) }=<1: 345,000<3 \text { ppm }
$$




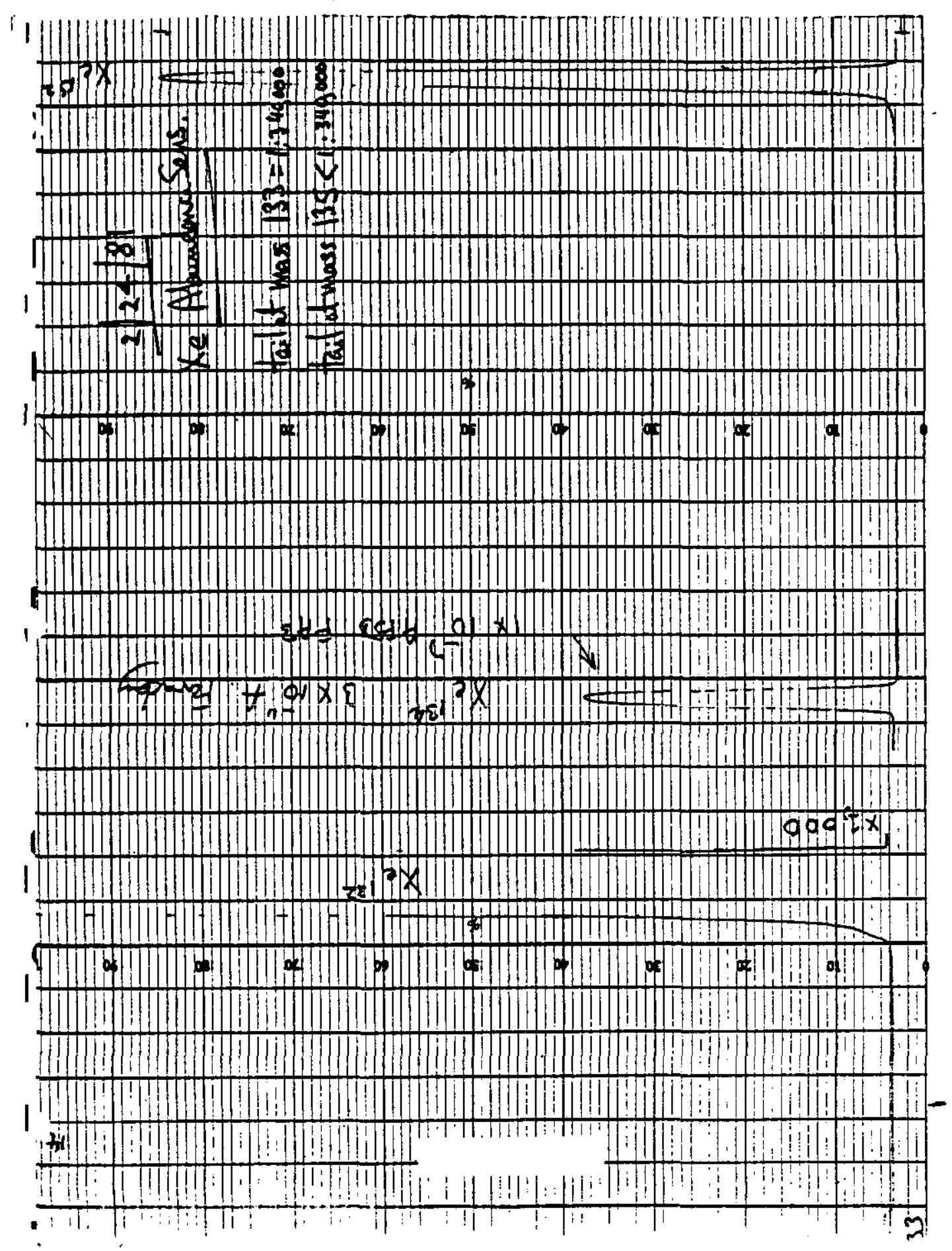




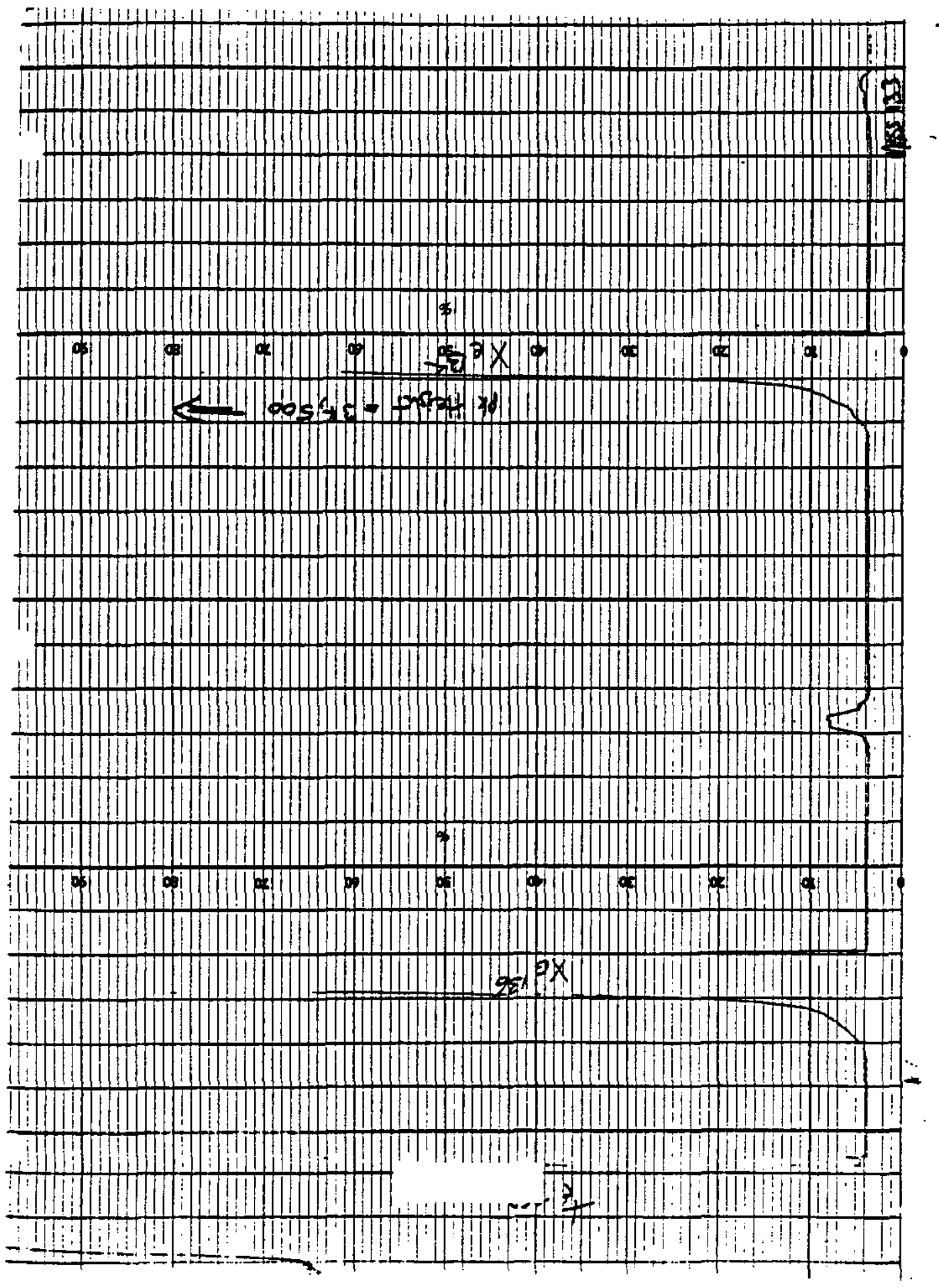

_. IV-31 


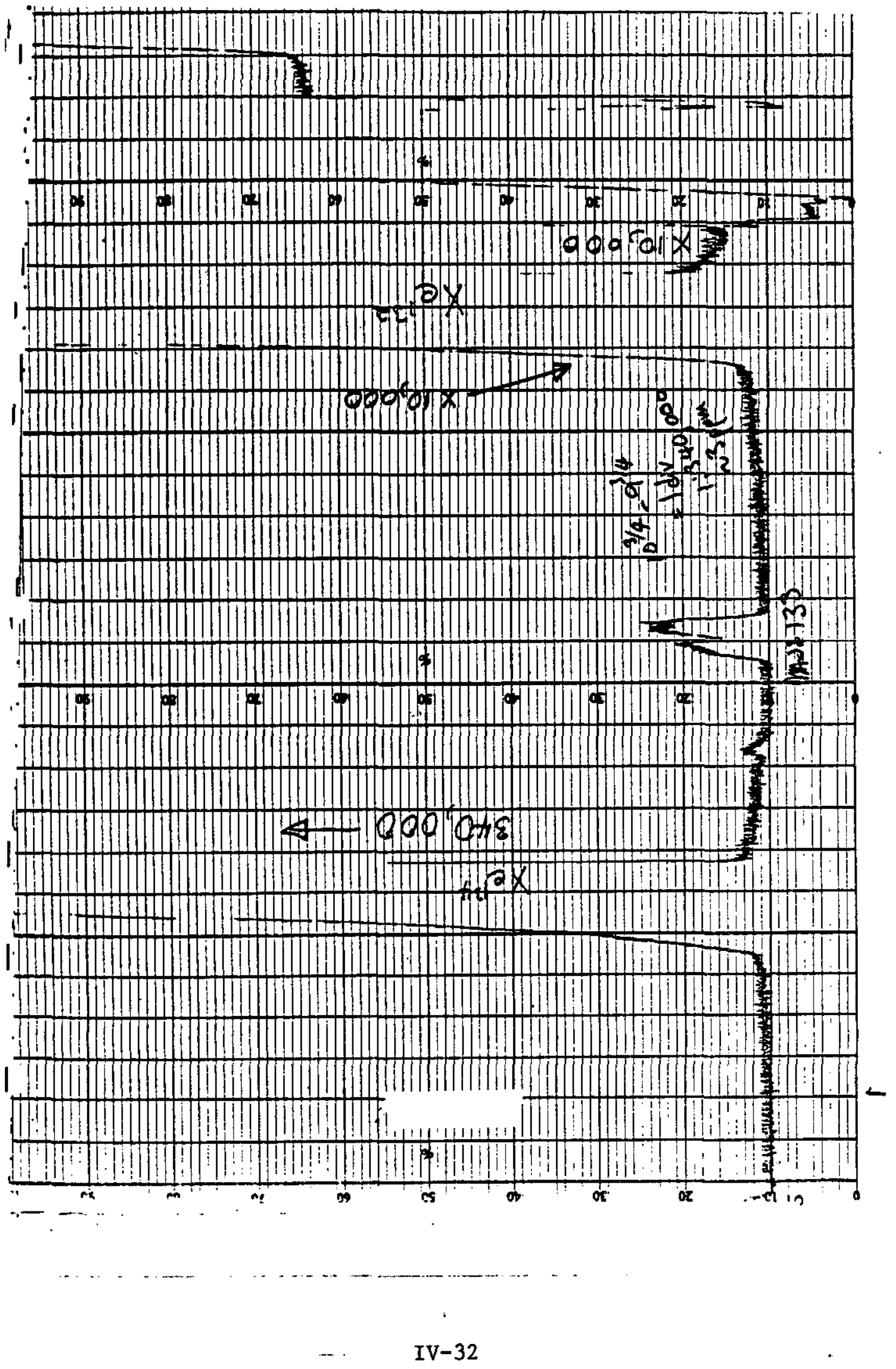




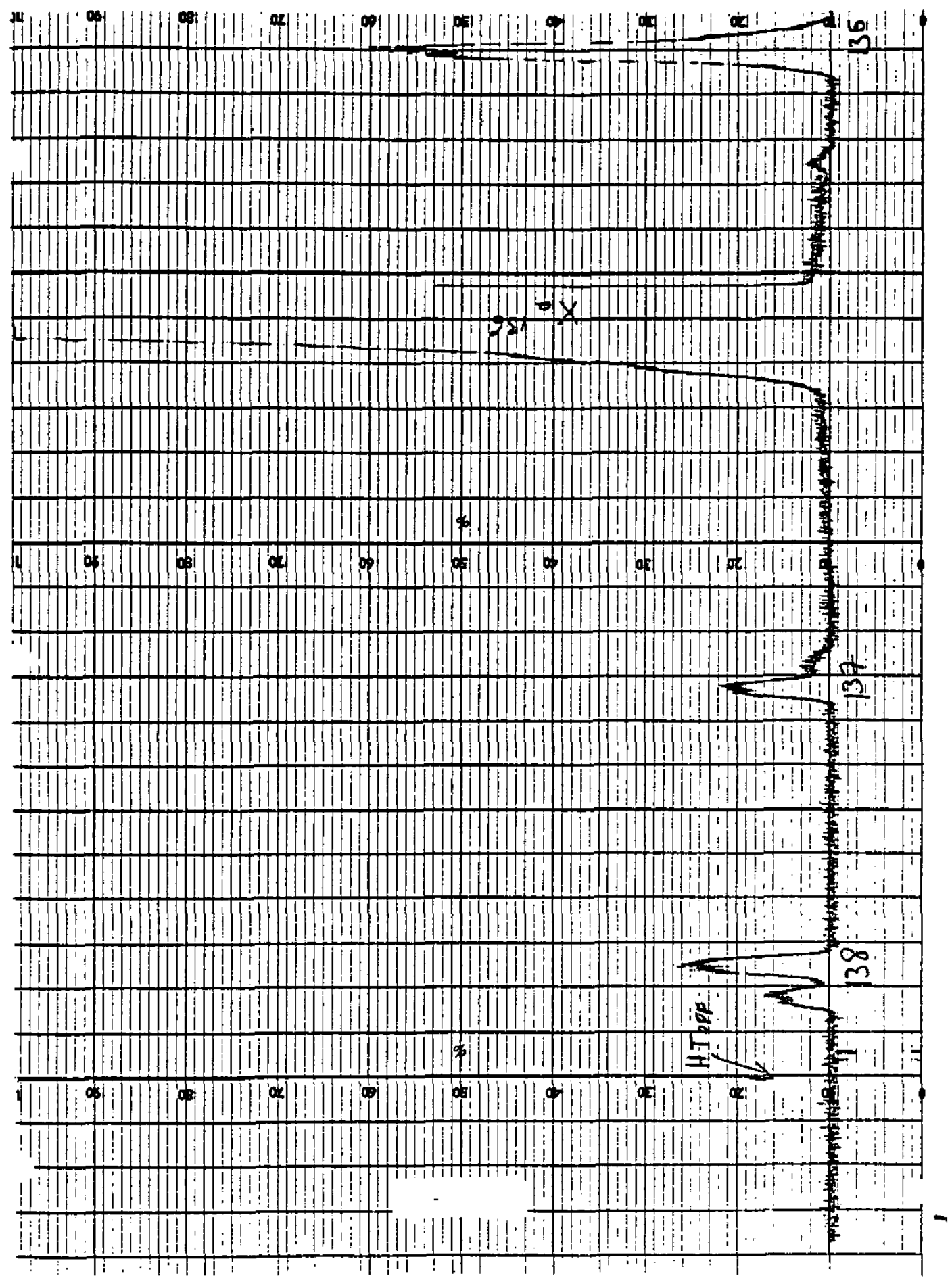




\section{APPENDIX V}

GAZAB PERFORMANCE AT A RESOLUTION OF 1300, MARCH AND APRIL 1981

v-1 


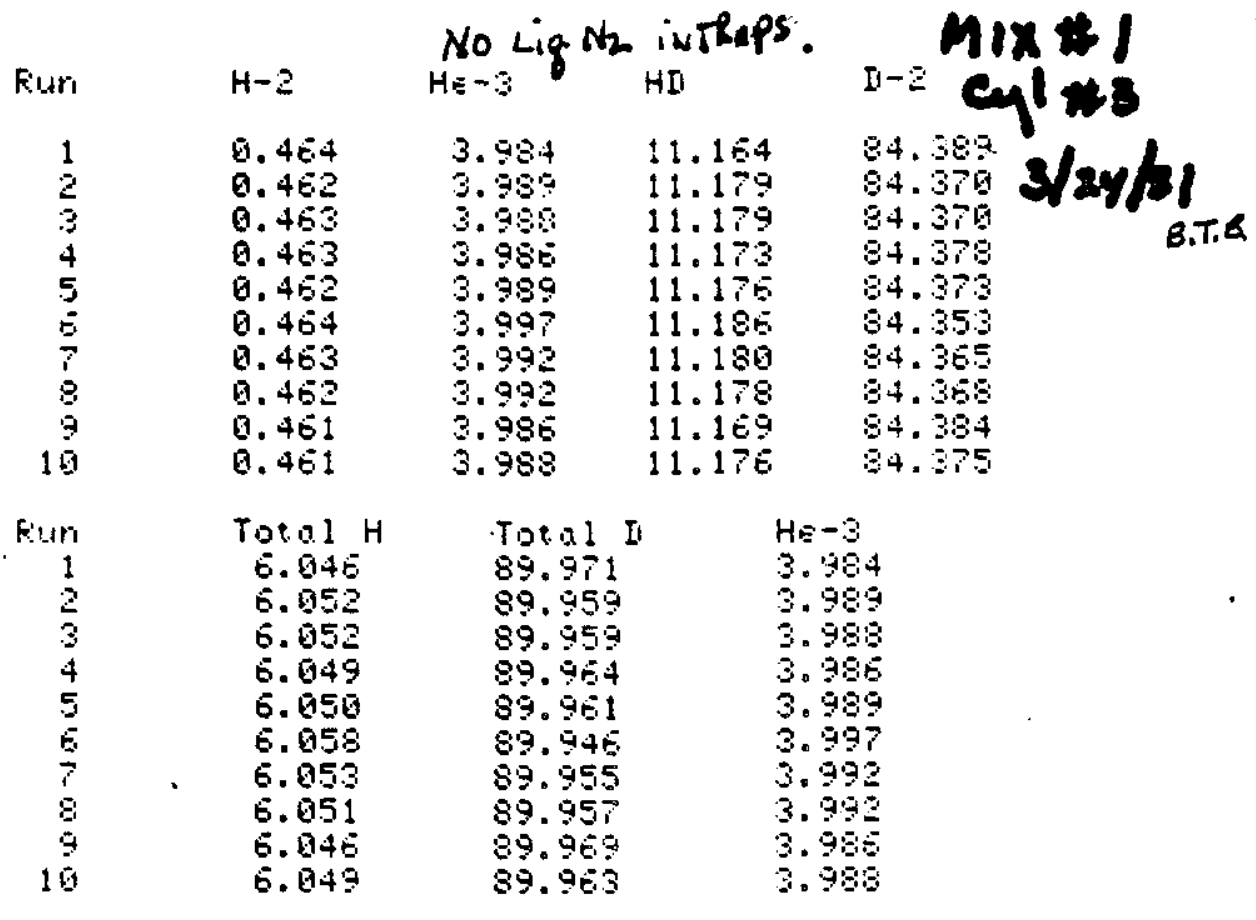

TVERTEE =

FVEFAEE $=0.051=0.050$

$4.3 \mathrm{II}=0.24 \%$

Ti!. II I

BUEFALE = 89. TE

STI IEU $=0.00769:=0.005$.

$4.25 \mathrm{I}=0.033 \%$

$H E-3$

AVEPATE = 3.989

GTI $M E Y=6.015 \%: 1=9.693$

$4.28 \mathrm{I}=6.391 \%$

RESOLUTION $=1300$

SOURCE FOCUSED FOR MAXIMUM ION BEAM

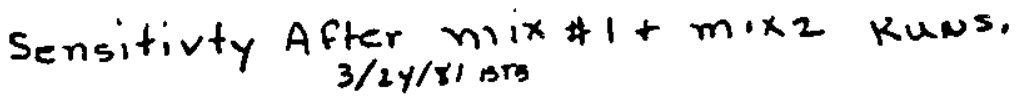

$\begin{array}{cccc}H 2 & D_{2} & H D & H e 3 \\ 199.41 & 216.09 & 209.43 & 56.24\end{array}$

Sencitivity

Before Runs 199.57

216.28

209.44

56.18

$\mathrm{V}-2$ 


\begin{tabular}{|c|c|c|c|c|}
\hline Run & $\mathrm{H}-2$ & $\mathrm{He}-3$ & $\mathrm{HI}$ & $\mathrm{D}-2$ \\
\hline $\begin{array}{r}1 \\
2 \\
3 \\
4 \\
5 \\
6 \\
7 \\
8 \\
9 \\
10\end{array}$ & $\begin{array}{l}84.492 \\
84.583 \\
84.513 \\
84.493 \\
84.499 \\
84.517 \\
84.595 \\
84.506 \\
84.511 \\
84.516\end{array}$ & $\begin{array}{l}3.937 \\
3.935 \\
3.933 \\
3.938 \\
3.938 \\
3.930 \\
3.934 \\
3.939 \\
3.935 \\
3.931\end{array}$ & $\begin{array}{l}11.117 \\
11.108 \\
11.101 \\
11.115 \\
11.111 \\
11.100 \\
11.108 \\
11.103 \\
11.101 \\
11.101\end{array}$ & $\begin{array}{l}0.454 \\
0.453 \\
6.453 \\
0.454 \\
0.453 \\
0.452 \\
0.453 \\
0.453 \\
0.452 \\
0.453\end{array}$ \\
\hline $\begin{array}{r}\text { Fun } \\
1 \\
2 \\
3 \\
4 \\
5 \\
6 \\
7 \\
8 \\
9 \\
10\end{array}$ & $\begin{array}{l}\text { Total H } \\
90.050 \\
90.057 \\
90.063 \\
90.051 \\
90.054 \\
90.057 \\
99.059 \\
90.057 \\
90.062 \\
90.006\end{array}$ & $\begin{array}{c}\text { Tot.al I } \\
6.012 \\
6.008 \\
6.004 \\
6.011 \\
6.098 \\
6.0192 \\
6.0197 \\
6.064 \\
6.093 \\
6.003\end{array}$ & & $\begin{array}{l}7 \\
8 \\
8 \\
4 \\
4 \\
4\end{array}$ \\
\hline
\end{tabular}

Totol $\mathrm{H}$

AVERTISE $=90.05$

STI IIEV $=0.00536(=0.067 \%$

$4.25 \mathrm{I}=0.027 \%$

Totol I

AVEFALE = $6.000^{\circ}$

STII IEV $=0.00353:=0.059 \%$

$4.25 \mathrm{II}=0.247 \%$

HE-3

STI IE $=0.0632=0.074 \%$

$4.251=6.311 \%$

RESOLNTHON $=1300$

SOURLE FUCUSED FOR MAXIMUM IUN BEAM 


\section{APPENDIX VI \\ SPECIFIED ACCEPTANCE TESTS FOR THE FINNIGAN MAT 250 HDT MASS SPECTROMETER}

The following tests shall be made at the factory in Bremen using Varian's inlet system, and also at SRP using either Varian's or SRP's inlet system. All tests shall be made under the following conditions:

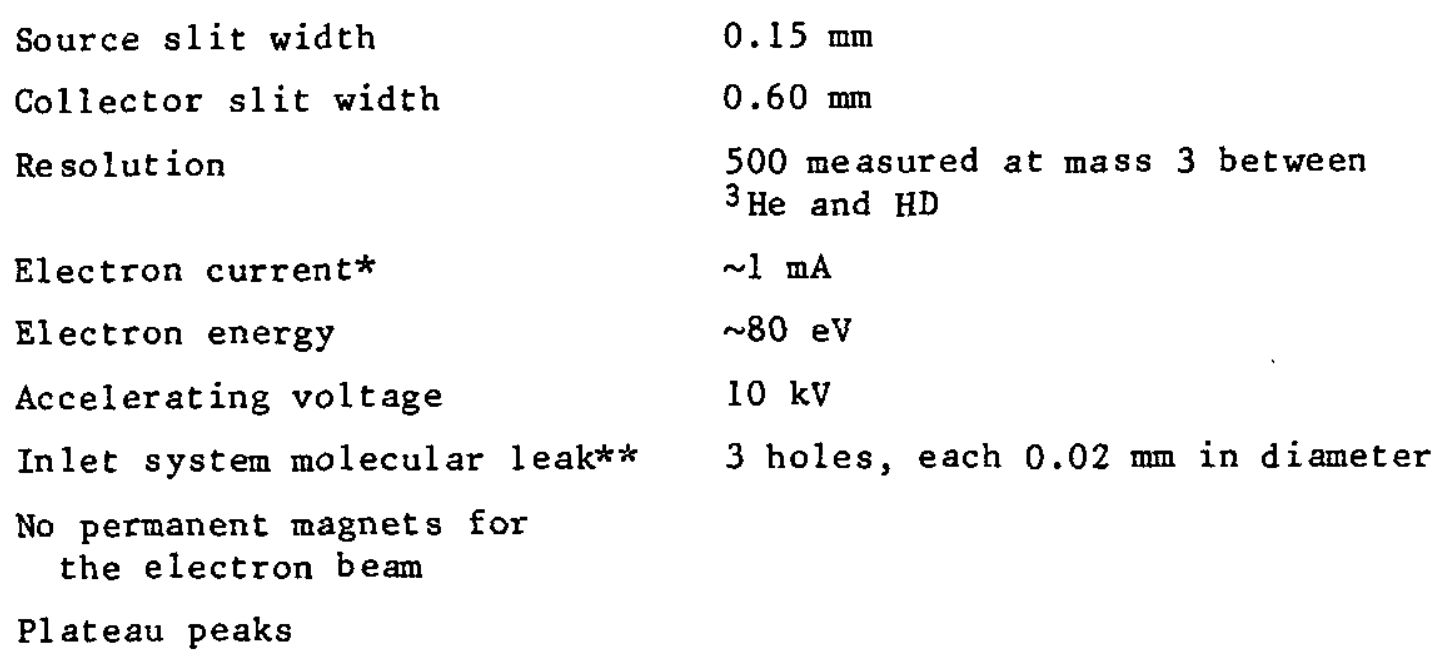

The following requirements must be met:

- The sensitivity for hydrogen shall be at least $10^{-9} \mathrm{~A} /$ torr . Sensitivity is defined as hydrogen ion current versus pressure inside the inlet system behind the molecular leak.

- Linearity of hydrogen sensitivity shall be less than 0.01 over a pressure range of 0.070 torr to 0.9 torr in the inlet system. $t$ Linearity is defined as the maximum sensitivity deviation divided by the mean sensitivity.

- Linearity of argon sensitivity shall be less than 0.01 over a pressure range of 0.030 torr to 0.6 torr in the inlet system. +

* The electron current is the total emission from the filament. The Germans call this the "ionizing current", thus the use of "IC" in the figures.

** The calculated conductance of the molecular leak is $0.11 \mathrm{~cm}^{3} / \mathrm{sec}$, which is $55 \%$ of the conductance of the MSTG reference leak $\left(0.2 \mathrm{~cm}^{3} / \mathrm{sec}.\right)$.

t A 1000-megohm resistor was used in all tests. 
- Mass discrimination between hydrogen and deuterium shall not be detectable.

- The abundance sensitivity shall exceed 20,000, measured at the high-mass side of the HD peak at a distance which is equal to the distance between the ${ }^{3} \mathrm{He}$ peak and the HD peak. Abundance sensitivity is defined as the ratio of the HD peak height divided by the (imaginary) ${ }^{3} \mathrm{He}$ peak height.

- $D_{3}$ production from $D_{2}$ shall be less than $1200 \mathrm{ppm}$ at a $D_{2}$ ion current of $10^{-9} \mathrm{~A}$.

- Flatness of the peak plateau shall be better than 0.001 over a width $\pm 5 \%$ from the center of the peak. The peak width shall be determined by measuring the peak width at $5 \%$ of peak height. 


\section{PURCHASE ORDER ADDENDUM}

cipy Fiank's specs $2 / 19 / 81$

ITEM NO.

1

\section{DESCRIPTION}

Mass spectrometer sygtem, Varian MAT Model 250 HDT, specially modified for hydrogen-helium lsotopic analyses. The instrument will be fitted with the lollowting:

(a) Triple Faraday collector system with amplifiers. Collector spacing will be specified later.

(b) $270 \mathrm{l} / \mathrm{sec}$ Iurbomolecular pump on the source.V

(c) A liquid nitrogen cooled trap between the source and the Turbomolecular pump. This trap shal:

have capacity of 520 hours This $12-15$ hr. frant

SAys is Brementine

(d) A 24 channel peak selector, programmable over the entire mass range.

(e) Temperature stabilized ion source controls with \pm 0.1 c regulation.

(f) Differential pumping for source and analyzer sections.

(g) A closed circuit cooling water system for all equipment requiring cooling water.

(h) An oil boostex pump between the Mechanical and Turbomolecular pump.

(1) An accelerating voltage supply capable of $10 k \nabla .4$

The instrument w121 operate on $60 \mathrm{~Hz}, 480$ volt (phase

to phase), 3-phase delta ( 3 wire) electrical power

at a current of not more than 30 amperes/phase.

The instrument will meet the attached performance specifications and will be tested at the vendor's factory in accordance with those specifications before 1t is shlpped. The tests may be witnessed by a representative of the purchaser. Written approval of the tests by the purchaser will be required before the instrument is shipped.

The final acceptance tests will be a repeat of those in the attached performance specification. 
ITEM

2

3

4
1

8

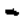

Sets of operating and maintenance manuals, parts lists, drawing and schematic diagrams.

Set of all alignment figs, special tools or other equipment not readily available on the open market and needed to service and maintain this inatrument.

SHIPPING ADDRESS

-E. I. du Pont de Nemours Co. $300 / 700$ Receiving Dept.

Dunbarton, SC

- Deliver directiy to P. Chastagner, Bldg. 773-A. DO NOT unload at $300 / 700$ Receiving Dept.

\section{NOTE:}

The mass spectrometer system should not include the programmable calculator unless the calculator is of the type that the program is hardwired in the system.

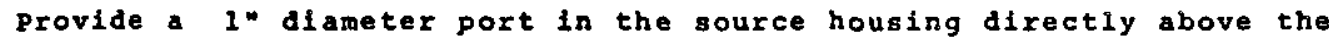
filament ares of the ion source. This port should be sealed with a varian standaxd 2-3/4" OD high vacuum flange. 


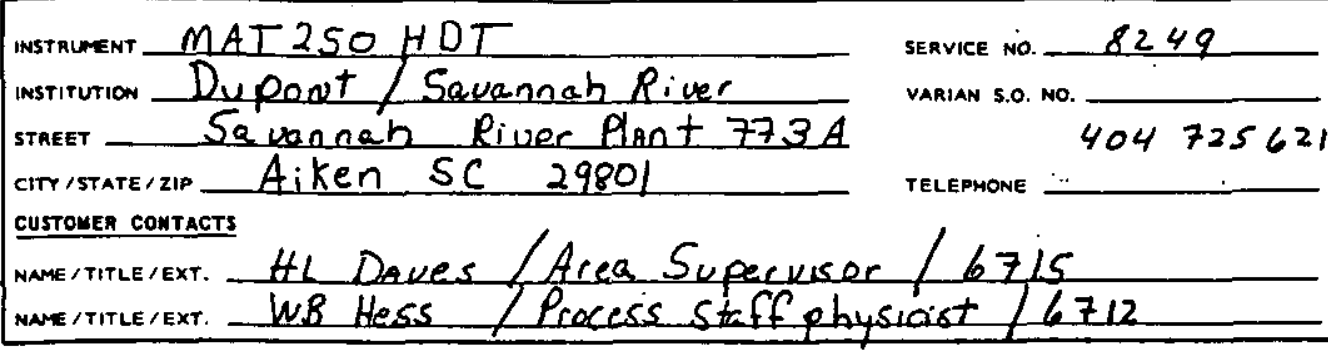

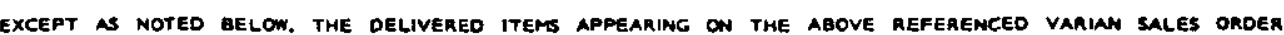
ACXNOWLEOCMENT (S) HAVE OEEN INSTALLED. THE SPECIFIED TESTS FOR THE OELIVERED ITEMS HAVE BEEN COMPLETED

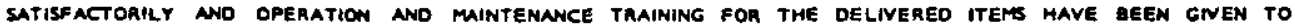
CLSTORER PERSONNEL.

DEUVERED ITEMS REQUIRHG FURTHER ACTION

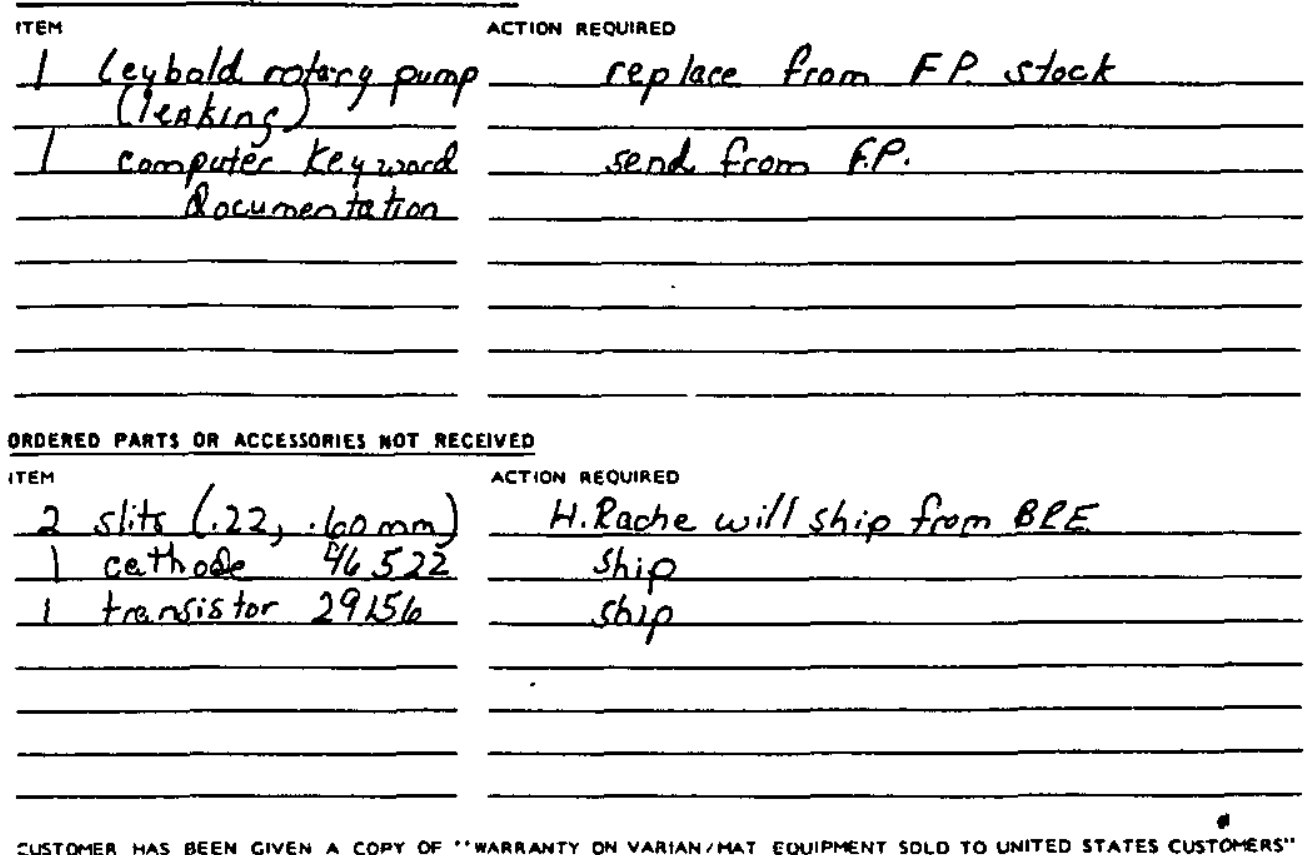

SUSTOMER HAS BEEN GIVEN A COPY OF " WARRANTY ON VARTAN IMAT EOUIPMENT SOLO TO UNITED STATES CUSTOMERS" CUSTOMER UNDERSTANOS THAT TME WARRANTY PERIODS ON THE ACCEPTABLE DELIVERED EOUIPMENT BEGIN ON THE SIGNATURE DATES SHOWN BELOW.

FOR CUSTOMER

FOR VARIAM

SIONEO SEAVICE ENOINEEA

Sianed Date Feb 201981 oate

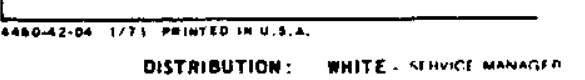

OATE

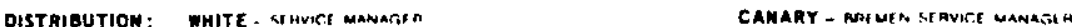

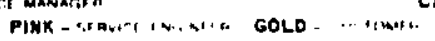


Argon Linearity 300 je

Linearity check Date: 190281

$l=1.2 \%$

P(torr) 0.5813

Sig(v) 1.223

$s / p$

2.1944

Hydrogen Linearity

Linearity check

Date: 19025 !

$\ell=1.1 \%$

P(torr) 0.5872

Sig(v) 1.5309

sip

$\begin{array}{ll}F(\operatorname{tor}) & 0.4129 \\ \text { sigiv) } & 0.8649 \\ \text { s/p } & 2.0946\end{array}$

$S / P$

1.7255

Firor)

0.7272

sig(y) 1.2539

$s / p$

1.7230 ..

Fitorr) $\quad 0.2454$

Sig(v) 0.5111

$F(t o r)$

0.5777

$s / P$

2.0826

S/P

0.9941

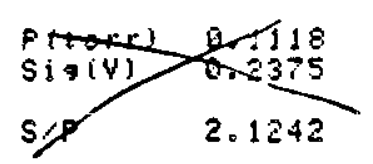

P(rorr)

sip(v)

1.7202

fior)

0.1113

Sig (v)

9. 2335

$S / P$

2. 0884

$S / P$

0.3547

0.6066

Fitori)

$s i \leq(v)$

9. 9549

6. 1150

F(ror

1.7158

$S / F$

2.0944

Sig(v)

0.295

$s / p$

0.3491

1.7130

F: Prrt a.6315

$\Delta=4$ a.

$F(t o r)$

sig (V)

0.1255

SiF

0. 2215

$S P=2.0905$

linearity $\pm .60 \%$

Fitorr)

$S i(w)$

1. 7112

$\begin{aligned} \frac{s}{x} & =17165^{190} \\ & \pm .55 \%\end{aligned}$

specification $\pm .5 \%$

$\pm .5 \%$ 


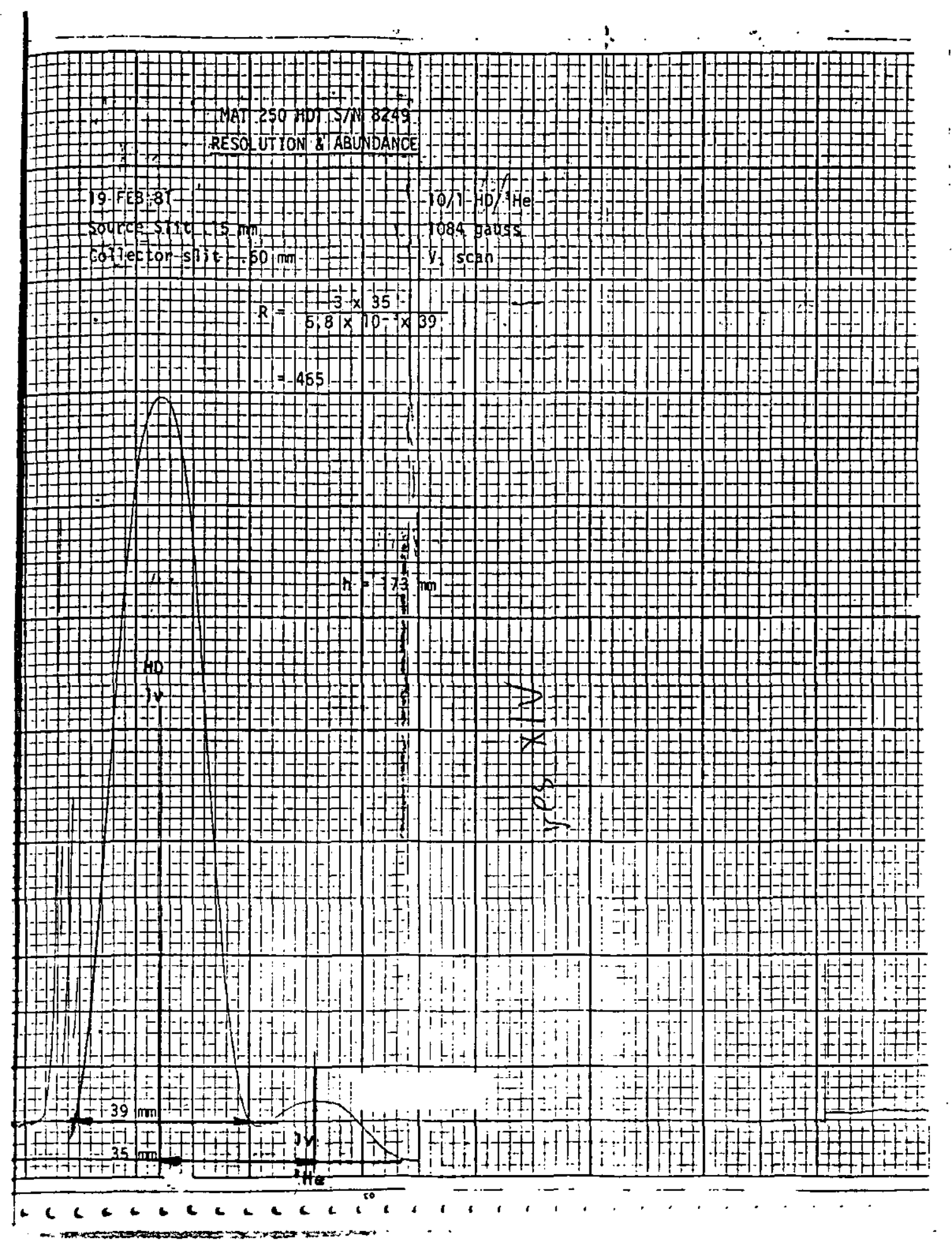




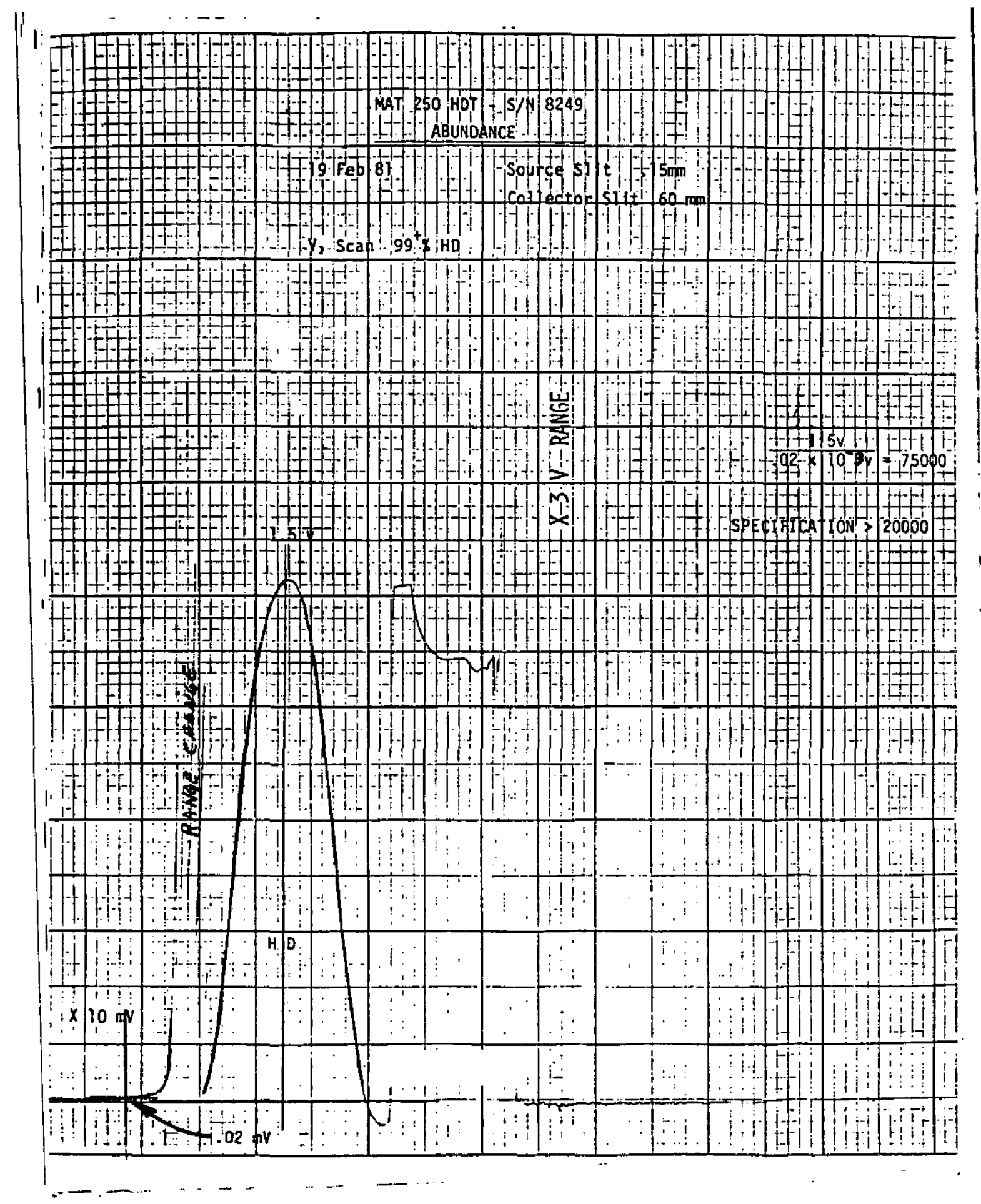




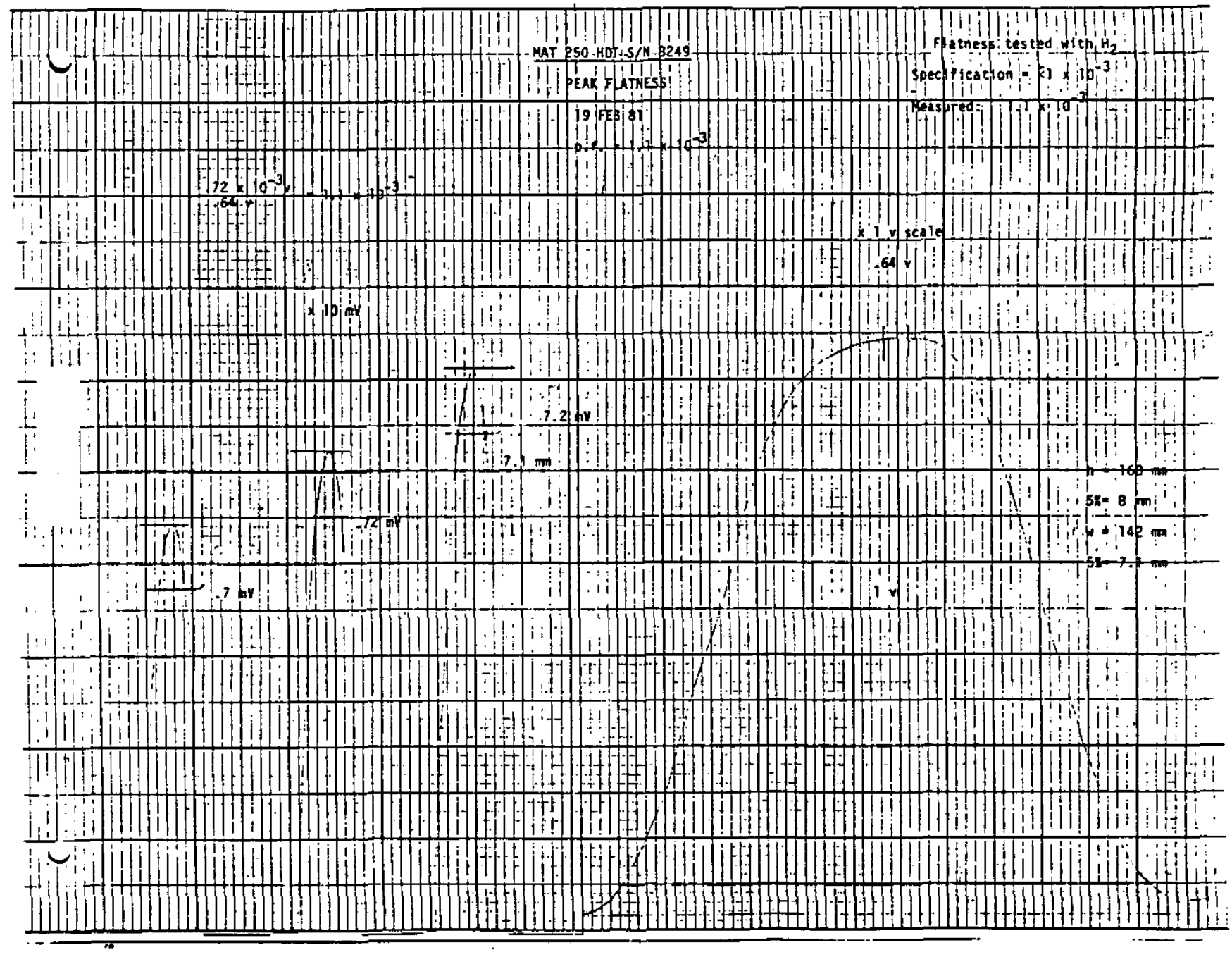



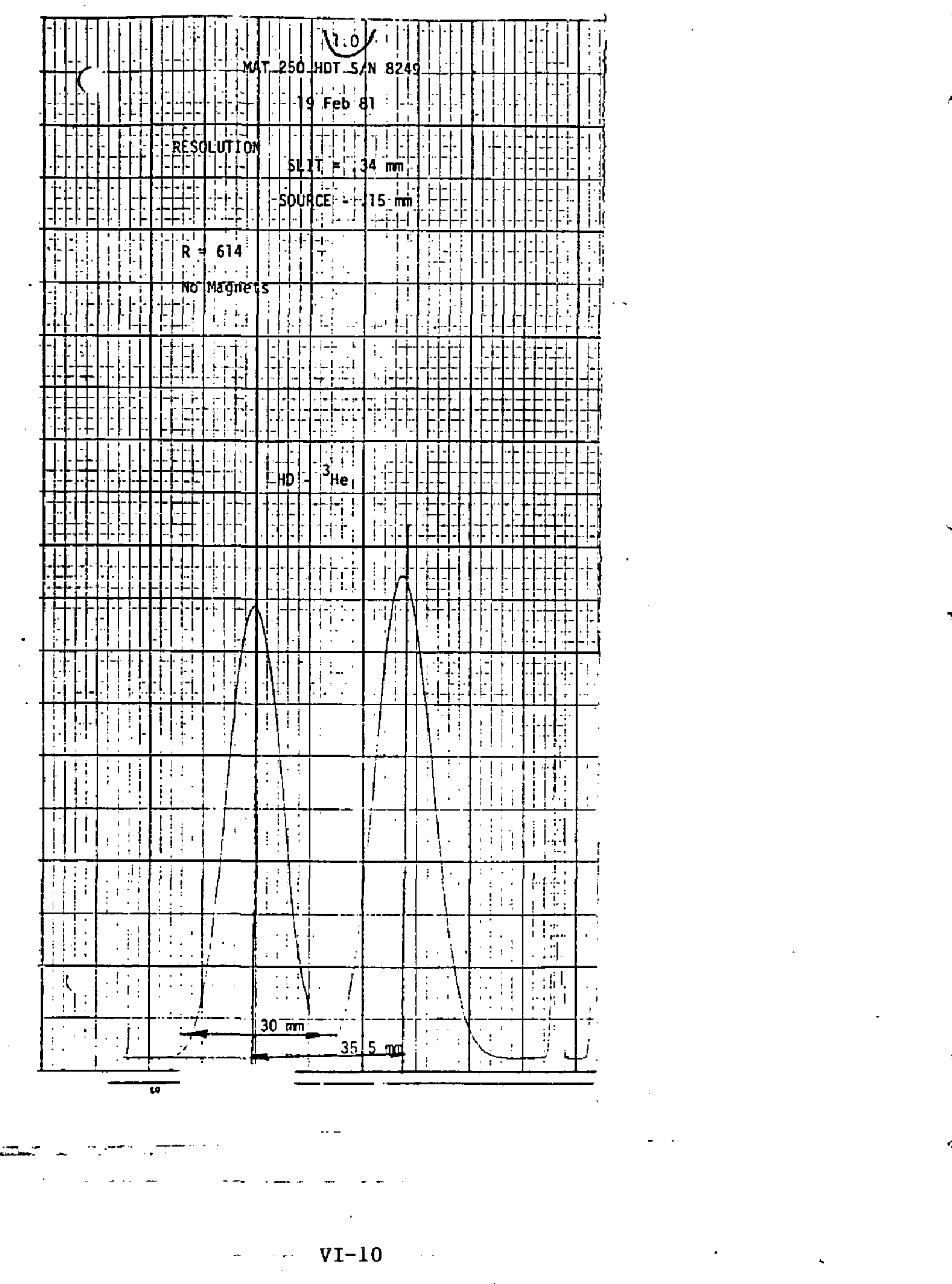


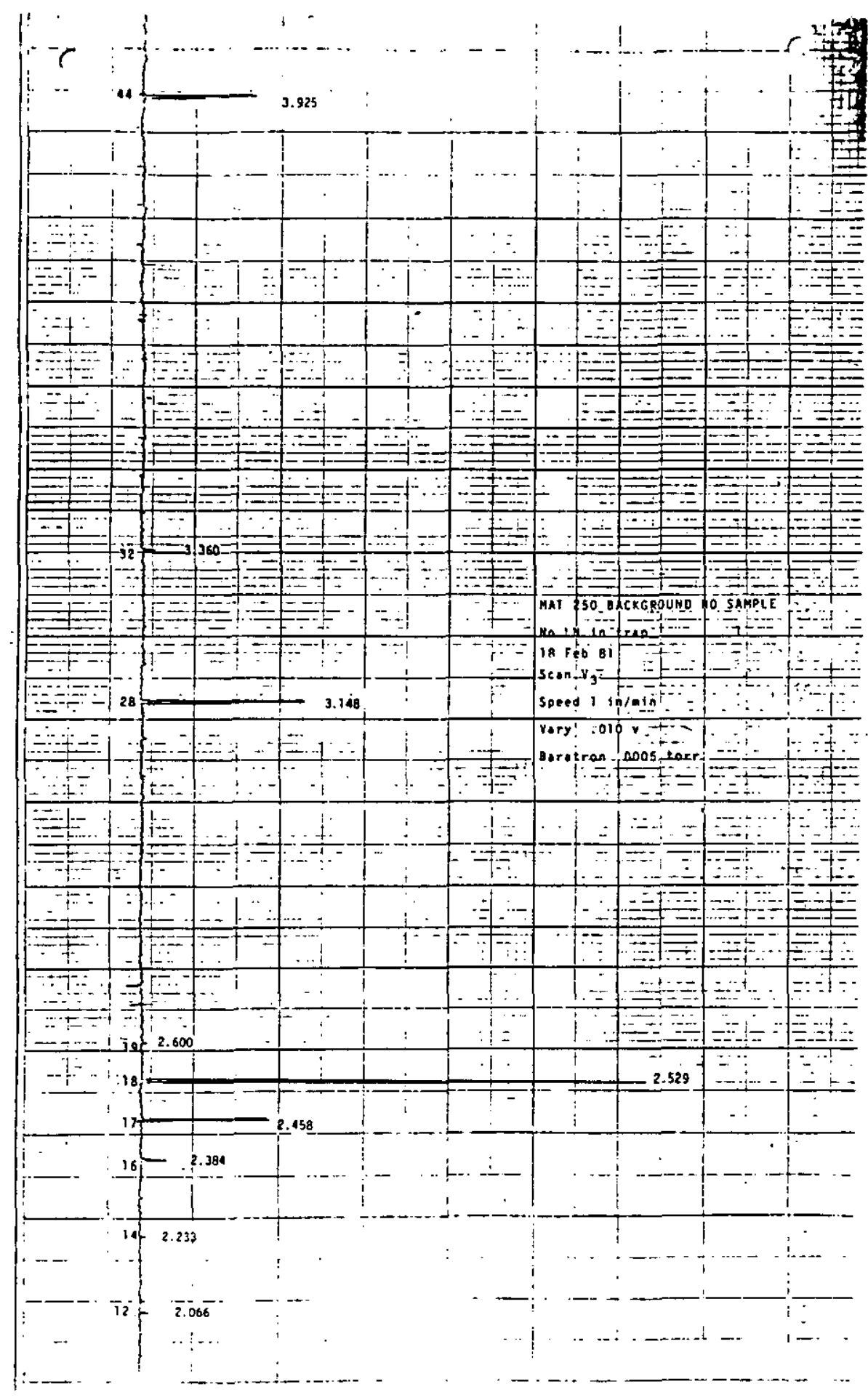




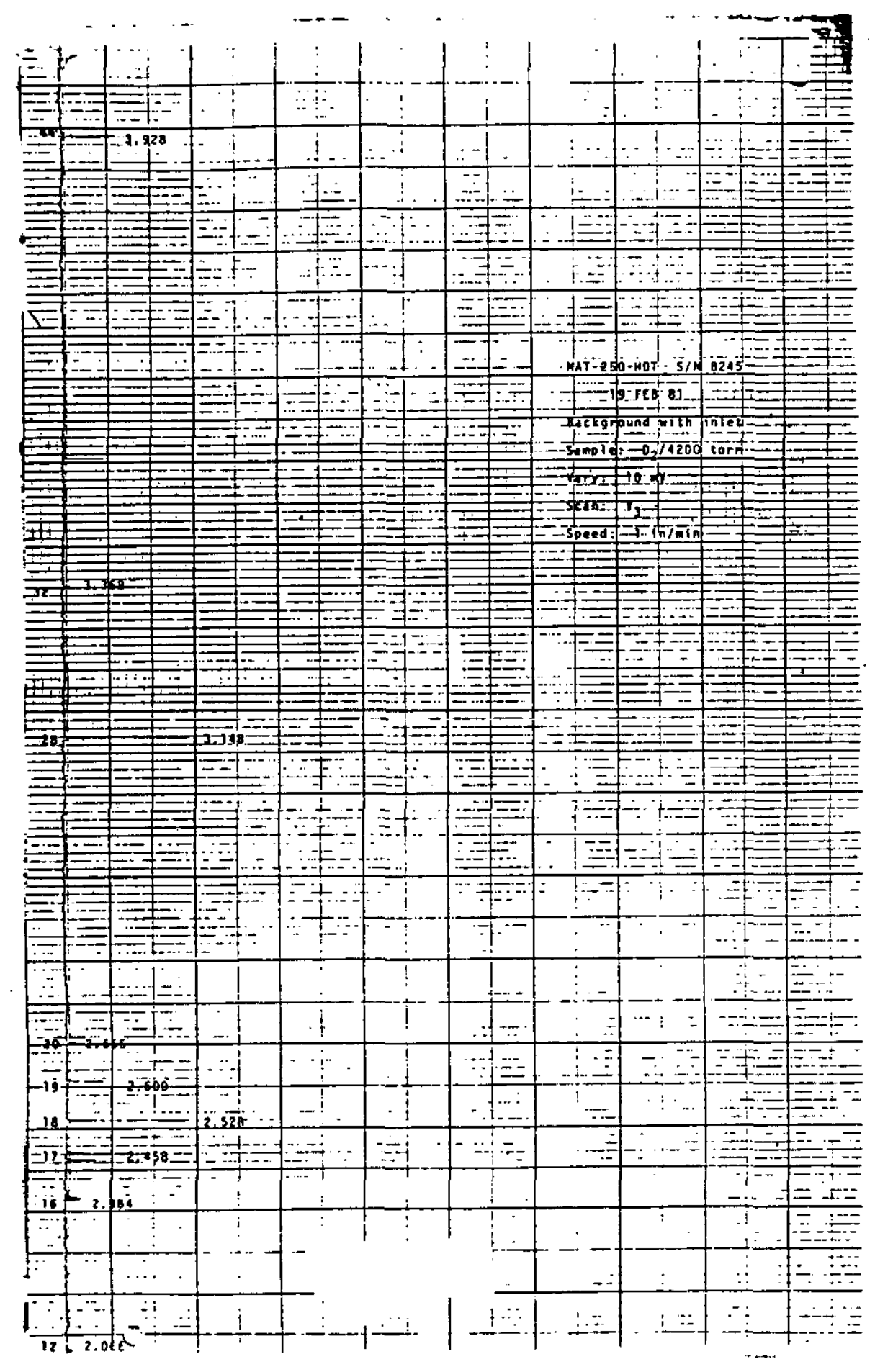




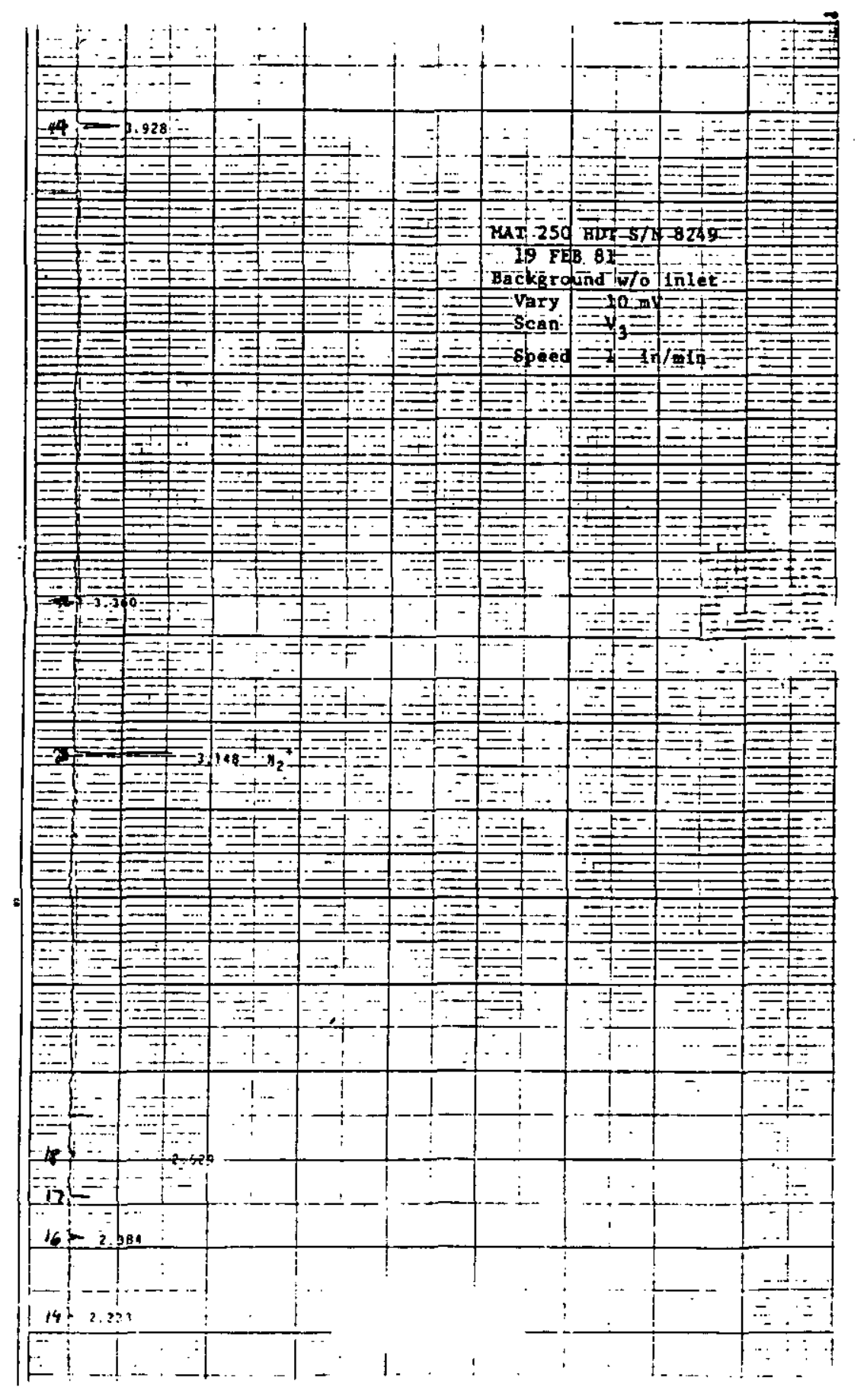


ACCEPTANCE TESTS OF THE FINNIGAN (FORMERLY VARIAN) MAT 250 HDT, FEBRUARY 1981 
February 19, 1981

\section{TEST CONDITIONS}

Source slit width

Input Resistor

II Collector slit width

Resolution

Cathode

Total Filament Emission

Electron Energy

Trap Voltage

Source Temperature

Accelerating Voltage

Molecular Leak (Varian)

Base Pressure w/o Sample
$0.15 \mathrm{~mm}-0.0059^{\prime \prime}$

$10^{9} \Omega$

$0.60 \mathrm{~mm}-0.0236^{\prime \prime}$

465 measured at mass 3 between

$3_{\text {He and } \mathrm{HD}}$

6.1 amps

I ma (300 ha for Argon Iinearity)

$80 \mathrm{ev}$.

135 volts

$160^{\circ} \mathrm{C}$

$10 \mathrm{kV}$

3 holes, (.00079") $0.02 \mathrm{~mm}$ diameter each.

Same molecular leak used in Bremen

September, 1980

Source $2 \times 10^{-8}$ torx - Analyzer $2 \times 10^{-7}$

torr

Liquid Nitrogen Trap Filled

No permanent magnets for the electron beam

Plateau peaks 


\section{SENSITIVITY FOR HYDROGEN}

$P$ inlet system 0.425 torr

$\mathrm{H}_{2}$ peak height $0.727 \mathrm{v}$

SENS. $\frac{0.727 v}{10^{9} \Omega \times .425 \text { torI }}=1.7 \times 10^{-9}$ amps/torr

Specification $>10^{-9}$ amps/torr 


\section{MASS DISCRIMINATION}

Sensitivity of $\mathrm{H}_{2}$ at $\sim 420 \mu-1.708 \times 10^{-9}$ amps/torr (inlet pressure)

Sensitivity of $D_{2}$ at $\sim 420 \mu=1.697 \times 10^{-9}$ amps/torr (Inlet pressure)

$$
\Delta .6 \%
$$

Specification: Msss discrimination shall not be detectable.

$D_{3}^{+}$Production from $D_{2}$

$564 \mu D_{2} 950 \mathrm{mv} D_{2} 10^{9} \Omega=.95 \times 10^{-9}$ amps

$D_{3} 32 \mathrm{mv}, 3 \times 10^{2} \Omega=1 \times 10^{-13}$ amps

$$
D_{3}=105 \text { ppm of } D_{2}^{+} \text {peak }
$$

Specification: $D_{3}$ from $D_{2}$ shall be $<120$ ppm at $10^{-9}$ amps $D_{2}$ ion current 